Florida International University

FIU Digital Commons

FIU Electronic Theses and Dissertations

University Graduate School

2-19-2019

\title{
Human Papilloma Virus Vaccine Acceptability among Parents of Adolescent Girls in Mysore, India
}

\author{
Abraham Degarege Mengist \\ Florida International University, ameng002@fiu.edu
}

Follow this and additional works at: https://digitalcommons.fiu.edu/etd

Part of the Epidemiology Commons

\section{Recommended Citation}

Mengist, Abraham Degarege, "Human Papilloma Virus Vaccine Acceptability among Parents of Adolescent Girls in Mysore, India" (2019). FIU Electronic Theses and Dissertations. 4063.

https://digitalcommons.fiu.edu/etd/4063

This work is brought to you for free and open access by the University Graduate School at FIU Digital Commons. It has been accepted for inclusion in FIU Electronic Theses and Dissertations by an authorized administrator of FIU Digital Commons. For more information, please contact dcc@fiu.edu. 


\title{
FLORIDA INTERNATIONAL UNIVERSITY
}

\author{
Miami, Florida
}

\section{HUMAN PAPILLOMAVIRUS VACCINE ACCEPTABILITY AMONG PARENTS OF ADOLESCENT GIRLS IN MYSORE, INDIA}

A dissertation submitted in partial fulfillment of

the requirements for the degree of

DOCTOR OF PHILOSOPHY

in

PUBLIC HEALTH

by

Abraham Degarege Mengist 
To: Dean Tomás R. Guilarte

Robert Stempel College of Public Health and Social Work

This dissertation, written by Abraham Degarege Mengist, and entitled Human Papillomavirus Vaccine Acceptability among Parents of Adolescent Girls in Mysore, India, having been approved in respect to style and intellectual content, is referred to you for judgment.

We have read this dissertation and recommend that it be approved.

$\begin{array}{r}\text { Kristopher Fennie } \\ \hline \text { Tan Li } \\ \hline \text { Dionne Stephens } \\ \hline \text { Purnima Madhivanan, Major Professor }\end{array}$

Date of Defense: February 19, 2019

The dissertation of Abraham Degarege Mengist is approved.

Dean Tomás R. Guilarte Robert Stempel College of Public Health and Social Work

Andrés G. Gil Vice President for Research and Economic Development and Dean of the University Graduate School

Florida International University, 2019 
(C) Copyright 2019 by Abraham Degarege Mengist

All rights reserved. 


\section{DEDICATION}

This dissertation is dedicated to my late mother Alemnat and father Degarege for their contribution for getting me where I am today. 


\section{ACKNOWLEDGMENT}

First and foremost, I acknowledge my God and His blessed mother Virgin Mary who has been my help and my solace in all things great and small throughout my entire life. I would like to sincerely thank also my academic adviser, Dr. Purnima Madhivanan, who guided and supported me throughout this study, and the committee Dr. Kristopher Fennie, Dr. Tan Li and Dr. Dionne Stephens, who kept me on track during the process. As the chair of my dissertation committee, Dr. Madhivanan has provided me with the necessary support and environment to be successful as a graduate student and complete my $\mathrm{PhD}$ in a timely manner. She has an open-door policy which allowed me to walk in anytime to discuss or ask her questions. I have seen her go above and beyond to help and guide me to be successful as a student and future researcher. In addition, the support of Dr. Fennie for the completion of my dissertation was very great. He has carefully read, commented and edited all the manuscripts that make up my dissertation leading to the publication of these manuscripts in scientific journals. While writing the manuscripts and discussing other academic issues, Dr. Fennie consistently and readily listened to my questions with compassion, concern, and patience before providing his advice. Dr. Li provided invaluable statistical advice for all the manuscripts published from this work.

To all faculty in the department of Epidemiology at FIU, I am truly grateful for all the support you have provided me towards the completion of the program. I am also indebted to my research collaborators at Aklilu Lemma Institute of Pathobiology, Professor Erko, Dr. Animut, Dr. G/Medhin and Dr. Legesse, who taught and advised me on how to conduct research before I joined FIU. In particular, I owe a debt of gratitude to 
Professor Erko who was my inspiration to pursue my doctoral degree in Public Health in the US.

Moreover, I wish to extend a word of appreciation to my brothers and sisters, who have provided moral support for the completion of this dissertation. All my friends, who have always been a constant source of support and encouragement during the challenges of my doctoral study deserve my wholehearted thanks as well. 


\section{ABSTRACT OF THE DISSERTATION \\ HUMAN PAPILLOMAVIRUS VACCINE ACCEPTABILITY AMONG PARENTS OF \\ ADOLESCENT GIRLS IN MYSORE, INDIA}

by

Abraham Degarege Mengist

Florida International University, 2019

Miami, Florida

Professor Purnima Madhivanan, Major Professor

This study examined factors that directly affect, mediate, and moderate parental intention-to-vaccinate adolescent daughters with HPV vaccine in Mysore district, India. A cross-sectional study was conducted among 1,609 parents of adolescent girls (778 urban and 831 rural) attending schools in Mysore between February 2010 and October 2011. A validated questionnaire in Kannada was used to assess parental attitudes and beliefs related with HPV infection, cervical cancer, HPV vaccine and general vaccinations. Structural equation modeling was used to estimate parameters and check if a proposed model based on the integrative behavior theory (IBT) could fit the current data.

More than two-thirds (78.0\%) of the parents would accept vaccinating their daughters with HPV vaccine. HPV vaccine acceptance significantly increased with an increase in the perception of parents about the benefits (standardized regression coefficient $(\beta=0.39)$ or sources of information about HPV vaccine $(\beta=0.24)$, but the rate decreased significantly with an increase in the perception about barriers to HPV vaccination $(\beta=-0.44)$. The effect of beliefs about severity of HPV infection or cervical 
cancer $(\beta=0.20)$, and beliefs about benefits $(\beta=0.20)$ or barriers $(\beta=-0.25)$ to vaccination in general on HPV vaccine acceptance were significantly mediated by parental attitudes or source of information about HPV vaccine. Geographical living area significantly moderated the effect of awareness about HPV on beliefs about severity of HPV infection or cervical cancer $(\beta=0.33)$, and the effect of religion on norms related to HPV vaccination $(\beta=0.19)$. Fit of the proposed model to the data was acceptable. [Root Mean Square Error of Approximation $(\mathrm{RMSEA})=0.025,95 \% \mathrm{CI}=0.024,0.026$; Comparative Fit Index $(\mathrm{CFI})=0.92$ and Tucker-Lewis Index $(\mathrm{TLI})=0.91]$

In conclusion, the current study identified modifiable parental attitudes about HPV vaccine and beliefs related with HPV infection, cervical cancer and vaccination, which predicted parental intention-to-vaccinate their adolescent daughters with HPV vaccine in Mysore district, India. Provision of health education interventions tailored against negative attitudes and beliefs about HPV vaccine and vaccination in general will be important for the Indian communities to promote HPV vaccination. 


\section{TABLE OF CONTENTS}

CHAPTER

PAGE

INTRODUCTION

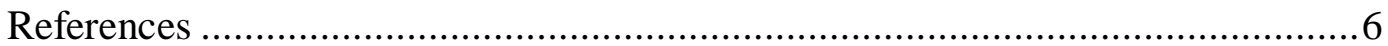

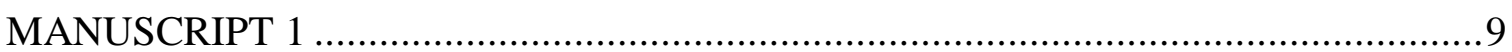

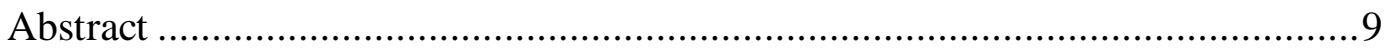

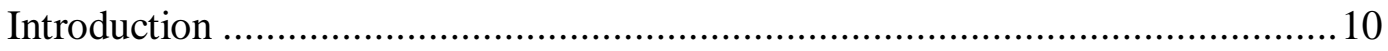

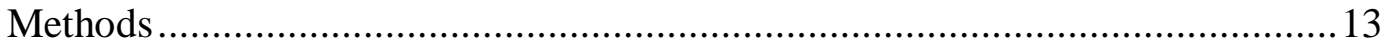

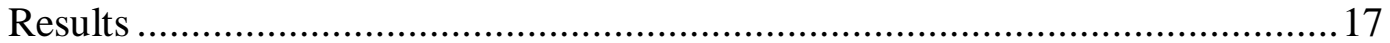

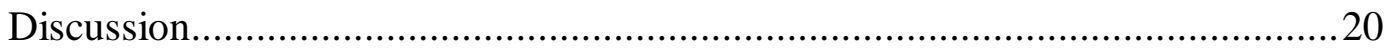

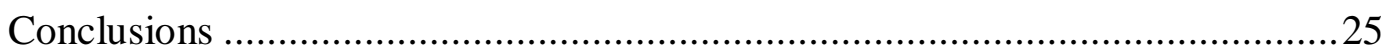

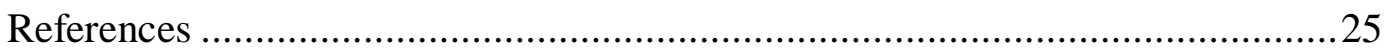

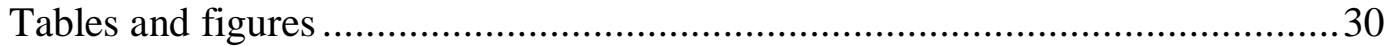

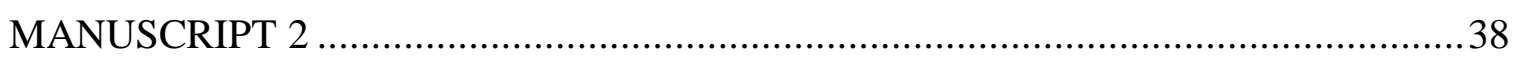

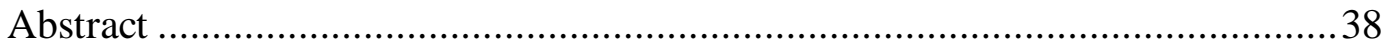

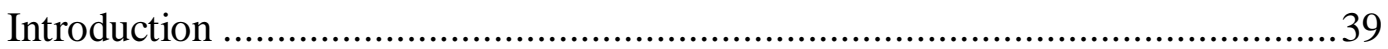

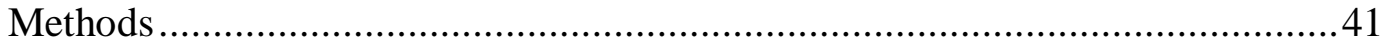

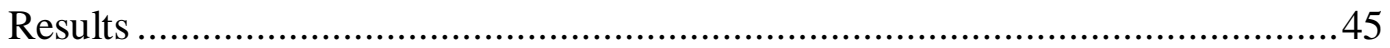

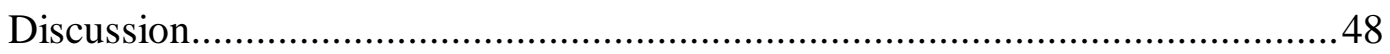

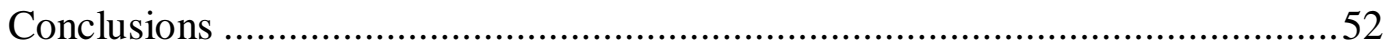

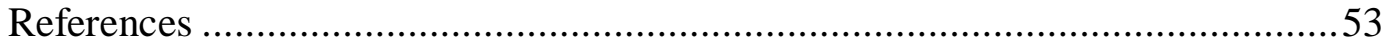

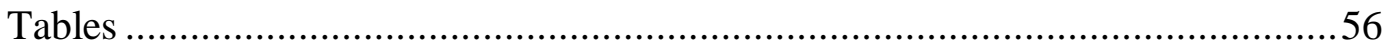

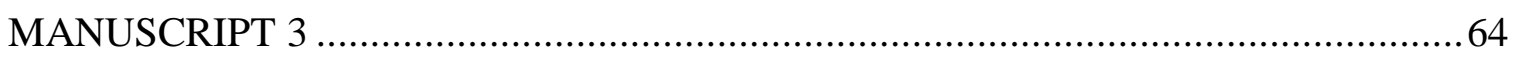

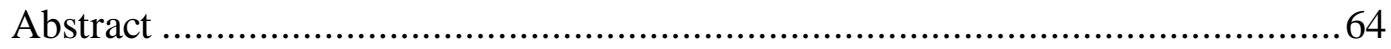

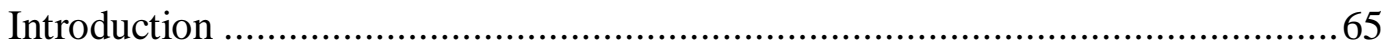

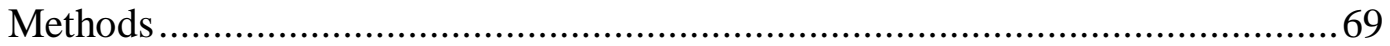

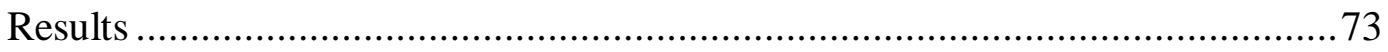

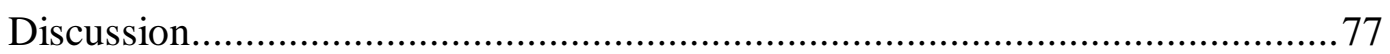

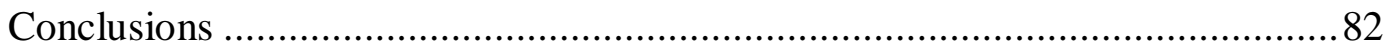

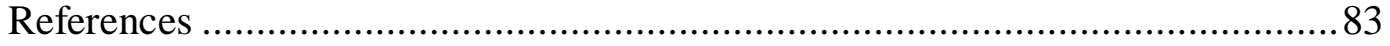

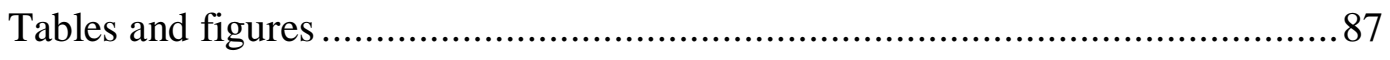

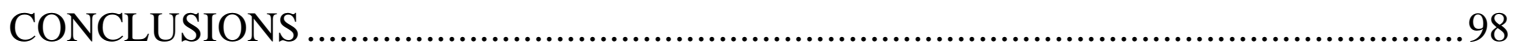

VITA 


\section{LIST OF TABLES}

TABLES

PAGE

Manuscript 3

1. Latent variables/constructs and the corresponding measuring items along

with their responses/scores

2. Unstandardized $(B)$ and standardized $(\beta)$ effects of factors affecting willingness to HPV vaccination for the structural model

3. Unstandardized (B) and standardized effects $(\beta)$ of parental beliefs about HPV, cervical cancer and vaccination on parental attitudes and source of information related to HPV vaccination for the structural model

4. Unstandardized (B) and standardized ( $\beta$ ) effects of background factors on parental beliefs about HPV, cervical cancer and vaccination for the Structural Model. .94

5. Unstandardized and standardized effects of interaction between area and background factors in predicting parental beliefs about HPV, cervical cancer and vaccination for the structural model .96 


\section{ABBREVIATIONS AND ACRONYMS}

\begin{tabular}{|c|c|}
\hline ANM & Auxiliary Nurse Midwife \\
\hline $\mathrm{aOR}$ & Adjusted odds ratio \\
\hline $\mathrm{CDC}$ & Centers for Disease Control and Prevention \\
\hline CFA & Confirmatory Factor Analysis \\
\hline CFI & Comparative Fit Index \\
\hline $\mathrm{CI}$ & Confidence interval \\
\hline GEE & Generalized Estimating Equations \\
\hline $\mathrm{HPV}$ & Human papillomavirus \\
\hline IAPCOI & Indian Academy of Pediatrics Committee on Immunization \\
\hline IBT & Integrative Behavior Theory \\
\hline OR & Odds Ratio \\
\hline PATH & Programme for Appropriate Technology in Health \\
\hline RMSEA & Root Mean Square Error of Approximation \\
\hline SEM & Structural Equation Model \\
\hline TLI & Tucker-Lewis Index \\
\hline USA & United States of America \\
\hline WHO & World Health Organization \\
\hline
\end{tabular}




\section{INTRODUCTION}

Cervical cancer is a major public health problem in the developing regions of the world (Ferlay et al., 2012; Forman et al., 2012). Globally, more than 500,000 women are estimated to be diagnosed with cervical cancer and 275,000 die annually. Almost $80 \%$ of these cases and $88 \%$ of the deaths occur in the developing world (Ferlay et al., 2012; Forman et al., 2012). The age-standardized incidence of the disease was estimated to be higher in India (14.7 women per 100,000) than any other South Asian countries (13.0 women per 100,000) or the world (13.1 women per 100,000) in 2018 (Bruni et al., 2018). Every year, about 122,844 women are diagnosed with the disease in India and 67,477 die from it (Mishra et al., 2016). Factors such as early age at marriage, early age at first sexual intercourse, early age at first full-term pregnancy, multiple pregnancies and longterm use of hormonal contraceptives, which facilitate the progression of HPV infection to neoplastic cervical lesions, might have contributed to the increased incidence of cervical cancer in India (Farooqui \& Zodpey, 2012; Sreedevi et al., 2015). In addition, the cause for increased incidence of cervical cancer in India could be the increased burden of highrisk Human papillomavirus (HPV) strains (HPV18 \& HPV16) in the country (Farooqui \& Zodpey, 2012; Sreedevi et al., 2015).

There are more than 100 different HPV strains, of which 40 can be sexually transmitted (Schiffman \& Castle, 2003). It is predicted that more than $75 \%$ of sexually active individuals will be infected with HPV during their lifetime (Schiffman \& Castle, 2003). While persistent infection with high-risk HPV strains $(16,18,31,33,35,39,51$, $52,56,58,59,66,68)$ can potentially cause cancer on or around the genitals, anus, mouth, or throat; most infections are asymptomatic and clear without any interventions 
within two years due to the body's own immune system (Schiffman \& Castle, 2003). While HPV type 16 and 18 cause majority of cervical and anal cancers, type 6 and 11 are reported to cause $90 \%$ of genital warts (Munoz et al., 2006).

Secondary prevention of cervical cancer using screening and treatment of precancerous lesions is available in most developed countries (WHO, 2015). However, due to logistical reasons, lack of infrastructure and acute shortage of skilled manpower, cervical cancer screening programs are not readily available in most developing countries, where the morbidity and mortality associated with the disease is high (WHO, 2015). Hence, HPV vaccination could be an additional prevention strategy to effectively reduce the burden of cervical cancer in the developing countries (WHO, 2015).

Currently, three types of HPV vaccines (bivalent Cervarix, quadrivalent Gardasil and nanovalent Gardasil 9) are available for preventing HPV infections (Kash et al., 2015). The quadrivalent Gardasil (Merck \& Co, New Jersey) was the first HPV vaccine licensed for use (Kash et al., 2015). The vaccine was first approved for females aged 9 to 26 years in 2006 in USA and later for males in 2009 (Kash et al., 2015). Following that, Cervarix (GlaxoSmithKline (Rixensart, Belgium)) was licensed for females in 2007 in Australia, the European Union and Philippines, and later in other countries of the world (Kash et al., 2015). In 2014, Gardasil 9, a new vaccine, was approved for females and males in USA (Kash et al., 2015). Gardasil prevents four strains of HPV $(6,11,16,18)$ and Cervarix is effective against two strains of HPV 16 and 18 (Kash et al., 2015). Gardasil 9 is effective against nine strains of $\operatorname{HPV}(6,11,16,18,31,33,45,52$, and 58) (Kash et al., 2015). These three vaccines are administered in two (if the first dose is taken before the age of 15) or three (if the first dose is taken at or after the age of 15 years or among 
immunocompromised individuals) doses over a six to 12-month period (HPV Vaccine, New Recommendation, 2010). Gardasil and Cervarix vaccines are safe, effective (90\% to $100 \%$ ) and prevent up to $70 \%$ of cervical cancers for up to seven years, if given to individuals' naïve to infection (De Vincenzo et al., 2014). However, the safety and efficacy of Gardasil 9 vaccine is not well studied.

Although HPV vaccines were shown to be safe and effective; the rate of uptake among at risk-individuals was not as high as anticipated, lowering its potential public health impact. Studies speculated several factors that could potentially hinder an individual's uptake of the vaccine, which include: i) intrapersonal factors such as knowledge, belief and attitude about HPV, cervical cancer and HPV vaccine; and sociodemographic factors that affect the individual's decision making process (Hofstetter \& Rosenthal, 2014; Galbraith et al. 2016; Radisic et al. 2017); ii) interpersonal factors such as peers, partner/marital status, families, health care providers or doctors or health officials (Dempsey et al., 2009; Gerend et al., 2009; Gottlieb et al., 2009; Caskey et al., 2009); and iii) Environmental/structural/political factors (Cunningham et al., 2015; Eberhardt \& Pamuk, 2004; Belani et al., 2014). A clear understanding of factors that may be responsible for influencing vaccine uptake in a specific community would help to implement vaccination programs successfully and achieve maximum coverage.

In order to effectively control cervical cancer, the government of India approved HPV vaccination for females aged 9 to 26 years in 2008 (IAPCOI, 2008). However, introducing HPV vaccine in India has had unique challenges due to unfounded concerns about the efficacy and safety of the vaccine leading to suspension of the HPV vaccination in 2010 (Larson et al., 2010; Lamontagne \& Sherris, 2013). Recently, the government of 
India has decided to include HPV vaccine in the National Immunization Programme (Vashishtha et al., 2014; Chatterjee et al., 2016).

There is, however, limited information on the uptake of the vaccine. HPV vaccination uptake might be low due to misperceptions about HPV infection, cervical cancer and HPV vaccine or due to different moral and cultural reasons in India (Madhivanan et al., 2009; Paul et al., 2014; Basu \& Mittal, 2011). There is a need to investigate factors that are related to HPV vaccine acceptability among parents in India. This will help design evidence-based strategies to achieve maximum HPV vaccine coverage by the target groups, when the National Immunization Programme starts.

Few studies have been conducted to assess the determinants of HPV vaccine acceptance among adolescents and parents in India (Madhivanan et al., 2009; Paul et al., 2014; Basu \& Mittal, 2011). As there is great diversity in social practices, ethnicity, culture, religion and economic composition, determinants of HPV vaccine acceptability are expected to vary geographically in India. Thus, studies in various populations are necessary to design appropriate evidence-based interventions and vaccine delivery strategies to achieve maximum vaccine acceptance on the Indian subcontinent.

The economic and education level of populations, and the nature of socio-cultural and physical environments, which may affect different health outcomes, tend to vary between rural and urban regions in India (Hnatkovska \& Lahir, 2017). The level of access to media, medical services, medical professionals and health insurance might be lower in rural than urban regions in the country due to poorer healthcare infrastructure (Balarajan et al., 2011). Thus, we hypothesized that the attitude and beliefs of parents towards cervical cancer, HPV infection and HPV vaccine may not be similar in rural and urban 
regions in India. As a result, determinants of intention to accept HPV vaccination for adolescents may not be similar among parents living in rural and urban areas in India. However, studies on HPV vaccine acceptability are very limited in rural areas in India. Hence, the objective of this dissertation was to assess the factors that predict intention to receive HPV vaccine among urban and rural parents in Mysore, India. In order to achieve this objective, we have conducted three studies. The first study compared parental attitudes and beliefs related to HPV infection, cervical cancer and HPV vaccine between urban and rural residents in Mysore, India. The second study examined factors associated with HPV vaccine acceptability among parents of adolescent girls in rural area Mysore, India. The third study examined the moderating effect of living area on the relationship of socioeconomic status with parental beliefs related to HPV infection, cervical cancer and vaccination, and the mediating effect of parental attitudes related to HPV vaccine on the relationship of beliefs related to HPV infection, cervical cancer and vaccination with HPV vaccine acceptability. In addition, the third study tested whether a proposed model based on the integrative behavior theory (IBT) could fit the current data and determined the reliability and validity of items used to measure different latent variables hypothesized to affect HPV vaccine acceptability. 


\section{References}

Balarajan, Y., Selvaraj, S., \& Subramanian, S.V. (2011). Health care and equity in India. Lancet, 377(9764): 505-515.

Basu, P., \& Mittal, S. (2011). Acceptability of human papillomavirus vaccine among the urban, affluent and educated parents of young girls residing in Kolkata, Eastern India. J Obstet Gynaecol 2011; 37: (5): 393-401.

Belani, H.K., Sekar, P., Guhaniyogi, R.,...\& Bohjanen, K. (2014). Human papillomavirus vaccine acceptance among young men in Bangalore, India. Int J Dermatol, 53(11):e486-91.

Bruni, L., Barrionuevo-Rosas, L., Albero, G.,..\&\& de Sanjosé S. (2018). ICO Information Centre on HPV and Cancer (HPV Information Centre). Human Papillomavirus and Related Diseases in India. Summary Report Summary Report 10 December 2018. Accessed January 13, 2019 from www.hpvcentre.net/statistics/reports/IND.pdf.

Caskey, R., Lindau, S.T., \& Alexander, G.C. (2009). Knowledge and early adoption of the HPV vaccine among girls and young women: Results of national survey. J Adolesc Health, 45: 453-462.

Chatterjee, S., Chattopadhyay, A., Samanta, L., \& Panigrahi, P. (2016). HPV and Cervical Cancer Epidemiology - Current Status of HPV Vaccination in India. Asian Pac J Cancer Prev, 17(8):3663-3673.

Cunningham, M.S., Skrastins, E., Fitzpatrick, R, ... \& Aronson, K.J. (2015). Cervical cancer screening and HPV vaccine acceptability among rural and urban women in Kilimanjaro Region, Tanzania. BMJ Open, 5(3): e005828.

De Vincenzo, R., Conte, C., Ricci, C., \& Capelli, G. (2014) Long-term efficacy and safety of human papillomavirus vaccination. Int J Womens Health, 6:999-1010.

Dempsey, A.F., Abraham, L.M., Dalton, V., \& Ruffin, M. (2009) Understanding the reasons why mothers do or do not have their adolescent daughters vaccinated against human papillomavirus. Ann Epidemiol, 19(8): 531-538.

Eberhardt, M.S., \& Pamuk, E.R. (2004). Rural Health and Health Care Disparities: The Importance of Place of Residence: Examining Health in Rural and Non rural Areas. American Journal of Public Health. 2004. Am J Public health, 94 (10): 1682.

Farooqui, H.H. \& Zodpey, S. (2012). Cervical cancer control in India: taking evidence to action. J Public Health Policy. 33(2):165-72.

Ferlay, J., Soerjomataram, I., Dikshit, R.,... \& Bray, F. (2015). Cancer incidence and mortality worldwide: sources, methods and major patterns in GLOBOCAN 2012. Int J Cancer, 136(5):E359-86. 
Forman, D., de Martel, C., Lacey, C.J...... \& Franceschi, S. (2012). Global burden of human papillomavirus and related diseases. Vaccine, 30S:F12-23.

Galbraith, K.V., Lechuga, J., Jenerette, C.M., \& Hamilton, J.B. (2016). Parental acceptance and uptake of the HPV vaccine among African-Americans and Latinos in the United States: A literature review. Soc Sci Med, 159:116-26.

Gerend, M., Weibley, E., \& Bland, H. (2009). Parental response to HPV vaccine availability: Uptake and intentions. J Adolesc Health, 45: 528-531.

Gottlieb, S.L., Brewer, N.T., Sternberg, M.R., \& Markowitz, L.E. (2009). Human papillomavirus vaccine initiation in an area with elevated rates of cervical cancer. $\mathbf{J}$ Adolesc Health, 45: 430-437.

Hnatkovska, V., \& Lahir, A. (2017). International growth center. The Rural-Urban Divide in India. Accessed on March 21, 2017 from http://www.theigc.org/wpcontent/uploads/2014/09/Hnatkovska-Lahiri-2012-Working-Paper-March.pdf.

Hofstetter, A.M., \& Rosenthal, S.L. (2014). Factors impacting HPV vaccination: lessons for health care professionals. Expert Rev Vaccines,13(8):1013-26.

HPV Vaccine, New Recommendation - Data Brief Vermont Immunization Registry. Accessed on March 18, 2017 from http://vtaac.org/wp-content/uploads/HPV-Data-Brief2016-Update.pdf.

Indian Academy of Pediatrics Committee on Immunization (IAPCOI) (2008). Consensus recommendations on immunization, 2008. Indian Pediatrics, 45: 635-648.

Kash, N., Lee, M.A., Kollipara, R., \& Tyring, S.K. (2015). Safety and Efficacy Data on Vaccines and Immunization to Human Papillomavirus. J Clin Med, 4(4):614-33.

Lamontagne, D.S., Sherris, J.D. (2013). Addressing questions about the HPV vaccine project in India. Lancet Oncol,14:e492.

Larson, H.J., Brocard, P., \& Garnett, G. (2010). The India HPV-vaccine suspension. Lancet, 376:572-3.

Madhivanan, P., Krupp, K., Yashodha, M.N., \& Reingold, A.L. (2009). Attitudes toward HPV vaccination among parents of adolescent girls in Mysore, India. Vaccine, 27(38):5203-5208.

Mishra, G.A., Pimple, S.A., \& Shastri, S.S. (2016). Prevention of Cervix Cancer in India. Oncology, 91:1-7. 
Munoz, N., Castellsague, X., de González, A.B., \& Gissmann, L. (2006). Chapter 1: HPV in the etiology of human cancer. Vaccine, 24(S3):1-10.

Paul, P., Tanner, A.E., Gravitt, P.E., \& Zimet, G.D. (2014). Acceptability of HPV Vaccine Implementation Among Parents in India. Health Care Women Int, 35 (10): 11481161.

Radisic, G., Chapman, J., Flight, I., \& Wilson, C. (2017). Factors associated with parents' attitudes to the HPV vaccination of their adolescent sons: A systematic review. Prev Med., 95:26-37.

Schiffman, M., \& Castle, P.E. Human papillomavirus: epidemiology and public health. Arch Pathol Lab Med 2003; 127 (8): 930-4

Sreedevi, A., Javed, R., \& Dinesh, A. (2015). Epidemiology of cervical cancer with special focus on India. Int J Womens Health. 2015; 7:405-14.

Vashishtha, V.M., Choudhury, P., Kalra, A., \& Indian Academy of Pediatrics. (2014). Indian Academy of Pediatrics (IAP) recommended immunization schedule for children aged 0 through 18 years - India, 2014 and updates on immunization. Indian Pediatr, 51:785-800.

WHO. New guidance for the prevention and control of cervical cancer. Accessed Sept 6, 2015 from http://www.who.int/reproductivehealth/topics/cancers/en/. 


\title{
MANUSCRIPT 1
}

(C) Copyright 2018

Degarege, A., Krupp, K., Fennie, K., Li, T., Stephens, D.P., Marlow, L.A.V., Srinivas, V., Arun, A., \& Madhivanan P. (2018). Urban-rural inequities in the parental attitudes and beliefs towards Human papillomavirus infection, cervical cancer and HPV vaccine in Mysore, India. J Pediat Adolesc Gynecol, 31(5):494-502.

\begin{abstract}
Objective: The aim of this study was to compare the parental attitudes and beliefs about HPV, cervical cancer and HPV vaccine between urban and rural areas, India.

Methods: A cross-sectional study was conducted among parents of school going adolescent girls in urban (between February, 2010 and January, 2011) and rural (September and October, 2011) areas in Mysore district, India. A self-administered questionnaire in English and Kannada was used to collect information about the sociodemographic characteristics, parental attitudes and beliefs about HPV infection, cervical cancer and HPV vaccine.
\end{abstract}

Results: A total of 1609 parents from urban $(n=778)$ and rural $(n=831)$ areas participated in this study. Majority of the parents had never heard about HPV (73.6\%), did not know that their daughters could get an HPV infection (62.7\%) or cervical cancer $(64.1 \%)$ in the future, and believed that HPV vaccine was not effective (67.1\%). Parents living in the urban area were more likely to believe that HPV infection (adjusted Odds Ratio (aOR) 2.69; 95\%CI:1.43, 5.06) and cervical cancer (aOR 2.68; 95\%CI:1.83, 3.91) could cause serious health problems than those living in the rural area. The odds of agreeing that HPV 
vaccination will make girls sexually active was lower among urban than rural parents (aOR 0.55; 95\%CI:0.33, 0.94). There was no significant difference among parents in the urban and rural areas in their beliefs about susceptibility of their daughter to HPV infection or cervical cancer, and beliefs about the safety and ability of HPV vaccine to protect cervical cancer.

Conclusions: Rural parents might be reluctant to recommend behaviors that can help prevent HPV infection and cervical cancer such as HPV vaccination for their daughters. Key words: Attitudes, Beliefs, Cervical Cancer, HPV infection, HPV vaccine, India

\section{Introduction}

Globally, an estimated 528,000 or more women are diagnosed with cervical cancer and 275,000 die each year (GLOBOCAN, 2012). Almost 80\% of these cases and $88 \%$ of the deaths occur in the developing world (GLOBOCAN, 2012). The agestandardized annual incidence of the disease was estimated to be higher in India (22 women per 100,000) than other South-Asian countries (19.3 women per 100,000) or the world (14 women per 100,000) in 2012 (Bruni et al., 2016). Factors such as early age at marriage, early age at first sexual intercourse, early age at first full-term pregnancy, multiple pregnancies and long term use of hormonal contraceptives, which facilitate the progression for HPV infection to neoplastic cervical lesions, may contribute to the increased incidence of cervical cancer in India (Sreedevi et al., 2015). In addition, the cause for the increased incidence of cervical cancer in India could be the increased burden of high-risk HPV strains in the country, with HPV-18 \& 16 being the most common (Sreedevi et al., 2015). 
There are more than 170 different HPV strains, of which 40 can be sexually transmitted. It is predicted that $>75 \%$ of sexually active individuals will be infected with HPV during their lifetime (Schiffman and Castle, 2003; Yudin, 2010). While persistent infection with high-risk HPV strains $(11,16,18,33,51,52,53,58,61)$ can potentially cause cancer or warts on or around the genitals, anus, mouth, or throat; most infections are asymptomatic and clear without any interventions within two years due to the body's own immune system (Schiffman and Castle, 2003; Hager, 2009). HPV type 16 and 18 cause the majority of cervical and anal cancers, while type 6 and 11 cause $90 \%$ of genital warts (Munoz et al., 2006).

Currently, three types of HPV vaccines (Cervarix, Gardasil and Gardasil 9) are available for preventing HPV infections (Harper \& DeMars, 2017). Gardasil prevents four strains of $\operatorname{HPV}(6,11,16,18)$. Cervarix is effective against two strains (16 and 18) and Gardasil 9 is effective against nine strains of $\operatorname{HPV}(6,11,16,18,31,33,45,52$, and 58) (Harper \& DeMars, 2017; Tyson, 2017). The three vaccines are safe and effective (90\% to $100 \%$ ) (Harper \& DeMars, 2017; Tyson, 2017). Cervarix and Gardasil potentially prevents $75 \%$ of cervical cancers related to HPV 16 and 18 , and Gardasil 9 prevents $89 \%$ of cancers related to HPV 16,18,31,33,45,52 and 58 (Hartwiga et al., 2015). In addition, Gardasil potentially prevents $47 \%$ pre-cancerous lesions related to HPV 6,11,16, 18 and Gardasil 9 prevents $82.0 \%$ of pre-cancerous lesions related to HPV 16,18,31,33,45,52 and 58 (Hartwiga et al., 2015).

Although HPV vaccines have been shown to be safe and effective; the rate of uptake among at-risk individuals is not as high as anticipated, lowering its potential public health impact. HPV vaccination was even suspended in India until recently after 
being approved in 2008 (IAPCOI, 2008). The factors that contributed to the suspension of HPV vaccination in India included lack of knowledge and misinformation about HPV, cervical cancer and HPV vaccine; negative attitudes and beliefs about HPV, cervical cancer and HPV vaccine; and sociodemographic and cultural factors (IAPCOI, 2008). Indeed, health behavior theories indicate that knowledge, sociodemographic and cultural factors affect attitudes and beliefs of people to a disease pathogenesis, treatment and prevention measures (Champion \& Skinner, 2008; Fishbein, 2009). The attitudes and beliefs of individuals towards a disease, in turn influences the behavior of individuals to prevent a disease (Champion \& Skinner, 2008; Fishbein, 2009).

As the economic and education level of populations, and the nature of sociocultural and physical environments, tend to vary between urban and rural areas (Eberhardt \& Pamuk, 2004), we hypothesized that the attitudes and beliefs of individuals towards HPV infection, cervical cancer and HPV vaccine are not similar among residents in urban and rural areas. However, evidence is limited to support this notion. Understanding the attitudes and beliefs of individuals about HPV infection, cervical cancer and HPV vaccine will help to inform the design of appropriate public health programs to prevent cancer. The information will be particularly important in rural areas, where $68.4 \%$ of the Indian population lives, and death rates due to cervical cancer are high (Dikshit et al., 2012). Given that previous studies have focused mostly on urban populations (Madhivanan et al., 2009; Ramavath \& Olyai, 2013), the objective of this study was to compare parental attitudes and beliefs about HPV infection, cervical cancer and HPV vaccine between urban and rural areas in Mysore district, India. 


\section{Methods}

Study area

A cross-sectional study was conducted among parents of school going adolescent girls who were living in urban and rural regions in Mysore district, India. Data from urban parents were collected between February, 2010 and January, 2011, and data from rural parents were collected between September and October, 2011. Mysore district is located in the southern part of the state of Karnataka, south west India. It ranks third in terms of population size $(3,001,127$, density: 450/km2) among 30 districts in the state (Census, 2011). (Fig 1). Majority of the population $(1,755,714)$ in Mysore district live in the rural areas (Census, 2011). Age-standardized annual cervical cancer mortality rate in Karnataka was 16.5 per 100, 000 in 2010 (Dikshit et al., 2012).

\section{[Insert figure 1 here]}

\section{Sampling techniques}

A total of 1,609 parents (778 urban and 831 rural) were involved in this study. Twelve schools (five government, four private and three religious) in Mysore city and 11 schools (10 government and 1 private) in rural Mysore Taluk were selected based on probability proportionate to size. First a program announcement was sent home with all girls attending $7^{\text {th }}$ through $10^{\text {th }}$ grades in the selected schools explaining the study and inviting eligible parents to participate. Then all girls aged 11 to 15 years in these schools were enumerated and 1631 female students randomly selected and provided with a questionnaire to take to their parents, who filled them out and returned within seven days. Only one parent in a family filled out the questionnaire. Only $2.7 \%$ of parents in the 
urban area and $2.2 \%$ parents in the rural area failed to return the completed questionnaire along with the signed consent form.

\section{Questionnaire and measures}

A self-administered questionnaire in English and Kannada was used to collect information about the socio-demographic characteristics, awareness about HPV, source of information about HPV vaccine, attitude and beliefs of parents about HPV infection, cervical cancer and HPV vaccine. The questionnaire contained 126 items, however only 26 items were selected for the analysis of this study based on the integrated model for behavior (IMB) (Fishbein, 2009) and the health belief model (HBM) (Champion \& Skinner, 2008). Out of 26, 15 items contained information on hypothesized correlates of attitudes and believes about HPV infection, cervical cancer and HPV vaccine (age, gender, employment, education, religion, marital status, area of residence, HPV awareness, source of information about HPV vaccine) based on literature, IMB and HBM (Fishbein, 2009; Champion \& Skinner, 2008). The items were validated and used in previous studies (Witte, 1996; Marlow et al., 2007). Parental awareness about HPV was assessed by asking the question "Have you ever heard of $H P V$ ". Responses were recoded as 'yes' and 'no'. Source of information about HPV vaccine was collected using eight items (Television, Newspaper or Radio, Internet, Doctor, ANM or Anganwadi teacher or, Worker, Friends or Neighbors, My daughter's school, Family member or relatives). Responses were recorded on a four point scale ( $1=$ never, $2=$ not often, $3=$ often, $4=$ very often), but were dichotomized into 'no' (never) and 'yes'(very often, often, not often) during data analysis. 
The remaining 11 items were used to assess information on parental attitude and beliefs about HPV infection, cervical cancer and HPV vaccine. Out of the 11 items, four were used to assess parental attitudes towards susceptibility to cervical cancer ('It is possible that my daughter will get cervical cancer in the future' and 'It is likely that my daughter may get cervical cancer someday' (Cronbach's alpha $(\alpha)=0.73$ ) and HPV infection ('It is likely that my daughter will get HPV in the future' and 'My daughter may be at-risk of getting HPV infection' $\alpha=0.72$ ). Other four items were used to assess beliefs towards severity of cervical cancer ('I believe that cervical cancer is serious disease' and 'I believe that cervical cancer can be extremely harmful', $\alpha=0.65)$ and HPV infection (' $I$ believe that HPV infection can cause serious health problem' and 'I believe that HPV infection can be extremely harmful', $\alpha=0.63$ ). Responses to these eight items were recorded a on a three-point scale (1=disagree, 2=Do not know, 3=Agree).

The remaining three items (out of the 12) were used to collect information about parental attitudes about HPV vaccine ('HPV vaccine is safe', 'HPV vaccine will prevent cervical cancer' and 'daughter receiving HPV vaccine may become sexually active'). Responses to the items ' $H P V$ vaccine is safe' and ' $H P V$ vaccine will prevent cervical cancer' were recorded on a three-point scale ('very important', 'important' and 'not important at all'). Similarly, responses to the questions about beliefs on whether HPV vaccination will make girls sexually active was recorded on a three-point scale $(1=$ 'disagree', 2='do not know', 3='agree') . 


\section{Ethical consideration}

Ethical approval to conduct this study was obtained from the Institutional Review Boards at Florida International University and Public Health Research Institute of India. The Block Education officer and school administrators were also asked for their permission to conduct the study. Only parents who provided written informed consent were included in the study.

\section{Data analysis}

Data were entered into an MS Access database, checked for completeness and analyzed using Stata software (Version 14, Texas, USA). The outcome variables were: i) parental attitudes about susceptibility of daughter to HPV infection, and susceptibility to cervical cancer (continuous); ii) parental belief about severity of HPV infection and cervical cancer (continuous) and; iii) parental attitude that HPV vaccine is safe (yes, no) and that HPV vaccine prevents cervical cancer (yes, no) and makes adolescents sexually active (disagree, do not know, agree). The main exposure variable was geographical area $(0=$ rural, $1=$ urban $)$. Other explanatory variables included: sex $(0=$ male, $1=$ female $)$, age in years (continuous), marital status $(0=$ unmarried, $1=$ married $)$, religion $(0=$ Hindus, $1=$ Muslims, $2=$ Christians/others $)$, employment $(0=$ Retired/unemployed, $1=$ Employed part-time, 2=Employed fulltime, 3=Self-employed, 4= Full time homemaker) and educational status $\left(0=\right.$ No formal education, $1=$ Grade 1 to $10^{\text {th }}, 2=$ High school or bachelor degree, 4=Vocational training (diploma), 5=Master degree or above) of parents and their awareness about HPV ( $0=$ no, $1=y e s)$ and source of information about vaccines. Parental response to questions assessing their beliefs about the safety of HPV vaccine and its

importance to protect cervical cancer was originally recorded in three categories as 'very 
important', 'important' and 'not important at all'. However, the three categories were merged into two during data analysis as 'yes' (very important and important) and 'no' (not important at all).

Percentages were used to describe the frequency of parental responses to questions addressing beliefs and attitudes towards cervical cancer, HPV infection and HPV vaccine. Chi-square test was used to check if there was a relationship between sociodemographic factors and parental attitudes and beliefs towards cervical cancer, HPV infection and HPV vaccine. Because of potential clustering of parental beliefs towards HPV vaccine by the school that the daughters attended, a Generalized Estimating Equations (GEE) using logit function (Stata command= xtgee) was used to test the hypothesis that area of residence is associated with parental attitudes about HPV vaccine (safety, protective ability against cervical cancer, belief that HPV vaccination make daughters sexually active). Similarly, a multinomial regression that accounts school as a clustering variable was used to test the hypothesis that area of residence was associated with parental attitudes about susceptibility of daughters to HPV infection or cervical cancer, and parental belief about severity of HPV infection or cervical cancer. Values for the within-school correlation matrix ranged from 0.012 to 0.067 for the different outcomes. Odds ratios (OR) were calculated along with their associated $95 \%$ confidence interval (CI). 


\section{Results}

Characteristics of the study participants

Of the 800 parents contacted in the urban area, $778(97.3 \%)$ returned the completed questionnaire along with the signed consent forms, and 831 (97.8\%) of the 850 parents contacted in the rural area returned the completed questionnaires along with the signed consent forms. The mean age ( \pm standard deviation) of the study participants was $38.3 \pm 6.58$ years. Majority of them were female (73.0\%), Hindu by religion (88.9\%), employed (54.8\%), educated (60.0\%), and married (93.0\%). There were significant differences in the composition of participants between urban and rural regions in terms of gender, age, education, occupation, religion and marital status (Table 1). The proportion of parents who were female, aged younger than 35 years and employed part-time were lower in the urban area than in the rural area $(\mathrm{p}<0.01$ for all). The proportion of parents who were married, Muslim, educated and full-time employees were greater in the urban area than the rural region ( $\mathrm{p}<0.01$ for all). About $71.6 \%$ of urban parents and $75.5 \%$ of rural parents had never heard about HPV. The proportion of parents who got information about HPV vaccine from television, newspaper or radio, internet or doctor was greater in urban than rural region $(\mathrm{p}<0.01$ for all).

[Insert Table 1 here]

Parental attitudes and beliefs about HPV infection, cervical cancer and HPV vaccine

Majority of the parents did not know that their daughters could be at-risk for HPV infection $(58.2 \%)$ or cervical cancer $(64.1 \%)$ in the future. However, majority of the study participants believed that HPV infection (65.3\%) and cervical cancer (68.9\%) could 
cause serious health problems. Majority of the parents also believed that HPV vaccine was safe $(90.6 \%)$ and could prevent cervical cancer (90.0\%). In addition, $21 \%$ agreed that HPV vaccination would make girls sexually active.

Greater percentage of parents in the rural region than in the urban region indicated that they did not know whether their daughter was at-risk of getting HPV infection $(62.9 \%$ vs $53.2 \%, \mathrm{p}<0.001)$ or cervical cancer $(66.8 \%$ vs $61.2 \%, \mathrm{p}=0.02)$. Similarly, the percentage of parents who did not know, and the percentage of parents who disagreed that HPV infection or cervical cancer could cause serious health problems was greater among rural residents than in the urban region (Table 2). However, parents living in the urban area tended to agree that HPV infection $(74.2 \%$ vs $57.0 \%, \mathrm{p}<0.001)$ or cervical cancer $(78.7 \%$ vs $59.7 \%, \mathrm{p}<0.001)$ caused serious health problems more often than parents in the rural area (Fig 2). The percentage of parents who agreed that HPV vaccine would make girls sexually active were greater among residents in the rural region than the urban one $(23.5 \%$ vs $18.5 \%, \mathrm{p}=0.001)$.

[Insert table 2 here]

[Insert figure 2 here]

Factors associated with parental attitudes and beliefs about HPV infection, cervical cancer and $H P V$ vaccine

Urban parents were more likely to believe that HPV infection could cause serious health problems (aOR 2.69; 95\%CI 1.43, 5.06) or that it can be extremely harmful (aOR $1.81 ; 95 \%$ CI $1.08,3.04)$ than rural parents. Similarly, parents living in the urban area were more likely to believe that cervical cancer is a serious disease (aOR 2.68; 95\% CI 
$1.83,3.91)$ or that it can be extremely harmful (aOR 2.28; 95\% CI 1.26, 4.12) than those living in the rural area. Parents living in the urban region also had lower odds of agreeing that HPV vaccination will make girls sexually active than those in the rural region (aOR 0.55; $95 \%$ CI $0.33,0.94)$. However, there was no significant difference among urban and rural parents in their beliefs about safety of HPV vaccine and ability of the vaccine to

prevent cervical cancer (Table 3). Furthermore, parental perception about the perceived susceptibility of their daughter to get HPV infection and cervical cancer was not significantly different between urban and rural parents (Table 3).

[Insert table 3 here]

\section{Discussion}

This study compared the parental attitudes and belief about HPV infection, cervical cancer and HPV vaccine among urban and rural areas of Mysore district, India. The study showed evidence of urban-rural differences in the parental attitudes and beliefs about HPV, cervical cancer and HPV vaccine. When compared to parents living in rural regions, urban parents were more likely to believe that HPV infection and cervical cancer caused serious health problems. In addition, urban parents were less likely to agree that HPV vaccination will make girls sexually active

The increased tendency of urban parents to believe that HPV infection and cervical cancer could cause serious health problems could be due to their knowledge about severity and morbidities related to HPV infection and cervical cancer. In one study of a school population, the proportion who knew about cervical cancer and HPV infection was greater in urban than rural areas of Noida and Delhi, India (Hussain et al., 2014). 
Although the difference was not significant, a relatively larger number of parents in the urban region compared to those in the rural region had ever heard of HPV in the current study. In addition, majority ( $>85 \%)$ of the parents living in the urban region had formal education and more than $30 \%$ had more than high school education. However, only $36.6 \%$ of rural parents had formal education and only $2.3 \%$ had more than high school education. Literacy rates in India are also greater among urban than rural populations (Das \& Pathak, 2012). Furthermore, different media such as radio and television, and health care centers, which could be potential sources of correct information about HPV and cervical cancer, are more common in urban areas (Das \& Pathak, 2012). Hence, parents in urban areas may have better knowledge about HPV and this may have positively influenced their beliefs about the severity of HPV infection and cervical cancer. However, in Tanzania, the proportion of individuals who believed that cervical cancer is fatal was lower in urban than rural area (Cunningham et al., 2015). The variation on the type of items used for assessing beliefs around severity of cervical cancer could be a reason for the difference (cervical cancer is fatal vs 'I believe that cervical cancer is serious disease' and 'I believe that cervical cancer can be extremely harmful'). A study in USA reported contradictory results on the beliefs about severity of colorectal cancer, when data were analyzed based on the responses for two items (Hughes et al. 2015). Rural residents were more likely to agree that colorectal cancer was severe than urban residents, when data were analyzed based on the response to the item 'colorectal cancer would change whole life'. However, rural residents were less likely to agree that colorectal cancer was severe when data were analyzed based on the response to the item 'would not live longer than five years if I develop colorectal cancer'. 
Similarly, the reduced odds of the belief that HPV vaccine makes girls sexually active among urban parents could be due to a greater knowledge about HPV vaccine in the urban area. Urban parents may know better and communicate the knowledge to their daughter, that HPV vaccine protects only some strains of HPV infection (Harper \& DeMars, 2017). In addition, urban parents may think that their daughter would get information about HPV vaccine from different reliable sources, thus decreasing their perception that HPV vaccination would lead to increased sexual activity. A study in northern India found that greater proportion of individuals in urban than in rural areas of Noida and Delhi were aware of the HPV vaccine (Hussain et al., 2014). Urban women in Wardha district, located in the northeastern part of the state of Maharashtra also reported more positive attitudes towards breast cancer treatment and screening as compared to rural women (Gangane et al., 2015).

While majority ( $\geq 90 \%)$ of study participants believed that HPV vaccine was safe and could protect against cervical cancer in both urban and rural areas; $18.5 \%$ of the urban parents and $23.5 \%$ of rural parents believed that HPV vaccination will make girls sexually active and over half of the parents in both areas did not know if HPV vaccination will make girls sexually active. As HPV vaccination targets adolescents aged 11-12 years to prevent cervical cancer and genital warts (Tyson, 2017), parents fear that it would give girls a false sense of security against infection with sexual transmitted infections other than HPV, and encourage them to become sexually active or practice risky sexual behavior if they are already sexually active (Tanday, 2014). Thus, parents might be reluctant to recommend HPV vaccination for their daughter. Hence, educational programs that can create awareness about infections that can be protected by HPV 
vaccine are necessary for both urban and rural area in Mysore, India. In addition, previous research findings, which confirmed that HPV vaccination does not affect sexual activity in USA, Europe, Africa and South America (Tanday, 2014; Hansen et al., 2014; Rysavy et al., 2014; Turiho et al., 2015; Ruiz-Sternberg \& Pinzón-Rondón, 2014), should be communicated to parents to increase their trust that HPV vaccination will not change the sexual behavior of their daughters. Rather, HPV vaccination may increase awareness of sexually transmitted infections, sexual health (e.g. condom use) and importance of pap smear screening (Ruiz-Sternberg \& Pinzón-Rondón, 2014; Ports et al., 2014;

Sopracordevole et al., 2013). Moreover, informing parents about the study findings by Grimaldi-Bensouda et al., (2017), and Jefferson and Jørgensen (2017), which showed lack of association between HPV vaccination and autoimmune disease, would increase their trust on the safety of the vaccine. This will further increase parental acceptance of HPV vaccination for their daughters. However, studies are necessary to make firm conclusion whether HPV vaccination will not affect adolescent sexual behavior in India population.

Almost three-quarters of the parents living in both the urban (71.6\%) and rural (75.4\%) areas had never heard of HPV. A study among women in Odisha, India reported lack of awareness about HPV by the majority of study participants (68.8\%) (Khanna et al., 2015). This relatively high level of unawareness about HPV in India is however lower, when compared to reports from other Asian countries. For example, the proportion of women who were unaware of HPV was $84.5 \%$ in a sample of six community clusters from three major cities (Shenyang, Shanghai and Beijing) and rural areas (Shanxi, Xinjiang and Henan) in China (Li et al., 2009), and 88.4\% in rural villages in states of 
Perak and Pahang in Malaysia (Wong, 2011). About 74\% parents of children aged 10-13 years were also unaware of HPV in the town Ankara, Turkey (Seven et al., 2015).The relatively greater rate of HPV awareness observed among the Indian parents could be due to increased media coverage associated with the demonstration study conducted in the country from 2009 to 2011 , to study feasibility and appropriate delivery strategies of HPV vaccine for girls (Lamontagne \& Sherris, 2013). Knowledge about HPV affects the acceptability of HPV vaccine by individuals (Patel et al., 2016). Thus, provision of HPV and health education in the community will be paramount to help increase uptake of the HPV vaccine in future government initiatives to include HPV vaccine in the national immunization program (Chatterjee et al., 2016; Vashishtha et al., 2014). Some states (Punjab, Delhi) in India have already included HPV vaccination in the immunization programme (WHO, 2017; Chatterjee, 2017).

To our knowledge, this is the first Indian study that assessed urban-rural differences and determinants of parental attitudes and beliefs about HPV, cervical cancer and HPV vaccine. These results will be useful when designing interventions to combat HPV infection and cervical cancer, and increase HPV vaccine uptake by target groups in rural and urban regions. The study involved a relatively large sample size with a response rate of over $95 \%$. This should increase the generalizability of the findings to target populations in India. However, this study was not without limitations: data were selfreported and there could be information bias as parents may have gotten support from other family members or friend when they responded to the questionnaire. In addition, the rural data were collected seven months after the urban data were collected, which may affect the findings of the study. The rural parents may acquire knowledge about 
HPV, cervical cancer and HPV vaccine during this period, particularly because HPV vaccine was approved in 2008 in India (IAPCOI, 2008). This may introduce bias to the current results underestimating the observed difference in the parental attitudes and beliefs about HPV, cervical cancer and HPV vaccine between urban and rural residents.

\section{Conclusions}

Rural parents might be reluctant to make decisions that can help prevent HPV infection and cervical cancer such as HPV vaccination for their daughters. Provision of health education about the different types of cancers caused by HPV infection that can be effectively prevented through HPV vaccination is necessary for rural Indian parents.

\section{Acknowledgement}

The study was funded by Investigator Initiated Award from Merck \& Co., Inc. KK is a Global Health Equity Scholar funded by the Fogarty International Center at National Institute for Health (D43 TW010540). The funders had no role in the study design, data collection, analysis, interpretation and publication of the manuscript. We would like to thank the study participants for taking time to complete the questionnaires. We would like thank also the Block Development Officer for Mysore and the administrative staff of the schools for their assistance during data collection.

\section{Conflict of interest}

The authors report no proprietary or commercial interest in any product mentioned or concept discussed in this article. 


\section{References}

Bruni, L., Barrionuevo-Rosas, L., Albero, G.,..\&\& de Sanjosé S. (2016). ICO Information Centre on HPV and Cancer (HPV Information Centre). Human Papillomavirus and Related Diseases in India. Summary Report 15 December 2016. Accessed March 20, 2017 from http://www.hpvcentre.net/statistics/reports/ind.pdf.

Census of India 2011, http://www.censusindia.gov.in/; 2011[accessed 20 July, 2017]

Champion, V.L., \& Skinner, C.S. (2008). The health belief model. In Glanz K, Rimer BK, Viswanath K (Eds) "Health behavior and health education: theory, research, and practice (2008). San Francisco: Jossey-Bass.

Chatterjee, P. (2017). Delhi First State to Launch HPV Vaccine as Public Health Programme in Schools, http://indianexpress.com/article/cities/delhi/delhi-first-state-tolaunch-hpv-vaccine-as-public-health-programme-in-schools/ [accessed 21 March 2017].

Chatterjee, S., Chattopadhyay, A., Samanta, L., \& Panigrahi, P. (2016). HPV and Cervical Cancer Epidemiology - Current Status of HPV Vaccination in India. Asian Pac J Cancer Prev, 17(8):3663-3673.

Cunningham, M.S., Skrastins, E., Fitzpatrick, R.,....\& Aronson, K.J. (2015). Cervical cancer screening and HPV vaccine acceptability among rural and urban women in Kilimanjaro Region, Tanzania. BMJ Open, 5(3):e005828.

Das, D., \& Pathak, M. (2012). The growing rural-urban disparity in India: Some issues. Int J of Adv Res Tech, 1: 1-7.

Dikshit, R., Gupta, P.C., Ramasundarahettige, C.,...\& Million Death Study Collaborators. (2012). Cancer mortality in India: a nationally representative survey. Lancet, 379:18071816.

Eberhardt, M.S., \& Pamuk, E.R. (2004). The Importance of Place of Residence: Examining Health in Rural and Non rural Areas. Am J Public Health, 94 (10): 1682.

Ferlay, J., Soerjomataram, I., Dikshit, R.,... \& Bray, F. (2015). Cancer incidence and mortality worldwide: sources, methods and major patterns in GLOBOCAN 2012. Int J Cancer,136(5):E359-86.

Fishbein, M. (2009). An integrative model for behavioral prediction and its application to health promotion. In DiClemente RJ, Crosby RA, Kegler MC(Eds) "Emerging theories in health promotion practice and research" (2009). San Francisco: Jossey-Bass.

Gangane, N., Ng, N., \& Sebastian, M.S. (2015). Women's Knowledge, Attitudes, and Practices about Breast Cancer in a Rural District of Central India. Asian Pac J Cancer Prev, 16(16):6863-70. 
Grimaldi-Bensouda, L., Rossignol, M., Koné-Paut, I., ...\& PGRx-AD Study Group (2017). Risk of autoimmune diseases and human papilloma virus (HPV) vaccines: Six years of case-referent surveillance. J Autoimmun, 79:84-90.

Hager, W.D. (2009). Human papilloma virus infection and prevention in the adolescent population. J Pediatr Adolesc Gynecol, 22(4):197-204.

Hansen, B.T., Kjær, S.K., Arnheim-Dahlström, L., ...\& Nygård, M. (2014). Human papillomavirus (HPV) vaccination and subsequent sexual behaviour: evidence from a large survey of Nordic women. Vaccine, 32(39):4945-4953.

Harper, D.M., \& DeMars, L.R. (2017). HPV vaccines - A review of the first decade. Gynecol Oncol.146(1):196-204.

Hartwiga, S., Baldauf, J.J., Dominiak-Felden, G.,... \& Castellsaguéd, X. (2015). Estimation of the epidemiological burden of HPV-related anogenital cancers, precancerous lesions, and genital warts in women and men in Europe: Potential additional benefit of a nine-valent second-generation HPV vaccine compared to first generation HPV vaccines. Papillomavirus, 1: 90-100.

Hughes, A.G., Watanabe-Galloway, S., Schnell, P., \& Soliman, A.S. (2015). Rural-Urban Differences in Colorectal Cancer Screening Barriers in Nebraska. J Community Health, 40(6):1065-74.

Hussain, S., Nasare, V., Kumari, M.,...\& Bharadwaj, M. (2014). Perception of human papillomavirus infection, cervical cancer and HPV vaccination in North Indian population. PLoS One, 9(11):e112861.

Indian Academy of Pediatrics Committee on Immunization (IAPCOI). (2008). Consensus recommendations on immunization, 2008. Indian Pediatr, 45: 635-648.

Indian Academy of Pediatrics Committee on Immunization (IAPCOI). (2008). Consensus recommendations on immunization, 2008. Indian Pediatr, 45: 635-648.

Jefferson, T., \& Jørgensen, L. (2017). Human papillomavirus vaccines, complex regional pain syndrome, postural orthostatic tachycardia syndrome, and autonomic dysfunction - a review of the regulatory evidence from the European Medicines Agency. Indian J Med Ethics, 2(1):30-37.

Khanna, N., Ramaseshan, A., Arnold, S.,....\& Panigrahi P. (2015). Community Awareness of HPV Screening and Vaccination in Odisha. Obstet Gynecol Int, 2015:694560.

Lamontagne, D.S., \& Sherris, J.D. (2013). Addressing questions about the HPV vaccine project in India. Lancet Oncol, 14: e492. 
Li, J., Li, L.K., Ma, J.F.,...\& Qiao YL (2009). Knowledge and attitudes about human papillomavirus (HPV) and HPV vaccines among women living in metropolitan and rural regions of China. Vaccine, 27(8):1210-15.

Madhivanan, P., Krupp, K., Yashodha, M.N., \& Reingold, A.L. (2009). Attitudes toward HPV vaccination among parents of adolescent girls in Mysore, India. Vaccine, 27(38):5203-5208.

Marlow, L.A., Waller, J., \& Wardle, J. (2007). Parental attitudes to pre-pubertal HPV vaccination. Vaccine, 25:1945-1952.

Munoz, N., Castellsague, X., de González, A.B., \& Gissmann, L. (2006). Chapter 1: HPV in the etiology of human cancer. Vaccine, 24(S3):1-10.

Patel, H., Jeve, Y.B., Sherman, S.M., \& Moss, E.L. (2016). Knowledge of human papillomavirus and the human papillomavirus vaccine in European adolescents: a systematic review. Sex Transm Infect, 92(6):474-9.

Ports, K.A., Barnack-Tavlaris, J.L., Mosavel, M., \& Murithi, L.K. (2014). Young Women's Sexual and Reproductive Health Post HPV Vaccination. Womens Reprod Health, 1(1): 43-55.

Ramavath, K.K., \& Olyai, R. (2013). Knowledge and Awareness of HPV Infection and Vaccination Among Urban Adolescents in India: A Cross-Sectional Study. J Obstet Gynaecol India, 63(6):399-404.

Ruiz-Sternberg, A.M., \& Pinzón-Rondón, Á.M. (2014). Risk perception and sexual behavior in HPV-vaccinated and unvaccinated young Colombian women. Int J Gynaecol Obstet, 126(3):205-208.

Rysavy, M.B., Kresowik, J.D., Liu, D.,...\& Ryan, G.L. (2014). Human papillomavirus vaccination and sexual behavior in young women. J Pediatr Adolesc Gynecol, 27(2):6771.

Schiffman, M., \& Castle, P.E. (2003). Human papillomavirus: epidemiology and public health. Arch Pathol Lab Med, 127 (8): 930-934.

Seven, M., Güvenç, G., Şahin, E., \& Akyüz, A. (2015). Attitudes to HPV Vaccination among Parents of Children Aged 10 to 13 Years. J Pediatr Adolesc Gynecol, 28(5):382-6.

Sopracordevole, F., Cigolot, F., Mancioli, F.,... \& Ciavattini, A. (2013). Knowledge of HPV infection and vaccination among vaccinated and unvaccinated teenaged girls. Int $\mathbf{J}$ Gynaecol Obstet, 122(1):48-51.

Sreedevi, A., Javed, R., \& Dinesh, A. (2015). Epidemiology of cervical cancer with special focus on India. Int J Womens Health, 7:405-414. 
Tanday, S. (2014). HPV vaccinations do not encourage risky sexual behavior. Lancet Oncol, 15(3):e109.

Turiho, A.K., Muhwezi, W.W., Okello, E.S.,...\& Katahoire, A.R. (2015). Human Papillomavirus (HPV) Vaccination and Adolescent Girls' Knowledge and Sexuality in Western Uganda: A Comparative Cross-Sectional Study. PLoS One,10(9):e0137094.

Tyson, N. (2017). HPV Update. J Pediatr Adolesc Gynecol, 30(2):262-264.

Vashishtha, V.M., Choudhury, P., Kalra, A., \& Indian Academy of Pediatrics. (2014). Indian Academy of Pediatrics (IAP) recommended immunization schedule for children aged 0 through 18 years - India, 2014 and updates on immunization. Indian Pediatr, 51:785-800.

WHO (2017). Punjab launches HPV vaccine with WHO support, http://www.searo.who.int/india/mediacentre/events/2016/Punjab HPV vaccine/en/. [accessed 15 August 2017].

Witte, K. (1996). Predicting risk behaviors: development and validation of a diagnostic scale. J Health Commun, 1: 317-342.

Wong, L.P. (2011). Knowledge and attitudes about HPV infection, HPV vaccination, and cervical cancer among rural Southeast Asian women. Int J Behav Med, 18(2):105-11.

Yudin, M.H. (2010). HPV vaccination: time to end the debate. J Pediatr Adolesc Gynecol, 23(1):55-6. 
Table 1. Sociodemographic characteristics of rural and urban parents of adolescent girls in Karnataka, India 2010/2011 ( $\mathrm{n}=1609)$

\begin{tabular}{|c|c|c|c|c|}
\hline Variables & Categories & $\begin{array}{l}\text { Urban } \\
(\mathrm{n}=778)\end{array}$ & $\begin{array}{c}\text { Rural } \\
(n=831)\end{array}$ & $\begin{array}{l}X^{2}-\mathrm{p}- \\
\text { value }\end{array}$ \\
\hline \multirow[t]{3}{*}{ Sex } & & & & $<0.001$ \\
\hline & Female & 69.0 & 76.8 & \\
\hline & Male & 31.0 & 23.2 & \\
\hline \multirow[t]{5}{*}{ Age in years } & & & & $<0.001$ \\
\hline & $\leq 35$ & 31.1 & 53.3 & \\
\hline & $36-40$ & 33.0 & 27.4 & \\
\hline & $41-50$ & 31.8 & 15.5 & \\
\hline & $>50$ & 4.1 & 3.7 & \\
\hline \multirow[t]{6}{*}{ Education } & & & & $<0.001$ \\
\hline & No formal education & 14.9 & 63.4 & \\
\hline & Grade 1 to $10^{\text {th }}$ & 50.6 & 34.3 & \\
\hline & $\begin{array}{l}\text { High school or bachelor } \\
\text { degree }\end{array}$ & 24.3 & 1.8 & \\
\hline & $\begin{array}{l}\text { Vocational training } \\
\text { (diploma) }\end{array}$ & 5.1 & 0.4 & \\
\hline & Master degree or above & 5.0 & 0.1 & \\
\hline \multirow[t]{6}{*}{ Employment } & & & & $<0.001$ \\
\hline & Employed fulltime & 27.5 & 7.0 & \\
\hline & Employed part-time & 10.7 & 43.0 & \\
\hline & Self-employed & 14.4 & 7.0 & \\
\hline & Full time homemaker & 43.6 & 41.8 & \\
\hline & Retired/unemployed & 3.9 & 1.3 & \\
\hline \multirow[t]{3}{*}{ Marital status } & & & & 0.010 \\
\hline & Married & 94.7 & 91.5 & \\
\hline & Unmarried & 5.3 & 8.5 & \\
\hline Religion & & & & $<0.001$ \\
\hline
\end{tabular}




\begin{tabular}{|c|c|c|c|c|}
\hline & Hindu & 78.0 & 99.0 & \\
\hline & Islam & 18.8 & 1.0 & \\
\hline & Christian/other & 3.2 & 0.0 & \\
\hline \multirow{3}{*}{$\begin{array}{l}\text { Have you ever heard } \\
\text { about HPV? }\end{array}$} & & & & 0.079 \\
\hline & Yes & 28.4 & 24.6 & \\
\hline & No & 71.6 & 75.4 & \\
\hline \multicolumn{5}{|c|}{ Source of information about vaccines } \\
\hline \multirow[t]{2}{*}{ Television } & Yes & 90.0 & 81.1 & $<0.001$ \\
\hline & No & 9.0 & 18.3 & \\
\hline \multirow{2}{*}{ Newspaper or Radio } & Yes & 88.7 & 75.3 & $<0.001$ \\
\hline & No & 10.0 & 24.2 & \\
\hline \multirow[t]{2}{*}{ Internet } & Yes & 59.0 & 43.9 & $<0.001$ \\
\hline & No & 37.7 & 53.3 & \\
\hline \multirow[t]{2}{*}{ Doctor } & Yes & 91.3 & 87.6 & 0.005 \\
\hline & No & 7.5 & 11.7 & \\
\hline ANM or Anganwadi & Yes & 70.7 & 80.4 & $<0.001$ \\
\hline teacher or Worker & No & 26.3 & 17.8 & \\
\hline \multirow[t]{2}{*}{ Friends or Neighbors } & Yes & 77.5 & 68.9 & $<0.001$ \\
\hline & No & 20.3 & 30.1 & \\
\hline \multirow[t]{2}{*}{ My daughter's school } & Yes & 91.8 & 93.6 & 0.193 \\
\hline & No & 8.2 & 6.4 & \\
\hline Family member or & Yes & 78.4 & 69.2 & $<0.001$ \\
\hline relatives & No & 20.4 & 30.0 & \\
\hline
\end{tabular}


Table 2. Comparison of the attitudes and beliefs about HPV infection, cervical cancer and HPV vaccine between rural and urban parents of adolescent girls in Mysore district, India $2010 / 2011(n=1609)$

\begin{tabular}{|c|c|c|c|c|}
\hline Attitudes and beliefs & Response & $\begin{array}{r}\text { Urban } \\
(\mathrm{n}=778\end{array}$ & $\begin{array}{c}\text { Rural } \\
(n=831)\end{array}$ & $\overline{p-v a l u e}$ \\
\hline Susceptibility to HPV & Disagree & 30.3 & 23.4 & \\
\hline My daughter may be at-risk of getting & Do not know & 53.2 & 62.9 & $<0.001$ \\
\hline HPV infection & Agree & 16.5 & 13.7 & \\
\hline It is likely that my daughter may get & Disagree & 23.65 & 20.70 & 0.209 \\
\hline \multirow[t]{2}{*}{ HPV infection in the future } & Do not know & 60.54 & 64.74 & \\
\hline & Agree & 15.81 & 14.56 & \\
\hline Susceptibility to cervical cancer & Disagree & 22.6 & 21.1 & 0.033 \\
\hline It is possible that my daughter will get & Do not know & 61.2 & 66.8 & \\
\hline cervical cancer in the future & Agree & 16.1 & 12.2 & \\
\hline \multirow{3}{*}{$\begin{array}{l}\text { It is likely that my daughter may get } \\
\text { cervical cancer someday }\end{array}$} & Disagree & 25.5 & 22.14 & 0.160 \\
\hline & Do not know & 59.3 & 63.90 & \\
\hline & Agree & 15.2 & 13.96 & \\
\hline Severity of HPV & Disagree & 4.0 & 8.9 & \\
\hline I believe that HPV infection can cause & Do not know & 21.9 & 34.1 & $<0.001$ \\
\hline serious health problem & Agree & 74.2 & 57.0 & \\
\hline \multirow{3}{*}{$\begin{array}{l}\text { I believe that HPV infection can be } \\
\text { extremely harmful. }\end{array}$} & Disagree & 6.04 & 10.11 & $<0.001$ \\
\hline & Do not know & 18.64 & 27.20 & \\
\hline & Agree & 75.32 & 62.70 & \\
\hline Severity of cervical cancer & Disagree & 5.3 & 10.8 & $<0.001$ \\
\hline I believe that cervical cancer is a & Do not know & 16.1 & 29.5 & \\
\hline serious disease & Agree & 78.7 & 59.7 & \\
\hline I believe that cervical cancer can be & Disagree & 4.8 & 8.8 & $<0.001$ \\
\hline extremely harmful. & Do not know & 15.9 & 28.3 & \\
\hline
\end{tabular}




\begin{tabular}{llccc} 
& Agree & 79.3 & 62.9 & \\
\hline Attitudes about HPV vaccine & & & & \\
\hline HPV vaccine is safe & & 7.2 & 8.4 & \\
& No & 92.2 & 91.6 & 0.387 \\
\hline HPV vaccine will prevent cervical & No & 8.5 & 9.3 & \\
cancer & Yes & 90.0 & 90.0 & \multirow{2}{*}{0.617} \\
\hline Having the HPV vaccination might & Disagree & 23.7 & 16.7 & \\
make girls more likely to have sex & Do not know & 56.3 & 58.6 & \\
& Agree & 18.5 & 23.5 & 0.001 \\
\hline
\end{tabular}

Notes:

Values in the tables are percentages

Percent values for some items categories do not add up to 100 due to missing data 
Table 3. Comparison of the attitudes and beliefs about HPV infection, cervical cancer and HPV vaccine among urban versus rural parents in Mysore district, India 2010/2011(n=1609)

\begin{tabular}{|c|c|c|c|}
\hline Attitudes and beliefs: Items & Response & Crude OR $(95 \% \mathrm{CI})$ & $\begin{array}{l}\text { Adjusted OR } \\
\qquad(95 \% \mathrm{CI})\end{array}$ \\
\hline Susceptibility to HPV & Disagree & & \\
\hline My daughter may be at-risk of & Do not know & $0.65(0.52,0.82)$ & $0.66(0.41,1.07)$ \\
\hline getting HPV infection & Agree & $0.92(0.67,1.26)$ & $0.65(0.35,1.22)$ \\
\hline \multirow{3}{*}{$\begin{array}{l}\text { It is likely that my daughter may } \\
\text { get HPV infection in the future }\end{array}$} & Disagree & & \\
\hline & Do not know & $0.82(0.64,1.04)$ & $0.88(0.58,1.33)$ \\
\hline & Agree & $0.95(0.69,1.320$ & $0.74(0.44,1.24)$ \\
\hline Susceptibility to cervical cancer & Disagree & & \\
\hline It is possible that my daughter & Do not know & $0.85(0.67,1.09)$ & $0.90(0.59,1.38)$ \\
\hline will get cervical cancer in the future & Agree & $1.23(0.88,1.72)$ & $1.28(0.68,2.43)$ \\
\hline \multirow{3}{*}{$\begin{array}{l}\text { It is likely that my daughter may } \\
\text { get cervical cancer someday }\end{array}$} & Disagree & & \\
\hline & Do not know & $0.81(0.64,1.02)$ & $0.78(0.54,1.14)$ \\
\hline & Agree & $0.94(0.68,1.31)$ & $0.86(0.51,1.45)$ \\
\hline Severity of HPV & Disagree & & \\
\hline I believe that HPV infection can & Do not know & $1.43(0.90,2.27)$ & $1.66(0.78,3.53)$ \\
\hline cause serious health problem & Agree & $2.91(1.88,4.50)$ & $2.69(1.43,5.06)$ \\
\hline \multirow{3}{*}{$\begin{array}{l}\text { I believe that HPV infection can } \\
\text { be extremely harmful }\end{array}$} & Disagree & & \\
\hline & Do not know & $1.15(0.76,1.73)$ & $1.30(0.82,2.04)$ \\
\hline & Agree & $2.01(1.38,2.92)$ & $1.81(1.08,3.04)$ \\
\hline Severity of cervical cancer & Disagree & & \\
\hline I believe that cervical cancer is a & Do not know & $1.12(0.73,1.72)$ & $1.78(1.21,2.63)$ \\
\hline serious disease & Agree & $2.71(1.84,3.99)$ & $2.68(1.83,3.91)$ \\
\hline I believe that cervical cancer can & Disagree & & \\
\hline \multirow[t]{2}{*}{ be extremely harmful. } & Do not know & $1.04(0.66,1.64)$ & $1.49(0.76,2.95)$ \\
\hline & Agree & $2.33(1.54,3.52)$ & $2.28(1.26,4.12)$ \\
\hline
\end{tabular}




\begin{tabular}{|c|c|c|c|}
\hline \multicolumn{4}{|l|}{ Attitudes about HPV vaccine } \\
\hline \multirow[t]{2}{*}{ HPV vaccine is safe } & No & & \\
\hline & Yes & $1.15(0.70,1.91)$ & $0.73(0.41,1.29)$ \\
\hline HPV vaccine will prevent cervical & No & & \\
\hline cancer & Yes & $1.05(0.52,2.14)$ & $0.80(0.40,1.57)$ \\
\hline Having the HPV vaccination & Disagree & & \\
\hline might make girls more likely to & Do not know & $0.68(0.53,0.88)$ & $0.89(0.58,1.37)$ \\
\hline have sex & Agree & $0.56(0.41,0.76)$ & $0.55(0.33,0.94)$ \\
\hline
\end{tabular}

Note: adjusted OR values are estimated based on generalized estimated equation using identity function (beliefs about HPV vaccine items) or multinomial regression (beliefs about susceptibility and severity HPV and cervical cancer) after controlling for age, gender, occupation, religion, marital status, education and awareness about HPV, source of information about HPV vaccine in the case of beliefs about HPV vaccine items. School was used as a cluster variable in all the analysis. 


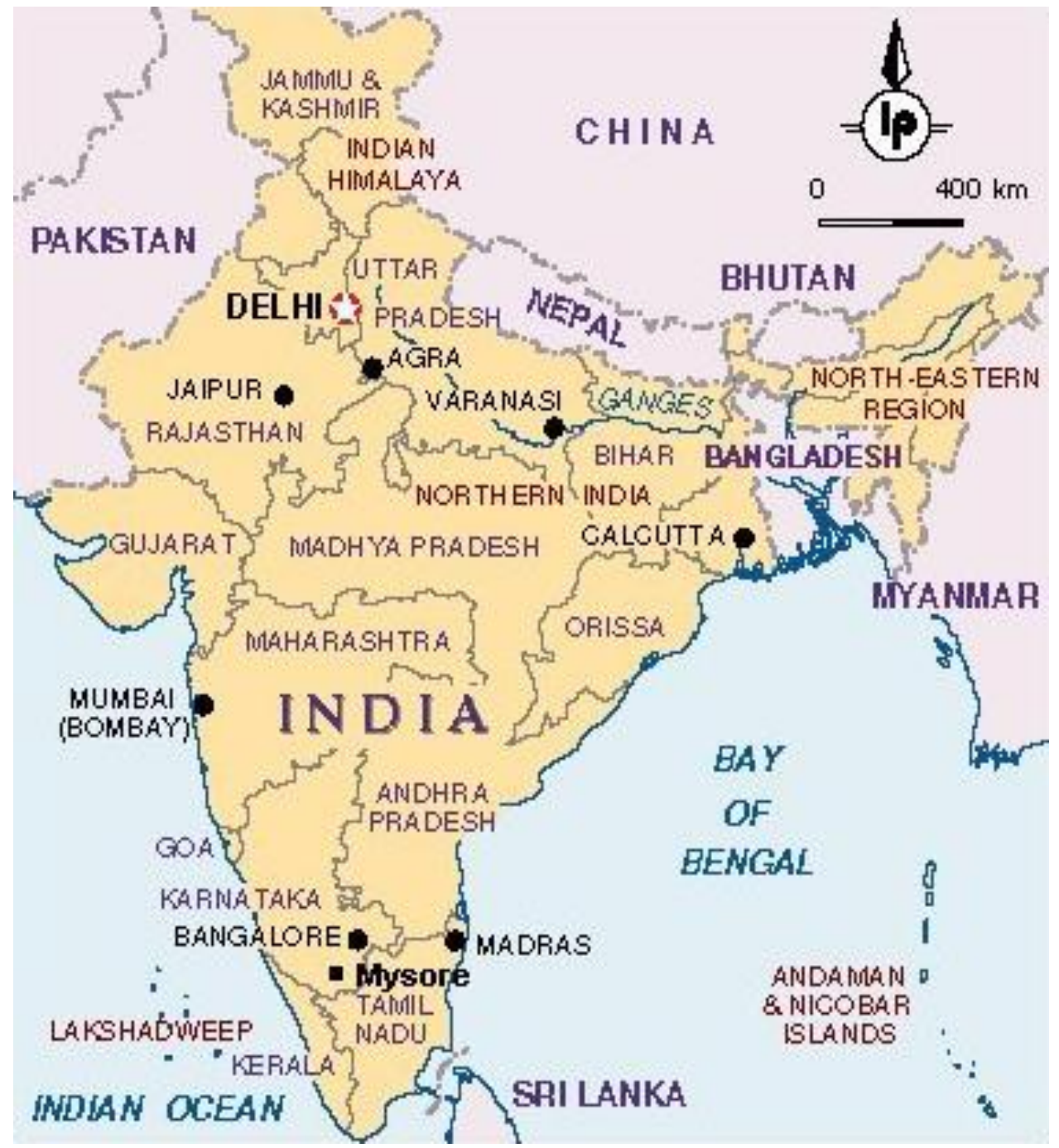

Fig 1. Map of India 


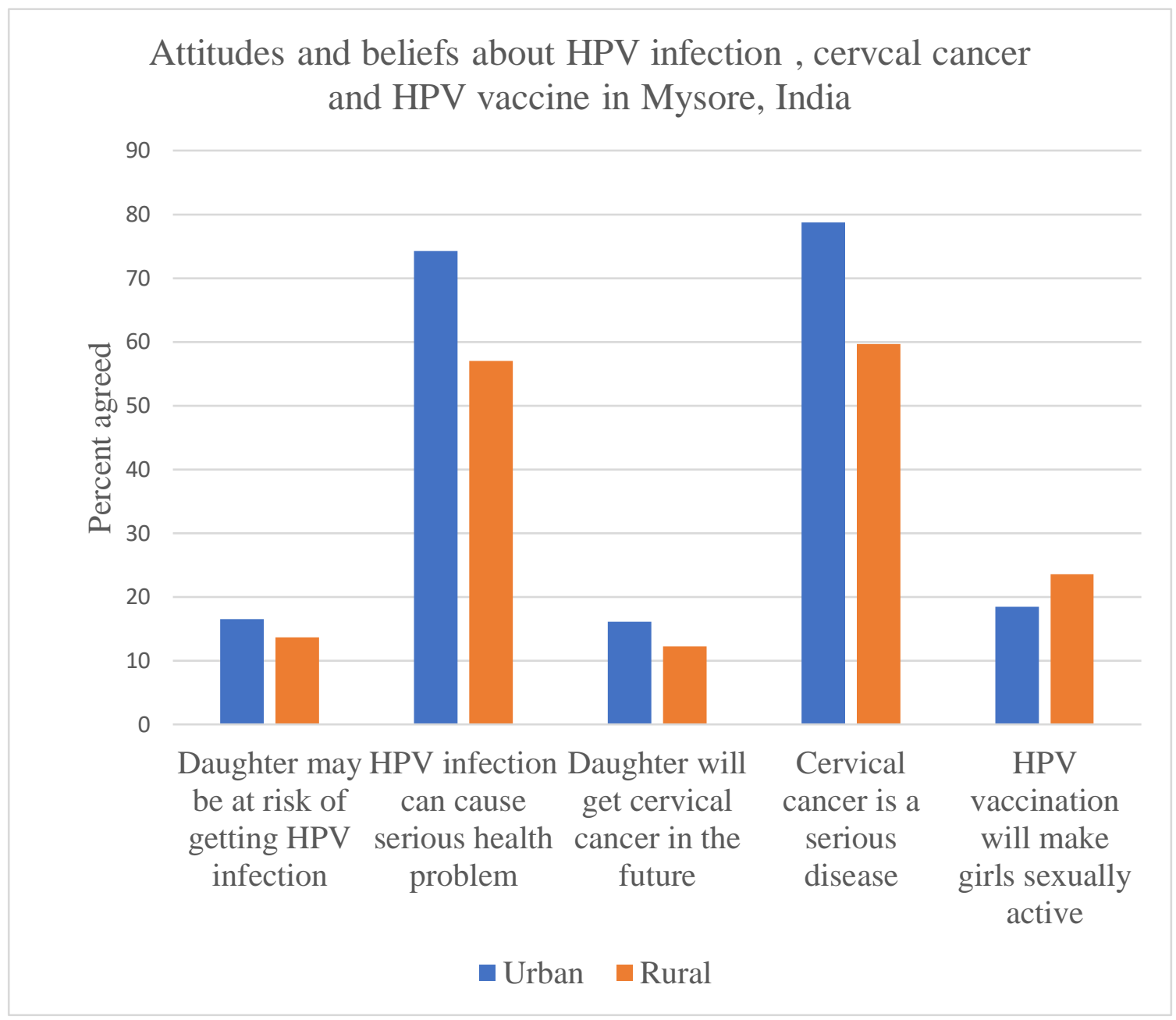

Fig 2. Attitudes and beliefs about HPV infection, cervical cancer and HPV vaccine among rural $(n=831)$ and urban $(n=778)$ parents of adolescent girls in Mysore district, India 2010/2011. 


\title{
MANUSCRIPT 2
}

(C) Copyright 2018

Degarege, A., Krupp, K., Fennie, K., Srinivas, V., Li, T., Stephens, D.P., Marlow, L.A.V., Arun, A., \& Madhivanan, P. (2018). HPV vaccine acceptability among parents of adolescent girls in a rural area Mysore, India. J Pediat Adolesc Gynecol, 31(6): 583-591.

\begin{abstract}
Objective: The purpose of this study was to examine factors predicting HPV vaccine acceptability among parents of adolescent girls in a rural area in Mysore district, India.
\end{abstract}

Methods: A cross-sectional study was conducted among a random sample of 831 parents of adolescent girls (ages 11 to 15 years) in villages in Mysore between September and October, 2011. A questionnaire designed in both English and Kannada was used to measure factors that can affect parental willingness to vaccinate daughters with HPV vaccine.

Results: Of the 831 parents participated in this study, $79.9 \%$ were willing to vaccinate their daughter with HPV vaccine sometime soon if they were invited to receive it. Higher odds of parental willingness to vaccinate their daughters with HPV vaccine was observed among those who believed that HPV vaccine is safe (Adjusted Odds Ratio [aOR] 2.11;95\% CI:1.01, 4.45); daughter may become sexually active (aOR1.84, 95\%CI:1.08, $3.13)$; they have support of other family members to vaccinate their daughter (aOR2.86,95\%CI:1.47,5.57); HPV infection causes severe health problems(aOR1.64,95\%CI:1.04,2.57). On the other hand, parents who believed that there is low risk that daughter will get cervical cancer(aOR0.52,95\%CI:0.29,0.95); family will 
disapprove of getting daughter vaccinated(aOR0.45,95\%CI:0.22,0.76); the injection may cause pain(aOR0.53, 95\%CI:0.31,0.89) and were older age parents (aOR0.96,95\%CI:0.93,0.99) had lower odds of willingness to vaccinate daughters with HPV vaccine.

Conclusions: Acceptance of HPV vaccination for daughters was high among rural parents in Mysore, India. However, health education to reduce the belief that injection is painful and daughters are at low risk to get cervical cancer is important to further improve parental HPV vaccine acceptability in Mysore. The public health education should target older aged parents and extended family members.

Key words: HPV, vaccine, acceptability, India, Mysore, Parents, Rural

\section{Introduction}

Cervical cancer is the second leading cause of cancer death among women in India (Mishra et al., 2016). Every year, about 122,844 women are diagnosed with the disease and 67,477 die from it (Mishra et al., 2016). The country ranked first in terms of the incidence of the disease among south Asian countries in 2012 (Bruni et al., 2016). In order to effectively control cervical cancer, the Indian Academy of Pediatrics Committee on Immunization (IAPCOI) approved HPV vaccination for females aged 10-12 years, who can afford the vaccine, in 2008 (IAPCOI, 2008). Nevertheless, introducing HPV vaccine in India has had unique challenges due to unconfirmed concerns about the efficacy and safety of the vaccine (Lamontagne \& Sherris, 2013). The death of seven girls reported during demonstration program in India conducted in 2009 raised several concerns (Lamontagne \& Sherris, 2013). The Indian parliament attributed the deaths to the HPV vaccine leading to suspension of the demonstration program in 2010 (Larson et 
al., 2010). However, subsequent studies and investigations confirmed that the deaths were not related to the HPV vaccine (Sachdeva S, Sachdeva R, 2016).

In 2014, the Government of India decided to include HPV vaccine in the National Immunization Programme (Chatterjee et al., 2016; Vashishtha et al., 2014). The vaccine, currently, is used by private practitioners in different regions of the country (Sachdeva \& Sachdeva, 2016; WHO, 2017; Science and chronicle, 2017). However, uptake of HPV vaccination in general has been low due to misperceptions about HPV infection, cervical cancer and HPV vaccine, and due to cultural reasons in India (Chatterjee et al., 2016; Madhivanan et al., 2009; Paul et al., 2014; Basu \& Mittal, 2011; Madhivanan et al., 2014). Further investigation of factors that are related to HPV vaccine acceptability among parents in India may help improve uptake and reduce the burden of cervical cancer in this country. Identifying factors associated with vaccine acceptance will also help clinicians and public health advocates to better design evidence-based strategies to achieve maximum HPV vaccine coverage in the target groups. Much of the research to date about HPV vaccine acceptability in India has been limited to urban areas with very limited information being available from rural India where $60 \%$ of the Indian population resides (Madhivanan et al., 2009; Paul et al., 2014; Basu \& Mittal, 2011; Madhivanan et al., 2014). The purpose of this study was therefore to examine factors predicting HPV vaccine acceptability among parents of adolescent girls in rural India in the south Indian state of Karnataka. 


\section{Methods}

Study setting

Between September and October, 2011, a cross-sectional survey was conducted among parents of adolescent girls living in villages of Mysore Taluk, in the Indian state of Karnataka. Karnataka ranks $9^{\text {th }}$ in terms of population (61 million) with the majority of residents living in rural areas (Census, 2017). The age-standardized cervical cancer mortality rate in Karnataka was 16.5 per 100,000 in 2010 (Dikshit et al. 2012).

\section{Ethical consideration}

This study was conducted after review and approval by the Institutional Review Boards at Florida International University and Public Health Research Institute of India. In addition, permission to conduct the study was obtained from the Block Education officer and school administrators. Parents participated in the study after they provided written informed consent.

\section{Study participants}

A total of 831 parents of adolescent girls (ages 11 to 15 years) attending $7^{\text {th }}$ through $10^{\text {th }}$ grades in a cluster of 11 schools located in rural Mysore sub-district were included in this study. One private and ten government schools were selected from a group of 43 schools available in the study area based on probability proportionate-to-size sampling. A program announcement was sent home with all eligible girls $(n=1,725)$ in the 11 schools (44 to 137 students from each school), explaining the objective of the study and inviting parents to participate. Of the 1725,850 were randomly selected and provided a questionnaire in Kannada to complete within a week's time. The number of 
female students needed from each school was determined based on multistage proportionate-to-size sampling. All (along with assigned number) eligible female students from each school were enumerated and listed in an excel sheet separately for each school. Using a computer program, the assigned number of students from each school were selected using a random sampling technique. Each selected and interested participant was provided with a questionnaire to take home to their parents, where one parent per household could complete it and return within seven days along with a signed consent form. Most parents (97.8\%) who received the questionnaire completed the questionnaire and returned it along with their signed consent form.

\section{Questionnaire and measures}

The items included in the questionnaire were adapted from previous studies (Madhivanan et al., 2009; Witte, 1996; Marlow et al., 2007). The questionnaire was validated in Kannada (local language in the study area) and has been used in another study (Madhivanan et al., 2014) before it was used in this study. As some of the parents living in a rural region were illiterate and may have lacked knowledge about HPV, cervical cancer and HPV vaccine, we included some basic information in the questionnaire (Table 1) to enable parents to answer some questions related to attitudes and beliefs about HPV vaccine and willingness to accept HPV vaccination. The questionnaire contained 126 items, 59 of which were used to measure psychosocial factors that have been shown to influence HPV vaccine acceptability in different countries including India.

[Insert Table 1 here] 
The current study was guided by the conceptual framework of factors that influence HPV vaccination proposed by Fernandez et al., (2010). Out of 126 items, 59 items representing different constructs that could potentially influence willingness to vaccinate were selected for the analysis (Fernandez et al., 2010). The constructs included sociodemographics, awareness about HPV, sources of information about HPV vaccine, perceived susceptibility to HPV and cervical cancer, perceived severity of HPV and cervical cancer, perceived facilitators and barriers to vaccination in general and specific to HPV vaccine, social norms that influence HPV vaccine acceptability, and willingness to accept HPV vaccine (Fernandez et al., 2010).

Awareness about HPV was assessed by one question (Have you ever heard of HPV?) with a 'yes' or 'no' response. Sources of information was assessed using seven items asking parents where they got information about HPV vaccine (Cronbach's alpha $[\alpha]=0.75)$. Perceived susceptibility, which measures parental attitudes towards susceptibility of their daughters to getting HPV infection and cervical cancer, was assessed using four items $(\alpha=0.78)$. Similarly, perceived severity measured parental beliefs about severity of HPV infection and cervical cancer using four items $(\alpha=0.73)$. Response to all the items that measured perceived susceptibility and severity constructs were recorded on a three-point scale ( $1=$ disagree, $2=$ do not know, $3=$ agree). Items that has a response of 'Don't know' were assumed to be ordinally neutral (Dempsey et al., 2006).

Questions used to assess parental beliefs and attitudes about HPV vaccine were grouped into two constructs: perceived facilitators/benefits and perceived barriers to HPV vaccination. Perceived facilitators were measured using eight items to assess the reasons 
why parents wanted to have their daughter's HPV vaccination $(\alpha=0.67)$. Similarly, perceived barriers to HPV vaccination construct was measured using eight items to assess reasons why parents might not want to have their daughters receive HPV vaccine $(\alpha=0.68)$. Responses to the 16 items were coded on a three-point scale ( $1=$ not important all, $2=$ important $3=$ =very important). Likewise, perceived facilitators $(\alpha=0.59)$ and perceived barriers $(\alpha=0.58)$ to vaccination in general were assessed using six and five items, respectively. These 11 items were recorded on a three-point scale (1=no, 2=not sure, $3=$ yes $)$. Social norms were assessed using seven items $(\alpha=0.75)$ by asking parents whose opinion such as doctors, spouse, friends, father and mother, other relatives, in-laws and neighbors might influence their decision in getting their daughter vaccinated.

Responses were recorded on three-point scale ( $1=$ no, $2=$ don't know, $3=y e s)$. Finally, the construct for willingness to accept HPV vaccine was assessed by asking parents 'If your daughter was invited to get HPV vaccine, would you agree to have it sometime soon'. Responses were coded on a four-point Likert scale $(1=$ definitely not, $2=$ probably not, $3=$ probably yes, $4=$ definitely yes). This variable was converted into a dichotomous variable as acceptors (who responded as 'probably or definitely' yes) and non-acceptors (who responded as 'probably or definitely' not) during data analysis (Marlow et al., 2007). Data analysis

Data were analyzed using Stata software (Version 14, Texas, USA). Reliability/internal consistency of items forming each construct, was assessed using Cronbach's alpha. The outcome variable was 'HPV vaccine acceptability'. The calculated internal reliabilities (Cronbach's $\alpha$ ) for the items forming the constructs were substantial 
or moderate. Thus, a composite score was developed by adding values of responses to the items that form each of the construct (Fernandez et al., 2010).

Percentages were used to describe the demographic status and the frequency of responses of parents to the questions addressing willingness to receive HPV vaccine, as well as beliefs and attitudes about HPV infection, cervical cancer and HPV vaccine. Chisquare tests were performed to check whether parental intention to accept HPV vaccine for their daughter was related to demographic characteristics, as well as beliefs and attitudes of parents about HPV, cervical cancer, and HPV vaccine. Multiple logistic regression was used to assess factors associated with HPV vaccine acceptance. To account for potential clustering of HPV acceptance by the school that the daughters attended, analysis was performed using the Generalized Estimating Equations (GEE) in Stata using the xtgee command. Estimated within-school correlation matrix value for HPV vaccine acceptability was 0.0078 . While fitting the regression models, factors that were included in the regression model were checked for multicollinearity. As there were missing values for some of the items (Missing range: 0.48 to $3.61 \%$ ) included in the regression model, a multiple imputation method (using chained equation) based on 20 iterations was used to estimate the missing values before fitting the GEE (Azur et al., 2011).

\section{Results}

Of the 850 parents who were contacted, 831 agreed to participate and returned the completed questionnaire within seven days. The mean age of the parents was $37.1 \pm 6.67$ years. Almost all study participants were Hindu by religion (99.0\%) and married (91.5\%). Most respondents were mothers (76.8\%), working part-time (43.0\%) and lacked formal 
education (63.4\%). Most had heard about HPV (75.4\%). Majority of the parents got information about HPV vaccines from their daughter's school (86.6\%), doctor (83.6\%), television (76.2\%), Auxillary Nurse Midwife or anganwadi teacher (72.0\%). Of the 831 parents, $79.9 \%$ (Yes probably $=30.2 \%$, Yes definitely=49.7\%) were willing to vaccinate their daughter with HPV vaccine sometime soon if they were offered the vaccine for their daughter (Table 2). When compared to mothers, fathers were more likely to be educated (55.4\% vs $30.9 \%)$, employed (92.2\% vs $46.2 \%)$, and older than 35 years of age $(87.6 \%$ vs $34.3 \%$ ). However, the proportion of parents who were Hindus, married, and were willing to vaccinate their daughter with HPV vaccine were similar between fathers $(99.5 \%$, $94.3 \%$ and $77.7 \%$, respectively) and mothers $(98.9 \%, 90.6 \%$ and $80.6 \%$, respectively).

\section{[Insert Table 2 here]}

Parents who were willing to vaccinate their daughter with HPV vaccine reported the following characters as main reasons for their willingness: recommendation from doctor or nurse (96.2\%), belief that HPV vaccine will prevent cervical cancer $(92.8 \%)$, belief that HPV vaccine is safe $(92.0 \%)$, having support from other family members to vaccinate daughter with HPV vaccine $(89.5 \%)$, and learning more about the relationship of HPV to cervical cancer (89.2\%) (Table 3).

Among parents who refused to vaccinate their daughter with HPV vaccine, the most frequent reasons for refusal were, being worried about safety of the vaccine $(67.1 \%)$, the perception that the vaccination may not be effective $(67.1 \%)$, that injection may cause pain $(65.9 \%)$ and their perception that their daughter is at low risk of becoming infected with HPV infection (65.9\%). Willingness to receive HPV vaccine was also lower among parents who were afraid of vaccinations in general. 
[Insert Table 3 here]

Based on multiple regression analysis, the odds ratio of willingness to vaccinate was positively associated with the perceived benefits of HPV vaccination (aOR 1.16, $95 \%$ CI: $1.07,1.25)$. The odds ratio of willingness to vaccinate was particularly greater among parents who believed that the vaccine was safe (aOR 2.11; 95\%CI: 1.01, 4.45); daughter may become sexually active (aOR 1.84, 95\%CI: 1.08, 3.13); and they have support from other family members to vaccinate their daughter (aOR 2.86, 95\%CI: 1.47 , 5.57). Willingness to vaccinate their daughter with HPV vaccination was also greater among parents who believed that vaccination was one way that parents could ensure their child's health (aOR 10.75, 95\% CI: 3.04, 38.0), and among those who believed that HPV infection could cause severe health problems (aOR 1.64, 95\%CI: 1.04, 2.57). Parents with 1 to 10 years of education were more willing to vaccinate their daughter as compared to parents who lacked any education $(1.92,95 \%$ CI: 1.13, 3.26) (Table 4).

On the other hand, the odds ratio of willingness to vaccinate was negatively associated with the perceived barriers of HPV vaccination (aOR 0.92, 95\%CI: 0.87, 0.99). The odds were particularly lower among parents who believed that their daughter was at low risk to get cervical cancer (aOR $0.52,95 \% \mathrm{CI}: 0.29,0.95$ ); the family may disapprove of getting their daughter vaccinated (aOR 0.45, 95\% CI: $0.22,0.76$ ) and the injection may cause pain (aOR $0.53,95 \% \mathrm{CI}$ : $0.31,0.89)$. Parental willingness to vaccinate their daughter also decreased with increasing age of the parent (aOR 0.96, 95\%CI: 0.93, 0.99) (table 3).

[Insert Table 4 here] 


\section{Discussion}

The purpose of this study was to examine facilitators and barriers to parental acceptability of HPV vaccine for adolescent girls in rural Mysore, India. The majority of the parents $(79.9 \%)$ were willing to vaccinate their daughter with HPV vaccine. The main factors associated with HPV vaccine acceptance were parental education, the belief that the vaccine was safe and HPV infection could cause severe health problems, daughter might become sexually active, having support of other family members to vaccinate daughter, and believing that vaccination is one way to ensure their child's health. On the contrary, low risk perception that daughter will get cervical cancer, fear that other family members might disapprove of getting daughter vaccinated, injection may cause pain, and increasing age of the parent were all associated with not intending to accept HPV vaccination for their daughter.

There was a higher rate of HPV vaccine acceptance in this population as compared to that reported among parents in the other regions of India (Range: $46 \%$ to 74\%) (Basu \& Mittal, 2011; Madhivanan et al., 2014; Montgomery et al., 2015) and other countries in south Asia (Range: $26.5 \%$ to $84.0 \%$ ) (Sam et al., 2009; Charakorn et al., 2011; Yu et al., 2016; Wang et al., 2015). Even within the same district, vaccine acceptance in this rural study population was greater than among parents living in the urban region (71.1\%) (Madhivanan et al., 2014). This increased rate of HPV vaccine acceptance in the current study could be due to better awareness about cervical cancer and HPV vaccine, or due to a more positive attitude towards vaccinations in general and the immunization programs run by the government. Indeed, a study reported higher levels of knowledge about general issues related to vaccination among parents who lived in 
rural than urban areas of the same district, where the current study was conducted (Madhivanan et al., 2009). The level of awareness about HPV in Senegal was also greater among adolescents and parents who were living in rural area than the urban ones (Massey et al., 2017). The National Rural Health Mission that was started in 2005 by the government of India to improve maternal child health outcomes in rural India has focused on improving immunization coverage at the village level in rural India. This initiative may have also helped increase knowledge, sensitize the rural residents about the importance of immunization in general and helped develop positive attitudes towards vaccination among rural parents in this area.

The perception that their daughters were at low risk to get cervical cancer, pain associated with injection, and disapproval by other family members for vaccinating daughters were significant predictors of low parental acceptability HPV vaccine for their daughters. A study among urban parents in the same district also reported association of the belief that injection may cause pain with a lower odds of HPV vaccine acceptance (Madhivanan et al., 2014). Parental beliefs that daughter may be at low risk of getting cervical cancer could be due to lack of knowledge that HPV infection is a cause for cervical cancer (Chatterjee et al., 2016). Disapproval of other family members to get daughter vaccinated may be due to lack of awareness that adolescents are susceptible to HPV infection (Burd, 2003). To reduce these barriers and promote HPV vaccination of girls in this area in the future, public health education programs for parents must focus on the transmission mechanisms of HPV infection, cancers caused by HPV infection (e.g. cervical cancer), and the fact that cervical cancer can be prevented by HPV vaccination (Hager, 2009; Haugsdal \& Ryan, 2015; Roussos-Ross et al., 2017; Tyson et al., 2017; 
Yudin, 2010). Scope of this education should be broadened to include extended family members as they have a large influence on parental decision making to recommend HPV vaccination for girls in the community.

Another barrier to HPV vaccine acceptability in this study was the older age of the parent. This finding is consistent with a previous report from Indonesia, which showed lower HPV vaccine acceptance among older age parents compared to the younger ones (Jaspers et al., 2011). A study in Thailand also showed lower acceptability of HPV vaccine for daughters among parents older than 45 years compared to those younger than 45 (Charakorn et al., 2011). More positive attitudes among younger parents could be due to changing sexual norms, access to information as compared to older age parents who may be less interested in health information related to sexually transmitted infection. In addition, older age parents may have negative beliefs about HPV vaccine due to previous experiences with and beliefs about vaccinations in general (side effects). Further research should focus on understanding the information needs of older parents to improve HPV vaccine acceptability in rural India.

A strength of this study was the focus on rural population - a population that has not been studied adequately. In addition, this study included a relatively large probability sample based on weighted random sampling methods. Almost all of the study participants contacted participated in this study as the population was interested and so few groups or organizations are interested in getting the opinion and understanding the needs of rural residents in this region. However, the study was not without limitations. Only parents of school going adolescent girls were included in this study. This would limit generalizability of the findings to parents who do not have school going children within 
that age group. Furthermore, due to variations in social practices, culture, religion and economic composition, all of which may affect individual beliefs about HPV, cervical cancer and HPV vaccine, the current study findings may not be generalizable to parents in other regions of India. The fact that only eight parents were Muslims in the current study may also limit generalizability of the results to other religions since the majority of the sample belonged to Hindu religion. Most of the Muslims in Mysore districts are concentrated in urban areas with very small percent living in rural regions. However, Muslims form a sizable portion of the overall population in India (Census, 2017). In addition, as the data were self-reported, some parents, especially the illiterate ones, may have received support from friends or extended family members while responding to some questions which may have caused information bias. Moreover, although provision of information about cervical cancer prevention methods, HPV and HPV vaccine enabled illiterate parents or those who lacked knowledge to answer some questions related to attitudes and beliefs about cervical cancer, HPV and HPV vaccine, this might have also overestimated the strength of association between HPV vaccine acceptability and attitudes about HPV, cervical cancer and HPV vaccine in this sample. Moreover, there were missing data for some questions, which might lead to a biased estimation of the observed association between parental beliefs and attitudes about HPV vaccine and cervical cancer with HPV vaccine acceptance. However, the multiple imputation method used to predict the missing values showed results that were comparable to those obtained with analysis with complete dataset after removing the missing values. There was a very minor difference in the magnitude of the odds ratio, standard errors and 95\% CI estimates. The current study assessed parents willingness to vaccinate their daughter with 
HPV vaccine. Hence, we cannot be sure if parents would actually vaccinate their daughter if the vaccine were offered. According to the conceptual framework proposed by Fernandez which guided this study, the nature of the environment will further modify the influence of parent's willingness to vaccinate daughter with HPV vaccine on the actual uptake of HPV vaccine (Fernandez et al., 2010). Finally, the study was conducted between September and October, 2011. There may have been changes in the beliefs and attitudes of parents regarding HPV infection, cervical cancer and HPV vaccine in the last seven years. This time delay in the conduct and the presentation of the study results may influence the nature of policy measures that can be designed to increase HPV vaccine acceptability among rural parents in Mysore, India.

\section{Conclusions}

In conclusion, this study is one of few studies that addresses public health issues among rural Indians. Willingness to vaccinate daughters with HPV vaccine was high among rural parents in Mysore district. However, public health education programs to reduce the false perception of low risk of getting cervical cancer, and fear of pain with injection will be important issues to focus among parents in Karnataka to reduce cervical cancer rates and further improve parental acceptability of HPV vaccine in the district. Health education programs should target older aged parents as well as extended family members to ensure increased vaccination uptake in the future in rural India.

\section{Acknowledgements}

The study was funded by Investigator Initiated Award from Merck \& Co., Inc. The funder had no role in the study design, data collection, analysis, interpretation and 
publication of the manuscript. AD is funded by Dissertation Year Fellowship, Florida International University. KK is a Global Health Equity Scholar funded by the Fogarty International Center at National Institute for Health (grant number: D43 TW010540). We would like to thank the study participants for taking time to complete the questionnaires. We would also like to acknowledge and thank the Block Development Officer for Mysore and the administrative staff of the schools for their assistance in conducting this study.

\section{Conflict of interest}

The authors report no proprietary or commercial interest in any product mentioned or concept discussed in this article.

References

Azur, M.J., Stuart, E.A., Frangakis, C., \& Leaf, P.J. (20110). Multiple Imputation by Chained Equations: What is it and how does it work? Int J Methods Psychiatr Res, 20(1):40-9.

Basu, P., \& Mittal, S. (2011). Acceptability of human papillomavirus vaccine among the urban, affluent and educated parents of young girls residing in Kolkata, Eastern India. J Obstet Gynaecol, 37(5): 393-401.

Bruni, L., Barrionuevo-Rosas, L., Albero, G.,...\& de Sanjosé S. (2016). ICO Information Centre on HPV and Cancer (HPV Information Centre). Human Papillomavirus and Related Diseases in India. Summary Report 15 December 2016. Accessed March 20, 2017 from http://www.hpvcentre.net/statistics/reports/ind.pdf.

Burd, E.M. (2003). Human Papillomavirus and Cervical Cancer. Clin Microbiol Rev, 16(1): $1-17$.

Charakorn, C., Rattanasiri, S., Lertkhachonsuk, A.A., ,...\& Wilailak, S. (2011).. Knowledge of Pap smear, HPV and the HPV vaccine and the acceptability of the HPV vaccine by Thai women. Asia Pac J Clin Oncol, 7(2):160-7.

Chatterjee, S., Chattopadhyay, A., Samanta, L., \& Panigrahi, P. (2016). HPV and Cervical Cancer Epidemiology - Current Status of HPV Vaccination in India. Asian Pac J Cancer Prev, 17(8):3663-3673. 
Dempsey, A.F., Zimet, G.D., Davis, R.L., \& Koutsky, L. (2006). Factors that are associated with parental acceptance of human papillomavirus vaccines: a randomized intervention study of written information about HPV. Pediatrics, 117(5):1486-93.

Dikshit, R., Gupta, P.C., Ramasundarahettige, C.,...\& Million Death Study Collaborators. (2012). Cancer mortality in India: a nationally representative survey. Lancet, 379:18071816.

Fernandez, M.E., Allen, J.D., Mistry, R., \& Kahn, J.A. (2010). Integrating clinical, community, and policy perspectives on human papillomavirus vaccination. Annu Rev Public Health, 31:235-52.

Hager, W.D. (2009). Human papilloma virus infection and prevention in the adolescent population. J Pediatr Adolesc Gynecol, 22(4):197-204.

Haugsdal, M.L., \& Ryan, G.L. (2015). HPV and Cervical Dysplasia in Adolescents: A Progressive March Toward Prevention. J Pediatr Adolesc Gynecol, 28(3):127-31.

Indian Academy of Pediatrics Committee on Immunization (IAPCOI) (2008). Consensus recommendations on immunization, 2008. Indian Pediatr, 45: 635-648.

Jaspers, L., Budiningsih, S., Wolterbeek, R., ....\& Peters, A.A. Parental acceptance of human papillomavirus (HPV) vaccination in Indonesia: a cross-sectional study. Vaccine 2011; 29(44):7785-93.

Lamontagne, D.S., \& Sherris, J.D. (2013). Addressing questions about the HPV vaccine project in India. Lancet Oncol, 14: e492.

Larson, H.J., Brocard, P., \& Garnett, G. (2010). The India HPV-vaccine suspension. Lancet, 376:572-3.

Madhivanan, P., Krupp, K., Yashodha, M.N., \& Reingold, A.L. (2009). Attitudes toward HPV vaccination among parents of adolescent girls in Mysore, India. Vaccine, 27(38):5203-5208.

Madhivanan, P., Li, T., Srinivas, V., Marlow, L.,...\& Krupp, K. (2014). Human papillomavirus vaccine acceptability among parents of adolescent girls: obstacles and challenges in Mysore, India. Prev Med, 64:69-74.

Marlow, L.A., Waller, J., \& Wardle, J. (2007). Parental attitudes to pre-pubertal HPV vaccination. Vaccine, 25: 1945-1952.

Massey, P.M., Boansi, R.K., Gipson, J.D., ...\& Glik, D.C. (2017). Human papillomavirus (HPV) awareness and vaccine receptivity among Senegalese adolescents. Trop Med Int Health, 22(1):113-121.

Mishra, G.A., Pimple, S.A., \& Shastri, S.S. (2016). Prevention of Cervix Cancer in India. Oncol, 91:1-7. 
Montgomery, M.P., Dune, T., Shetty, P.K., \& Shetty, A.K. (2015). Knowledge and acceptability of human papillomavirus vaccination and cervical cancer screening among women in Karnataka, India. J Cancer Educ, 30(1):130-7.

Paul, P., Tanner, A.E., Gravitt, P.E., \& Zimet, G.D. (2014). Acceptability of HPV Vaccine Implementation Among Parents in India. Health Care Women Int, 35 (10): 11481161.

Registrar General and Census Commissioner (2011) Census of India, http://www.census2011.co.in/census/state/karnataka.html. [Accessed 07 July 7 2017].

Roussos-Ross, K., Foster, L., Peterson, H.V., \& Decesare, J. (2017). Do Educational Seminars for the Human Papillomavirus Vaccine Improve Attitudes Toward the Value of Vaccination? J Pediatr Adolesc Gynecol, 30(4):456-459.

Sachdeva, S., \& Sachdeva, R. (2016). Human papillomavirus vaccination: Review and roll out plan in Delhi. CHRISMED J Health Res, 3:252-7.

Sam, I.C., Wong, L.P., Rampal, S., ...\& Kahar-Bador, M. (2009). Maternal acceptance of human papillomavirus vaccine in Malaysia. J Adolesc Health, 44(6):610-2.

Science and Chronicle (2017). Growing interest in HPV vaccination in India. https://journosdiary.com/2017/10/04/hpv-vaccination-india/. [Accessed Dec 30, 2017].

Tyson, N. (2017). HPV Update. J Pediatr Adolesc Gynecol, 30(2):262-264.

Vashishtha, V.M., Choudhury, P., Kalra, A., \& Indian Academy of Pediatrics. (2014). Indian Academy of Pediatrics recommended immunization schedule for children aged 0 through 18 years - India, 2014 and updates on immunization. Indian Pediatr, 51:785-800.

Wang, W., Ma, Y., Wang, X.,.\& Ma, W. (2015). Acceptability of human papillomavirus vaccine among parents of junior middle school students in Jinan, China. Vaccine, 33(22):2570-76.

WHO (2017). Punjab launches HPV vaccine with WHO support, http://www.searo.who.int/india/mediacentre/events/2016/Punjab HPV vaccine/en/. [Accessed 15 August 2017].

Witte, K. (1996). Predicting risk behaviors: development and validation of a diagnostic scale. J Health Commun, 1: 317-342.

Yu, Y., Xu, M., Sun, J.,...\& Xu, A. (2016). Human Papillomavirus Infection and Vaccination: Awareness and Knowledge of HPV and Acceptability of HPV Vaccine among Mothers of Teenage Daughters in Weihai, Shandong, China. PLoS ONE, 11(1): e0146741.

Yudin, M.H. (2010). HPV vaccination: time to end the debate. J Pediatr Adolesc Gynecol, 23(1):55-6. 
Table 1. HPV, cervical cancer and HPV vaccine information presented to the participants in Mysore, India, 2011

\section{What is cervical cancer?}

- Cervical cancer is a disease which affects the entrance to the uterus (womb). It is the result of uncontrolled growth of abnormal cells which eventually form a lump or tumour

- If cervical cancer is not detected and treated early, it can lead to serious health consequences including death.

\section{What causes cervical cancer?}

- Scientists have linked most cases of cervical cancer to a common virus called human papillomavirus or HPV

\section{How is HPV related to cervical cancer?}

- There are over $100 \mathrm{HPV}$ virus types but only about 15 that cause cancer. The two most common types, 16 and 18, are responsible for most cases of cervical cancer

- HPV infection that causes cervical cancer has no symptoms.

- Women who develop cervical cancer are usually unaware of their HPV infection

- While HPV may clear up on its own without treatment, some women are unable to rid themselves of the infection. Often, these women are at higher risk for cervical cancer

- When an HPV infection persists, it can cause cell changes which eventually lead to cervical cancer if left untreated

- HPV can also cause genital warts, small lumps or growths on the genitals. While these are unrelated to cervical cancer and are generally not dangerous, they can be prevented through vaccination

\section{How does HPV Cause Cervical Cancer?}

- HPV is generally spread through sexual contact. In India, most women acquire the infection when they marry.

- Sexual intercourse is not required to spread an HPV infection. The virus easily travels from person to person by skin-to-skin contact alone

- HPV causes cancer through a slow process. If a woman is unable to clear the infection, the cells in her cervix gradually change. If these abnormal cells are not detected and treated, they can become a cancerous tumour

\section{What is the HPV vaccine?}

- A vaccination has now been developed that will protect women against infection with HPV

- The vaccination will help prevent cervical cancer

- It will also protect against genital warts

- Trials of the vaccination have shown it to be $99 \%$ effective in protecting against infection with the most common cancer-causing HPV viruses

- The vaccination must be given to girls before they become sexually active, in order to get full protection 
Table 2. Sociodemographic characteristics of participants and HPV vaccine acceptability in Mysore, India, $2011(\mathrm{~N}=831)$

\begin{tabular}{|c|c|c|c|c|}
\hline & & Total & $\begin{array}{l}\text { Percent of willing } \\
\text { to vaccinate }\end{array}$ & $\mathrm{p}$-value \\
\hline \multirow[t]{2}{*}{ Sex } & Male & 193 & 77.7 & \\
\hline & Female & 638 & 80.6 & 0.388 \\
\hline \multirow[t]{4}{*}{ Age in years } & $\leq 35$ & 443 & 81.5 & 0.125 \\
\hline & $36-40$ & 228 & 80.3 & \\
\hline & $41-50$ & 129 & 77.5 & \\
\hline & $>50$ & 31 & 64.5 & \\
\hline \multirow[t]{3}{*}{ Education } & No formal education & 527 & 76.1 & 0.006 \\
\hline & Grade 1 to $10^{\text {th }}$ & 285 & 86.3 & \\
\hline & More than $10^{\text {th }}$ grade & 19 & 89.5 & \\
\hline \multirow[t]{5}{*}{ Occupation } & Retired/unemployed & 11 & 72.7 & 0.030 \\
\hline & Full-time homemaker & 347 & 82.1 & \\
\hline & Self-employed & 58 & 87.9 & \\
\hline & Employed part-time & 357 & 75.4 & \\
\hline & Employed full-time & 58 & 87.9 & \\
\hline \multirow[t]{2}{*}{ Marital Status } & Separated/widowed & 71 & 78.9 & 0.821 \\
\hline & Married & 760 & 80.0 & \\
\hline \multirow[t]{2}{*}{ Religion } & Hindus & 823 & 80.0 & 0.728 \\
\hline & Muslim & 8 & 75.0 & \\
\hline Have you ever & No & 204 & 83.3 & 0.159 \\
\hline $\begin{array}{l}\text { heard about } \\
\text { HPV? }\end{array}$ & Yes & 627 & 78.8 & \\
\hline
\end{tabular}


Table 3. Attitudes and beliefs about HPV, cervical cancer and vaccination and HPV vaccine acceptability in Mysore, India, 2011 (N=831)

Total Percent willing p-value to vaccinate

\begin{tabular}{|c|c|c|c|c|}
\hline \multicolumn{5}{|l|}{ Susceptibility to HPV or cervical cancer } \\
\hline \multirow{3}{*}{$\begin{array}{l}\text { My daughter may be at risk of getting } \\
\text { HPV infection }\end{array}$} & Disagree & 194 & 76.8 & \multirow[t]{3}{*}{0.419} \\
\hline & Do not know & 523 & 80.5 & \\
\hline & Agree & 114 & 82.5 & \\
\hline \multirow{3}{*}{$\begin{array}{l}\text { It is likely that my daughter may get } \\
\mathrm{HPV} \text { infection in the future }\end{array}$} & Disagree & 172 & 77.3 & \multirow[t]{3}{*}{0.168} \\
\hline & Do not know & 538 & 79.4 & \\
\hline & Agree & 121 & 86.0 & \\
\hline \multirow{3}{*}{$\begin{array}{l}\text { It is possible that my daughter will get } \\
\text { cervical cancer in the future }\end{array}$} & Disagree & 175 & 76.6 & \multirow[t]{3}{*}{0.290} \\
\hline & Do not know & 555 & 81.4 & \\
\hline & Agree & 101 & 77.2 & \\
\hline \multirow{3}{*}{$\begin{array}{l}\text { It is likely that my daughter may get } \\
\text { cervical cancer someday }\end{array}$} & Disagree & 184 & 77.2 & \multirow[t]{3}{*}{0.532} \\
\hline & Do not know & 531 & 81.0 & \\
\hline & Agree & 116 & 79.3 & \\
\hline \multirow{4}{*}{$\begin{array}{l}\text { Severity of HPV or cervical cancer } \\
\text { I believe that HPV infection can cause } \\
\text { serious health problem }\end{array}$} & & & & \multirow{4}{*}{$<0.001$} \\
\hline & Disagree & 74 & 70.3 & \\
\hline & Do not know & 283 & 73.1 & \\
\hline & Agree & 474 & 85.4 & \\
\hline \multirow{3}{*}{$\begin{array}{l}\text { I believe that HPV infection can be } \\
\text { extremely harmful. }\end{array}$} & Disagree & 84 & 64.3 & \multirow[t]{3}{*}{$<0.001$} \\
\hline & Do not know & 226 & 71.2 & \\
\hline & Agree & 521 & 86.2 & \\
\hline \multirow{3}{*}{$\begin{array}{l}\text { I believe that cervical cancer is a serious } \\
\text { disease }\end{array}$} & Disagree & 90 & 68.9 & \multirow[t]{3}{*}{$<0.001$} \\
\hline & Do not know & 245 & 73.9 & \\
\hline & Agree & 496 & 84.9 & \\
\hline \multirow{3}{*}{$\begin{array}{l}\text { I believe that cervical cancer can be } \\
\text { extremely harmful. }\end{array}$} & Disagree & 73 & 65.8 & \multirow[t]{3}{*}{$<0.001$} \\
\hline & Do not know & 523 & 84.7 & \\
\hline & Agree & 235 & 73.6 & \\
\hline \multicolumn{5}{|c|}{ Perceived facilitators to HPV vaccination } \\
\hline \multirow[t]{2}{*}{ Recommendation from doctor or nurse } & No & 40 & 57.5 & \multirow[b]{2}{*}{$<0.001$} \\
\hline & Yes & 787 & 81.2 & \\
\hline \multirow{2}{*}{$\begin{array}{l}\text { Worry about daughter getting cervical } \\
\text { cancer }\end{array}$} & No & 346 & 77.5 & \multirow{2}{*}{0.180} \\
\hline & Yes & 470 & 81.3 & \\
\hline \multirow[t]{2}{*}{ Believe that HPV vaccine is safe } & No & 68 & 54.4 & \multirow[b]{2}{*}{$<0.001$} \\
\hline & Yes & 740 & 82.6 & \\
\hline \multirow{2}{*}{$\begin{array}{l}\text { Worry that daughter may become } \\
\text { sexually active }\end{array}$} & No & 379 & 76.0 & \multirow[b]{2}{*}{0.01} \\
\hline & Yes & 403 & 83.4 & \\
\hline \multirow{2}{*}{$\begin{array}{l}\text { Support from family members to } \\
\text { vaccinate your daughter }\end{array}$} & No & 107 & 59.8 & \\
\hline & Yes & 716 & 82.9 & $<0.001$ \\
\hline Knowing more about the relationship of & No & 103 & 64.1 & \\
\hline HPV to cervical cancer & Yes & 722 & 82.0 & $<0.001$ \\
\hline
\end{tabular}




\begin{tabular}{|c|c|c|c|c|}
\hline \multirow[t]{2}{*}{ Government approval of vaccine } & No & 117 & 67.5 & \\
\hline & Yes & 698 & 81.8 & $<0.001$ \\
\hline \multirow{2}{*}{$\begin{array}{l}\text { Belief that vaccine will prevent cervical } \\
\text { cancer }\end{array}$} & No & 77 & 57.1 & \\
\hline & Yes & 748 & 82.3 & $<0.001$ \\
\hline \multicolumn{5}{|c|}{ Perceived facilitators to vaccination in general } \\
\hline \multirow{3}{*}{$\begin{array}{l}\text { Vaccinations are effective in preventing } \\
\text { disease }\end{array}$} & No & 123 & 72.4 & \\
\hline & Not sure & 168 & 78.6 & \\
\hline & Yes & 515 & 82.5 & 0.034 \\
\hline \multirow{3}{*}{$\begin{array}{l}\text { It is very important that my daughter } \\
\text { receive all her vaccinations }\end{array}$} & No & 15 & 53.3 & \\
\hline & Not sure & 42 & 66.7 & 0.002 \\
\hline & Yes & 767 & 81.4 & \\
\hline \multirow{3}{*}{$\begin{array}{l}\text { Vaccination is one way that parents can } \\
\text { ensure their child health }\end{array}$} & No & 23 & 39.1 & \\
\hline & Not sure & 64 & 59.4 & \\
\hline & Yes & 732 & 83.5 & $<0.001$ \\
\hline \multirow{3}{*}{$\begin{array}{l}\text { I have a responsibility to have my } \\
\text { children vaccinated for the protection of } \\
\text { all children. }\end{array}$} & No & 17 & 76.5 & \\
\hline & Not sure & 27 & 55.6 & 0.004 \\
\hline & Yes & 770 & 81.2 & \\
\hline \multirow{3}{*}{$\begin{array}{l}\text { The government does a good job } \\
\text { providing vaccine and health services }\end{array}$} & No & 33 & 84.8 & \\
\hline & Not st & 75 & 68.0 & 0.016 \\
\hline & Yes & 708 & 81.5 & \\
\hline \multirow{3}{*}{$\begin{array}{l}\text { I would feel responsible if anything bad } \\
\text { happened I did not my child vaccinated }\end{array}$} & No & 105 & 76.2 & \\
\hline & Not sure & 97 & 71.1 & \\
\hline & Yes & 600 & 83.7 & $<0.005$ \\
\hline \multicolumn{5}{|l|}{ Perceived barriers to HPV vaccination } \\
\hline \multirow[t]{2}{*}{ High cost of the vaccine } & No & 281 & 75.8 & \\
\hline & Yes & 544 & 81.8 & 0.042 \\
\hline \multirow{2}{*}{$\begin{array}{l}\text { Low risk that daughter will be infected } \\
\text { with HPV }\end{array}$} & No & 230 & 75.2 & \\
\hline & Yes & 590 & 81.4 & 0.050 \\
\hline \multirow{2}{*}{$\begin{array}{l}\text { Low risk that daughter will get cervical } \\
\text { cancer }\end{array}$} & No & 255 & 78.8 & \\
\hline & Yes & 562 & 80.3 & 0.638 \\
\hline \multirow{2}{*}{$\begin{array}{l}\text { Family will disapproval of getting } \\
\text { daughter vaccinated }\end{array}$} & No & 383 & 83.0 & \\
\hline & Yes & 430 & 77.4 & 0.047 \\
\hline \multirow[t]{2}{*}{ Injection may cause pain } & No & 360 & 85.0 & \\
\hline & Yes & 459 & 76.0 & 0.001 \\
\hline \multirow{2}{*}{$\begin{array}{l}\text { Not enough information available about } \\
\text { HPV vaccine }\end{array}$} & No & 253 & 75.1 & \\
\hline & Yes & 563 & 82.2 & 0.018 \\
\hline \multirow[t]{2}{*}{ Worried about safety of the vaccine } & No & 228 & 77.1 & \\
\hline & Yes & 591 & 81.0 & 0.131 \\
\hline \multirow[t]{2}{*}{ Vaccination may not be effective } & No & 257 & 78.6 & \\
\hline & Yes & 569 & 80.3 & 0.569 \\
\hline \multicolumn{5}{|c|}{ Perceived barriers to vaccination in general } \\
\hline \multirow{3}{*}{$\begin{array}{l}\text { I would feel responsible if anything bad } \\
\text { happened I had my child vaccinated }\end{array}$} & No & 226 & 77.9 & \\
\hline & Not sure & 133 & 84.2 & 0.278 \\
\hline & Yes & 442 & 81.9 & \\
\hline \multirow{2}{*}{$\begin{array}{l}\text { I am concerned about side effects of } \\
\text { vaccinations }\end{array}$} & No & 314 & 79.9 & \\
\hline & Not sure & 189 & 80.4 & 0.811 \\
\hline
\end{tabular}




\begin{tabular}{llccl} 
& Yes & 299 & 81.9 & \\
\hline I am afraid of vaccinating my children & No & 521 & 83.7 & \\
& Not sure & 63 & 57.1 & $<0.001$ \\
& Yes & 238 & 78.2 & \\
\hline It is better to get the disease and get & No & 158 & 87.3 & \\
protected naturally than vaccinated & Not sure & 92 & 75.0 & \multirow{2}{*}{0.027} \\
& Yes & 563 & 78.9 & \\
\hline There are too many vaccines already & No & 83 & 59.0 & \\
included in childhood vaccine schedule & Not sure & 180 & 80.6 & $<0.001$ \\
& Yes & 556 & 82.9 & \\
\hline
\end{tabular}

***Numbers for some items do not add up to 831 due to missing data 
Table 4. Facilitators and barriers to accept HPV vaccination among 831 rural parents in Mysore in Mysore, India, 2011

\begin{tabular}{|c|c|c|c|}
\hline Variables & Categories & $\begin{array}{l}\text { Unadjusted OR } \\
\qquad(95 \% \mathrm{CI})\end{array}$ & $\begin{array}{l}\text { Adjusted OR } \\
(95 \% \mathrm{CI})\end{array}$ \\
\hline \multicolumn{4}{|l|}{ Sociodemographic factors } \\
\hline Sex & Female & $1.17(0.78,1.73)$ & $1.11(0.59,2.10)$ \\
\hline Age & Continuous & $0.98(0.95,1.00)$ & $0.96(0.93,0.99)$ \\
\hline \multirow[t]{2}{*}{ Education } & Grade 1 to $10^{\text {th }}$ & $1.95(1.32,2.90)$ & $1.92(1.13,3.26)$ \\
\hline & $\geq$ High school & $2.59(0.59,11.26)$ & $2.09(0.36,12.11)$ \\
\hline Occupation & Employed & $0.81(0.57,1.15)$ & $1.17(0.71,1.92)$ \\
\hline Marital Status & Married & $1.05(0.58,1.92)$ & $0.48(0.21,1.11)$ \\
\hline Religion & Muslims & $0.71(0.14,3.47)$ & $0.68(.09,5.02)$ \\
\hline Awareness about HPV (Have you ever heard about HPV?) & Yes & $1.33(0.88,2.03)$ & $1.22(0.70,2.10)$ \\
\hline Susceptibility to HPV and cervical cancer & Continuous & $1.06(0.97,1.16) *$ & $0.99(0.89,1.10)^{*}$ \\
\hline HPV & Continuous & $1.33(0.95,1.85)$ & $1.50(.86,2.61)$ \\
\hline Cervical cancer & Continuous & $1.08(0.77,1.51)$ & $0.90(0.52,1.56)$ \\
\hline Severity of HPV and cervical cancer & Continuous & $1.31(1.20,1.42) *$ & $1.21(1.10,1.33) *$ \\
\hline HPV & Continuous & $2.42(1.80,3.24)$ & $1.64(1.04,2.57)$ \\
\hline Cervical cancer & Continuous & $2.09(1.58,2.77)$ & $1.16(0.73,1.83)$ \\
\hline Perceived facilitators to HPV vaccination & Continuous & $1.17(1.10,1.24)^{*}$ & $1.16(1.07,1.25) *$ \\
\hline Recommendation from doctor or nurse & Yes & $3.20(1.67,6.14)$ & $1.07(0.41,2.79)$ \\
\hline Worry about daughter getting cervical cancer & Yes & $1.23(0.88,1.74)$ & $0.82(0.48,1.39)$ \\
\hline Belief that HPV vaccine is safe & Yes & $3.96(2.37,6.63)$ & $2.11(1.01,4.45)$ \\
\hline Worry that daughter may become sexually active & Yes & $1.27(1.01,1.59)$ & $1.84(1.08,3.13)$ \\
\hline Support from family members to vaccinate your daughter & Yes & $3.21(2.08,4.95)$ & $2.86(1.47,5.57)$ \\
\hline Knowing about the relationship of HPV to cervical cancer & Yes & $2.54(1.62,3.96)$ & $0.92(0.44,1.95)$ \\
\hline Government approval of vaccine & Yes & $2.23(1.44,3.44)$ & $0.94(0.49,1.80)$ \\
\hline Belief that vaccine will prevent cervical cancer & Yes & $3.49(2.14,5.69)$ & $1.57(0.73,3.36)$ \\
\hline Perceived facilitators to vaccination in general & Continuous & $1.26(1.13,1.40)^{*}$ & $1.09(0.95,1.25)^{*}$ \\
\hline Vaccinations are effective in preventing disease & $\mathrm{Ye}$ & $1.85(1.17,2.93)$ & $1.01(0.51,2.00)$ \\
\hline $\begin{array}{r}\text { It is very important that my daughter receive all her } \\
\text { vaccinations }\end{array}$ & Yes & $4.00(1.43,11.20)$ & $1.63(0.28,9.35)$ \\
\hline
\end{tabular}




\begin{tabular}{|c|c|c|c|}
\hline $\begin{array}{r}\text { Vaccination is one way that parents can ensure their child } \\
\text { health }\end{array}$ & Yes & $7.56(3.22,17.74)$ & $10.75(3.04,38.0)$ \\
\hline $\begin{array}{l}\text { I have a responsibility to have my children vaccinated for the } \\
\text { protection of all children }\end{array}$ & Yes & $1.76(0.62,4.98)$ & $0.33(0.05,2.08)$ \\
\hline $\begin{array}{r}\text { The government does a good job providing vaccine and } \\
\text { health services }\end{array}$ & Yes & $0.88(0.33,2.39)$ & $0.31(0.07,1.32)$ \\
\hline $\begin{array}{r}\text { I would feel responsible if anything bad happened I did not } \\
\text { have my child vaccinated }\end{array}$ & Yes & $1.67(1.02,2.75)$ & $1.04(0.50,2.15)$ \\
\hline Perceived barriers to HPV vaccination & Continuous & $0.99(0.95,1.04)^{*}$ & $0.92(0.87,0.99) *$ \\
\hline High cost of the vaccine & Yes & $1.40(0.98,1.98)$ & $1.77(1.06,2.96)$ \\
\hline Low risk that daughter will be infected with HPV & Yes & $1.43(0.99,2.07)$ & $1.17(0.64,2.14)$ \\
\hline Low risk that daughter will get cervical cancer & Yes & $1.07(0.74,1.53)$ & $0.52(0.29,0.95)$ \\
\hline Family will disapproval of getting daughter vaccinated & Yes & $0.68(0.48,0.97)$ & $0.45(0.26,0.76)$ \\
\hline Injection may cause pain & Yes & $0.57(0.40,0.82)$ & $0.53(0.31,0.89)$ \\
\hline Not enough information available about HPV vaccine & Yes & $1.51(1.05,2.16)$ & $1.86(1.09,3.18)$ \\
\hline Worried about safety of the vaccine & Yes & $1.29(0.89,1.86)$ & $0.87(0.49,1.54)$ \\
\hline Vaccination may not be effective & Yes & $0.91(0.63,1.31)$ & $1.00(0.57,1.77)$ \\
\hline Perceived barriers to vaccination in general & Continuous & $0.97(0.89,1.07)^{*}$ & $0.99(0.89,1.10)^{*}$ \\
\hline $\begin{array}{r}\text { I would feel responsible if anything bad happened I had my } \\
\text { child vaccinated }\end{array}$ & Yes & $1.27(0.85,1.88)$ & $1.05(0.58,1.89)$ \\
\hline I am concerned about side effects of vaccinations & Yes & $1.09(0.72,1.66)$ & $0.95(0.55,1.66)$ \\
\hline I am afraid of vaccinating my children & Yes & $0.68(0.46,1.01)$ & $0.77(0.44,1.35)$ \\
\hline $\begin{array}{r}\text { It is better to get the disease and get protected naturally than } \\
\text { vaccinated }\end{array}$ & Yes & $0.56(0.33,0.93)$ & $1.05(0.54,2.04)$ \\
\hline $\begin{array}{r}\text { There are too many vaccines already included in childhood } \\
\text { vaccine schedule }\end{array}$ & Yes & $3.37(2.06,5.49)$ & $1.90(0.94,3.84)$ \\
\hline Do you know someone with cervical cancer? & Yes & $0.65(0.36,1.15)$ & $0.61(0.27,1.38)$ \\
\hline Social norms & Continuous & $1.03(0.99,1.07)^{*}$ & $1.01(0.97,1.04)^{*}$ \\
\hline \multicolumn{4}{|l|}{$\begin{array}{l}\text { Do you think the following people would want you to } \\
\text { vaccinate your daughter against HPV infection }\end{array}$} \\
\hline Your Doctors & Yes & 1.94(1.23, 3.07) & $1.55(0.83,2.92)$ \\
\hline Your spouse & Yes & $2.14(1.42,3.24)$ & $2.25(1.22,4.12)$ \\
\hline Your friends & Yes & $1.19(0.77,1.83)$ & $1.06(0.53,2.09)$ \\
\hline
\end{tabular}




\begin{tabular}{|c|c|c|c|}
\hline Your father \& mother & Yes & $1.77(1.14,2.74)$ & $0.84(0.44,1.64)$ \\
\hline Other relatives & Yes & $0.72(0.48,1.10)$ & $0.44(0.20,0.94)$ \\
\hline Your in-laws & Yes & $1.33(0.89,1.98)$ & $1.48(0.76,2.88)$ \\
\hline Your neighbors & Yes & $0.87(0.54,1.40)$ & $0.78(0.35,1.74)$ \\
\hline Source of information about HPV vaccine & Continuous & $1.09(1.00,1.18)^{*}$ & $1.05(0.95,1.16)^{*}$ \\
\hline Television & Yes & $1.96(1.32,2.92)$ & $1.16(0.57,2.38)$ \\
\hline Newspaper or Radio & Yes & $1.26(0.86,1.85)$ & $0.78(0.41,1.51)$ \\
\hline Internet & Yes & $1.07(0.76,1.52)$ & $1.49(0.89,2.50)$ \\
\hline Doctor & Yes & $2.07(1.29,3.30)$ & $1.50(0.70,3.19)$ \\
\hline ANM or Anganwadi teacher or Worker & Yes & $1.14(0.74,1.77)$ & $0.53(0.27,1.03)$ \\
\hline Friends or Neighbours & Yes & $1.20(0.83,1.73)$ & $0.71(0.38,1.31)$ \\
\hline My daughter's school & Yes & $0.80(0.38,1.67)$ & $0.90(0.35,2.31)$ \\
\hline Family member or relatives & Yes & $1.25(0.87,1.80)$ & $1.80(0.94,3.45)$ \\
\hline Recommended age for HPV vaccination & Continuous & $1.13(0.96,1.35)$ & $1.10(0.88,1.38)$ \\
\hline
\end{tabular}

*Odds ratio estimates are based on a GEE that included constructs with composite scores estimated based on the sum of scores of individual items that formed the constructs.

Reference for 'yes' categories are 'no' 


\title{
MANUSCRIPT 3
}

(C) Copyright 2019

Degarege, A., Krupp, K., Fennie, K., Li, T., Stephens, D.P., Srinivas, V., \& Madhivanan P. (2019). An integrative behavior theory derived model to assess factors affecting HPV vaccine acceptance using structural equation modeling. Vaccine, 37(7):945-955.

\begin{abstract}
Objective: The study examined factors that directly affect, mediate, and moderate parental intention-to-vaccinate adolescent daughters with HPV vaccine in Mysore district, India.
\end{abstract}

Methods: A cross-sectional study was conducted among 1,609 parents of adolescent girls attending schools in Mysore between February 2010 and October 2011. A validated questionnaire was used to assess parental attitudes and beliefs related with HPV infection, cervical cancer, HPV vaccine and vaccination. Structural equation modeling was used to estimate parameters and assess whether a model based on the integrative behavior theory would fit the current data.

Results: More than two-thirds (78.0\%) of parents would accept vaccinating their daughters with HPV vaccine. HPV vaccine acceptance significantly increased with an increase in the perception of parents about the benefits (standardized regression coefficient $(\beta)=0.39)$ or sources of information about HPV vaccine $(\beta=0.24)$, but the rate decreased significantly with an increase in the perception about barriers to HPV vaccination $\beta=-0.44)$. The effect of beliefs about severity of HPV infection or cervical cancer $(\beta=0.20)$, and beliefs about benefits $(\beta=0.20)$ or barriers $(\beta=-0.25)$ to vaccination in general on HPV vaccine acceptance were significantly mediated by 
parental attitudes or source of information about HPV vaccine. Geographical living area significantly moderated the effect of awareness about HPV on beliefs about severity of HPV infection or cervical cancer $(\beta=0.33)$, and the effect of religion on norms related to HPV vaccination $(\beta=0.19)$.

Conclusions: This study identified modifiable parental attitudes about HPV vaccine and beliefs related with HPV infection, cervical cancer and vaccination, which predicted parental intention-to-vaccinate their adolescent daughters with HPV vaccine in Mysore district, India. Health education interventions tailored to counter parental negative attitudes and beliefs about HPV vaccine and vaccination in general would be important for the Indian community to promote HPV vaccination.

Keywords: HPV vaccine, Acceptability, Daughter, Parent, India

\section{Introduction}

About 67,477 women in India die every year due to cervical cancer (Mishra et al. 2016). Identifying and treating precancerous lesions would greatly reduce the incidence of invasive cervical cancer in the country (Saxena et al., 2012; Bobdey et al., 2016). However, due to shortage of infrastructure and trained experts, organized populationbased cervical cancer screening programs are practically non-existent in India at present (Mishra et al., 2016; Chatterjee et al., 2016). Primary prevention practices such as vaccination are important to effectively reduce the incidence of cervical cancer in the country.

The Indian government approved Human Papillomavirus (HPV) vaccination for females aged 10 to 12 years in 2008 (IAPCOI, 2008). However, HPV vaccination in India was suspended in 2010 due to the death of seven girls during a clinical trial in the 
country conducted from 2009 to 2011 by the Programme for Appropriate Technology in Health, the Indian Council of Medical Research, and the state governments of Andhra Pradesh and Gujarat. The aim of the clinical trial was to study the appropriate delivery strategy and feasibility of HPV vaccine to prevent HPV infection among girls (Lamontagne \& Sherris, 2013). A few years later, the Indian government received $\$ 500$ million in aid from Global Alliance for Vaccines and Immunization, to roll out different vaccines, including HPV vaccine (Indian Express, 2018). As a result, the Ministry of Health in the country ordered the Immunization Technical Advisory Committee to check the safety and efficacy of the HPV vaccine in order to determine whether to include the vaccine in the immunization programme, at least on a pilot basis (Asian Age, 2018). In 2015, HPV vaccine was approved to be included in the National Immunization Programme by the Government of India (Vashishtha et al., 2014; Chatterjee et al., 2016; Indian Express, 2018). In 2016, the states of Punjab and New Delhi included HPV vaccination in their immunization/public health programme (Sabeena et al., 2018). To date, due to some controversies by the government officials (Das, 2018), HPV vaccine was partially introduced in the Immunization Programme for eligible girls in India (WHO, 2018). However, the vaccine is commercially available at a subsidized cost, for eligible girls in most regions of the country in two (if the first dose is taken before the age of 15) or three (if the first dose is taken at or after the age of 15 years or among immunocompromised girls) doses over a six to 12-month period (Arora, 2017; Sabeena et al., 2018).

When the HPV vaccine is fully included in the Immunization Program in India, uptake of the vaccine among eligible girls might be low due to misperceptions about 
HPV infection, cervical cancer and HPV vaccine, or vaccination in general (Basu et al., 2011; Paul et al., 2014; Montgomery et al., 2015; Santhanes et al., 2018). Lower intention to HPV vaccination was associated with parental negative beliefs about HPV vaccine (e.g. side effects, high cost, less efficacious, promote sexual promiscuity) in India (Basu et al., 2011; Paul et al., 2014; Montgomery et al., 2015), Indonesia (Jaspers et al., 2011), Thailand (Charakorn et al., 2011), Japan (Hanley et al., 2012) and Malaysia (Sam et al., 2009). Studies also showed a decreased intention to vaccinate daughters with HPV vaccine among parents who had poor perception of susceptibility to HPV infection or cervical cancer, and severity of the disease in India (Montgomery et al., 2015), Indonesia (Grandah et al., 2018), Japan (Hanley et al., 2012) and Thailand (Grandah et al., 2018; Juntasopeepun \& Thana, 2018).

Studies among parents in urban and rural regions in Mysore district, India also showed an association of parental attitudes and beliefs about HPV infection, cervical cancer and HPV vaccine with their intention-to-vaccinate daughters with HPV vaccine (Madhivanan et al., 2009; Madhivanan et al., 2014; Degarege et al., 2018). However, of the three previously published articles on intention to HPV vaccination in Mysore district (Madhivanan et al., 2009; Madhivanan et al., 2014; Degarege et al., 2018), one was qualitative (Madhivanan et al., 2009), and two quantitative studies assessed factors associated with HPV vaccine acceptance among parents in urban (Madhivanan et al., 2014) and rural (Degarege et al., 2018) regions by examining items used to measure the constructs related to HPV infection, cervical cancer and HPV vaccine in the models independently, but not as a group. In addition, analysis of the factors associated with HPV vaccine acceptance in the previously published quantitative studies in Mysore 
district (Madhivanan et al., 2014; Degarege et al., 2018) was conducted using generalized estimated equations following the conceptual model proposed by Fernandez et al. (2010). Fernandez et al. (2010) proposed that sociodemographic factors, attitudes, and beliefs related with HPV infection, cervical cancer and HPV vaccine are all immediate antecedents of HPV vaccine acceptance. However, the Integrated Behavior Theory (IBT) and theory of planned behavior suggests that attitudes, norms and self-efficacy affect intention to practice a behavior directly, but the effect of belief factors on intention to practice a behavior is indirect through attitudes and norms (Montaño \& Kasprzyk, 2008; Fishbein, 2000). In turn, sociodemographics, knowledge, and personality traits indirectly influence attitudes, subjective norms, and self-efficacy by affecting belief factors. The IBT synthesizes the constructs of knowledge, beliefs, attitudes, norms, self-efficacy, environmental constraints and intention from the theory of reasoned action, theory of planned behavior, social cognition theory and health belief theory to effectively explain factors that influence preventive health behavior particularly vaccination (Montaño \& Kasprzyk, 2008; Fishbein, 2000). Due to the complex and overlapping nature of the factors that could affect preventive health behavior, models that follow an integrative approach will be more appropriate to examine determinants/antecedents to preventive health behavior. However, most studies in India examined factors associated with HPV vaccine acceptance after including sociodemographic factors, attitudes, and beliefs related with HPV infection, cervical cancer and HPV vaccine in a logistic regression model as direct predictors of HPV vaccine acceptance (Basu et al., 2011; Paul et al., 2014; Montgomery et al., 2015; Madhivanan et al., 2014; Degarege et al., 2018). In addition, most of these studies were conducted in urban areas of India (Basu et al., 2011; 
Paul et al., 2014; Montgomery et al., 2015; Madhivanan et al., 2014). Thus, the current study analyzed data from urban (Madhivanan et al., 2014) and rural regions (Degarege et al., 2018) following an IBT-derived model using a more robust analytic technique (i.e. structural equation modeling) to better understand parental HPV vaccine acceptance in Mysore, India.

Identifying factors that are related to HPV vaccine acceptance among parents in India will help guide the development of the contents and delivery mechanisms of health education programs to achieve maximum HPV vaccine coverage among the target population in Mysore. Results from this study could also be used to design evidencebased health education programs to increase HPV vaccine acceptance in other areas of India as well as other South Asian countries after modifying/adjusting to the context of culture, religion and sociodemographic status of the population in the country. The current study aimed to assess: i) direct and indirect predictors of HPV acceptance; ii) moderating effects of area of living on the relationship between socioeconomic status and indirect predictors of HPV acceptance; and iii) appropriateness of a model based on the IBT to fit the current data.

\section{Methods}

Study setting

A survey was conducted among parents in urban and rural areas in Mysore district, India. The survey in the urban area was done between February 2010 and January 2011 and the survey in the rural area was conducted between September and October 2011. In 2010, cervical cancer mortality rate was 16.5 per 100,000 in Karnataka (Dikshit 
et al., 2012). Mysore district is the third (out of 30) most populous $(3,001,127$, density= 450/km2) administrative district located in the southern part of Karnataka (Census, 2011). Greater proportion of the inhabitants $(1,755,714)$ in Mysore district live in rural areas (Census, 2011).

\section{Ethical consideration}

This study was conducted after ethical approvals were obtained from the Institution Review Boards at Florida International University and Public Health Research Institute of India. Block Education officer and school administrators in the relevant villages also granted permission to conduct the study, and written informed consent was obtained from parents who participated in this study.

\section{Study design and participants}

This study was cross-sectional in design and the study participants were parents who had daughter(s) aged 11 to 15 years attending $7^{\text {th }}$ through $10^{\text {th }}$ grades. A total of 778 parents living in the urban area and 831 parents living in the rural areas of Mysore district participated in this study. Detailed description of the study procedures are available elsewhere (Degarege et al., 2018). In brief, 12 schools located in the urban area and 11 schools located in the rural area were selected based on probability proportionate-to-size sampling. Second, all eligible girls in the selected schools were given a program announcement that explained the study and invited parents to participate. Then 800 girls attending schools located in the urban area and 850 girls attending schools located in the rural area of the Mysore district were randomly selected and provided with a questionnaire and consent form to be completed by the parents. The questionnaire was 
completed by one parent in a family. Majority of the parents in both the urban $(97.3 \%)$

and rural $(97.8 \%)$ areas returned the completed questionnaires and signed consent forms.

\section{Measures}

Health behavior theories appropriate for examining HPV vaccine acceptability and studies that reported factors related to HPV vaccine acceptance were referred to while developing the questionnaire used in this study (Madhivanan et al., 2009; Montaño \& Kasprzyk, 2008; Fishbein, 2000; Marlow et al., 2007). The items in the questionnaire were grouped into eight constructs (beliefs about susceptibility to HPV infection or cervical cancer, beliefs about severity of HPV infection or cervical cancer, beliefs about benefits of vaccination, beliefs about barriers to vaccination, attitudes about benefits of HPV vaccination, attitudes about barriers to HPV vaccination, subjective norms about HPV vaccination, source of information about HPV vaccine) according to IBT. Details about the items used to measure the eight constructs are summarized in Table 1. In addition, there were eight items used to assess the socioeconomic, demographic, cultural and other relevant background factors of the study participants (age, gender, religion, marital status, occupation, educational status, awareness about HPV, knowing someone with cancer). In case some parents were not knowledgeable about HPV, cervical cancer and HPV vaccine, we had included basic information about HPV, cervical cancer and HPV vaccine, into the questionnaire. This basic information about HPV, cervical cancer and HPV vaccine would have helped parents to respond to the items used to measure attitudes and beliefs related to HPV, cervical cancer and HPV vaccine. 


\section{Data analysis}

Data were first checked and cleaned using Stata software (Version 14, Texas, USA). As there were missing values for some of the items used to measure the constructs included in the SEM (benefits of HPV vaccination, barriers to HPV vaccination, subjective norms about HPV vaccine; missing range: $0.6 \%$ to $4.9 \%$ ), a multiple imputation method (using chained equation) based on 20 iterations was used to estimate the missing values (Azur et al., 2011). Then the cleaned data that included the estimated missing values were transferred to Mplus version 8 for confirmatory factor analysis (CFA) and SEM analysis (Muthén LK \& Muthén BO, 2017). CFA was performed by including each of the eight latent variables listed in Table 1 independently, and altogether simultaneously in the measurement model. CFA was used to assess the validity of the items employed to measure the latent variables/constructs and to check fit of the measurement model to the data. After determining appropriate measurement models for the latent factors using CFA (Fig 1), SEM was used to check if the proposed model (Fig 2) approximated/fit the data. SEM was also used to assess the parameters including the factor loadings, measurement errors, disturbances, covariance and path coefficients while examining factors that directly affect, mediate and moderate parental intention-tovaccinate daughters with HPV vaccine. All the eight latent, background, and the outcome (willingness to vaccinate daughter with HPV vaccine) variables were entered into the SEM model simultaneously (Fig 3). There was adequate participant to parameter ratio (i.e. acceptable power cut off value =7) for final full SEM model (1609/47=34) (Bentler $\&$ Chou, 1987). As the response variables were categorical in nature (multivariate normal distribution does not exist), the variance-covariance matrix with the Weighted 
Least Squares Estimation Method was used to assess the parameters (Muthe'n et al., 2018). Model fit statistics were assessed using Root Mean Square Error of Approximation (RMSEA), Comparative Fit Index (CFI) and Tucker-Lewis Index (TLI). Models were assumed good/close fit when RMSEA $<0.06$, and TLI and CFI $>0.95$ (Hu \& Bentler, 1999). Models were acceptable/fair fit if RMSEA was 0.06 to 0.08 and TLI and CFI was between 0.90 and 0.95 (Hu \& Bentler, 1999). We re-specified miss-fitting models following the IBT soundness and modification indices outputs from Mplus (Byrne, 2011).

\section{Results}

\section{Characteristics of the study participants}

We invited 1,650 parents to participate in the study. However, 22 parents from the urban area and 19 parents from the rural area did not return the completed questionnaire or had not signed the consent form, making the number of participants in this study to be 1609. Of the 1609 parents, $6.0 \%$ had formal education, $88.8 \%$ were Hindus, and $86.9 \%$ were employed. The mean age of the parents was $38.3 \pm 6.58$ years (range $=23$ to 75 years) and $73.0 \%$ were females. More than two-thirds $(78.0 \%)$ of the parents were willing to vaccinate daughter with HPV vaccine. Details of the study participant characteristics are described elsewhere (Degarege et al., 2018).

\section{Measurement model}

The measurement model that included all the items used to measure the eight latent factors in Table 1 fit the data fairly well (RMSEA $=0.032,95 \%$ CI: 0.031, 0.034; $\mathrm{CFI}=0.92, \mathrm{TLI}=0.92$ ). However, we further modified the measurement model by allowing some residual terms associated with similar items in the same construct to freely 
covary (Fig 1). Additionally, we modified the model by removing two items from the construct 'beliefs about benefits of vaccination' (D4 and D5) and one item from the construct 'subjective norms about HPV vaccination' (G1) with standardized factor loadings $(\beta) \leq 0.3$. These modifications improved the model fit statistics of the measurement model $(\mathrm{RMSEA}=0.028,95 \% \mathrm{CI}: 0.026,0.029 ; \mathrm{CFI}=0.95, \mathrm{TLI}=0.95)$. Items used to measure the different constructs significantly loaded with $\beta \geq 0.4$ with the exception of one item (D1: $\beta=0.24)$.

The measurement model for each construct independently showed a good fit between the proposed model and the data; perceived benefits of HPV vaccination $(\mathrm{RMSEA}=0.03, \mathrm{CFI}=0.99, \mathrm{TLI}=0.98$, factor loading range $(\beta)=0.42$ to 0.88$)$, perceived barriers to $\mathrm{HPV}$ vaccination $(\mathrm{RMSEA}=0.05, \mathrm{CFI}=0.98, \mathrm{TLI}=0.96, \beta=0.46$ to 0.80$)$, beliefs about severity of HPV infection or cervical cancer $(\mathrm{RMSEA}=0.00, \mathrm{CFI}=1.0$, $\mathrm{TLI}=1.0, \beta=0.69$ to 0.91 ), beliefs about susceptibility to HPV infection or cervical cancer $(\mathrm{RMSEA}=0.06, \mathrm{CFI}=1.0, \mathrm{TLI}=0.99, \beta=0.69$ to 0.91$)$, beliefs about benefits of vaccination $(\mathrm{RMSEA}=0.00, \mathrm{CFI}=1.00, \mathrm{TLI}=1.00, \beta=0.41$ to 0.85$)$, beliefs about barriers to vaccination $(\mathrm{RMSEA}=0.00, \mathrm{CFI}=1.00, \mathrm{TLI}=1.00, \beta=0.50$ to 0.69$)$, subjective norms about HPV vaccine $(\mathrm{RMSEA}=0.11, \mathrm{CFI}=0.99, \mathrm{TLI}=0.98, \beta=0.61$ to $0.85)$.

\section{Structural model}

The final full structural model based on IBT was identified; total parameter estimated $\{n=184=$ number of factor loadings $(39)+$ variances $(65)+$ covariance $(25)+$ structural paths (55)\} was less than the number of unique (co)variances of measured variables $\{n=1653=57 \times(57+1) / 2$, where 57 is the total number of measured variables $\}$ 
(Fig 3). The RMSEA statistics showed close fit of the proposed model to the observed data covariance matrix (RMSEA: $0.025,95 \% \mathrm{CI}=0.024,0.026)$. The CFI $(0.92)$ and TLI (0.91) values also indicated that the proposed model fit the data acceptably. Furthermore, the ratio of the model chi-square statistic $\left(\chi^{2}=4580.45\right)$ to the degrees of freedom $(\mathrm{df}=1616)\left(\chi^{2} / \mathrm{df}=2.83\right)$ was less than the recommended threshold for good model fit (5) (Carmines \& McIver, 1981; Marsh \& Hocevar, 1985). However, the chi-square statistics comparing the covariance matrix by the proposed model and the observed data were significant $(\chi 2=3120, \mathrm{df}=1616, \mathrm{p}<0.01)$.

Factors directly affecting willingness to HPV vaccination

Willingness to vaccinate daughters with HPV vaccine was significantly greater among parents who perceived that HPV vaccine had greater benefits (unstandardized regression coefficient $(B)=0.51$, standardized regression coefficient $(\beta)=0.39, p<0.001$ for both) and among those who received information about HPV vaccine from several sources $(B=0.32, \beta=0.240, p<0.001$ for both). On the other hand, lower willingness to vaccinate daughters was observed among parents expressing greater perceived barriers to vaccinating daughters with HPV vaccine $(B=-0.92, \beta=-0.44, p<0.001$ for both).

However, subjective norms related with HPV vaccine did not affect parental willingness to vaccinate their daughters with the vaccine $(B=0.05, \mathrm{p}=0.412, \beta=-0.44, \mathrm{p}=0.411)$ (Table 2 and Fig 3).

Factors indirectly affecting willingness to HPV vaccination

Parental beliefs about benefits $(B=0.39, \beta=0.20)$ or barriers $(B=-1.04, \beta=-0.25)$ to vaccination, and that HPV infection and cervical cancer are severe $(B=0.26, \beta=0.20)$, significantly and indirectly affected their willingness to vaccinate daughters with HPV 
vaccine ( $p<0.001$ for all) (Table 2 and Fig 3). The effect of parental beliefs about benefits of vaccination on their willingness to vaccinate daughters with HPV vaccine was significantly mediated by their perceptions about the benefits $(B=0.40, \beta=0.20, p$ $<0.001$ for both) or barriers ( $B=-0.14, p=0.013 ; \beta=-0.08, \mathrm{p}=0.004)$ to HPV vaccination, and parental sources of information about HPV vaccine $(B=0.13 ; \beta=0.07, p<0.001$ for both). The effect of the parental beliefs about barriers to vaccination on their willingness to vaccinate daughters with HPV vaccine was also significantly ( $(p<0.001$ for all) mediated by their perception about the benefits $(B=0.70 ; \beta=0.17)$ or barriers $(B=-$ $1.80 ; \beta=-0.43)$ to HPV vaccination. Similarly, the effect of parental beliefs that HPV infection or cervical cancer are severe on their willingness to vaccinate daughters with HPV vaccine was significantly mediated by their perception about the benefits $(B=0.24$; $\beta=0.18, p<0.001$ for both $)$ or barriers $(B=-0.07, p=0.022 ; \beta=-0.05, \mathrm{p}=0.02)$ to HPV vaccination, and sources of information about HPV vaccine $(B=0.09 ; \beta=0.07, p<0.001$ for both).

Belief that daughters are susceptible to HPV infection or cervical cancer, that HPV infection or cervical cancer are severe, and beliefs about benefits or barriers to vaccination were significantly $(\mathrm{p}<0.01$ for all) positively related to parental perceived benefits, and barriers to HPV vaccination, as well as sources of information about the vaccine (Table 3).

Effect of background factors on beliefs about HPV infection, cervical cancer, and vaccination

Muslims were more likely to perceive that their daughters were susceptible to HPV infection or cervical cancer $(B=0.38, p=0.001 ; \beta=0.50, p=0.001)$, and were less 
likely to have negative beliefs about vaccination $(B=-0.13, p=0.027 ; \beta=-0.51, p$ $=0.019$ ), but were also less likely to expect that other people will recommend HPV vaccination for their daughters $(B=-0.40, p=0.027 ; \beta=-0.64, p<0.001)$ as compared to non-Muslims (Hindus and Christians). Parents who were aware of HPV were more likely to believe that their daughters were susceptible to HPV infection or cervical cancer $(B=$ $0.29, p=0.008 ; \beta=0.38, p=0.007)$. An increase in the educational status of the parents was also associated with an increase in parental beliefs that HPV infection and cervical cancer are severe $(B=0.17, p=0.008 ; \beta=0.22, p=0.007)$.

There was significant interaction between the area where the participants lived and awareness about HPV in predicting parental beliefs about severity of HPV infection or cervical cancer $(B=0.25, p=0.035 ; \beta=0.33, p=0.034)$ (Table 5). Similarly, there was significant interaction between the area where participants lived and awareness about someone with cancer in predicting parental beliefs about susceptibility of their daughters to HPV infection or cervical cancer $(B=0.33, \mathrm{p}=0.037 ; \beta=0.14, p=0.023)$, and parental beliefs about barriers to vaccination $(B=-0.14, p=0.026 ; \beta=-0.18, p=0.017)$. There was also significant interaction between the area of residence and religion in predicting norms related to vaccinating of daughters with HPV vaccine $(B=0.43, p=0.001 ; \beta=0.19, p=$ $0.001)$.

\section{Discussion}

In this cross-sectional survey of parents of adolescent girls in Mysore district, India, parental perception about the benefits of HPV vaccination and sources of information about HPV vaccine were the strongest direct positive predictors of parental intention-to-vaccinate daughters with HPV vaccine. Parental beliefs about severity of 
HPV infection or cervical cancer, and beliefs about benefits of vaccination in general were indirect positive predictors of intention-to-vaccinate. Studies among parents in another region of India (Madhivanan et al., 2009), Hong Kong, China (Wang et al., 2017), Indonesia (Jaspers et al., 2011) and Thailand (Charakorn et al., 2011; Grandah et al., 2018; Juntasopeepun \& Thana, 2018) also also showed a positive relationship between attitudes about benefits of HPV vaccine (e.g. effective, prevent HPV infection and cervical cancer, affordable) and parents' intention-to-vaccinate with HPV vaccine. Acceptance of HPV vaccination among the Indonesian (Jaspers et al., 2011) and Japanese (Hanley et al., 2012) parents was also positively related with their attitudes about HPV vaccine (e.g. effective, prevent HPV infection and cervical cancer, important, affordable) and beliefs about severity of cervical cancer.

However, perceived barriers to HPV vaccination, which was measured by assessing parental negative attitudes about HPV vaccine - side effects, high cost, low family support, low risk of HPV infection/cervical cancer, not enough information about HPV vaccine, negatively predicted intention-to-vaccinate with HPV vaccine. The more parents' attitudes were negative towards the HPV vaccine, the less they accepted it. In addition, parents who had negative beliefs about vaccination in general were less interested in recommending HPV vaccine for their daughters. Studies among parents in Mysore city (Madhivanan et al., 2009) and Andhra Pradesh, India (Paul et al., 2014) also showed reduced acceptance of HPV vaccine among parents who had negative attitudes about HPV vaccine. Another study among Indonesian parents reported negative parental attitudes about HPV vaccine and vaccination in general as reasons for decreased acceptance of the vaccine (Jaspers et al., 2011). Thai and Japanese women also reported 
negative attitudes about HPV vaccine - high cost, side effects, low efficacy as reasons for not accepting HPV vaccine for their daughters (Charakorn et al., 2011; Hanley et al., 2012). A study among Malaysian mothers also showed cost as a main reason for a low intent to vaccinate children with HPV vaccine (Sam et al., 2009).

Additionally, the current study showed that area of residence significantly moderated the effect of background factors - particularly religion, awareness about HPV and someone with cancer, on parental beliefs about vaccination, HPV infection and cervical cancer. The level of access to medical services, medical professionals, health information, as well as educational level, and cultural characteristics of populations, which can influence parental knowledge about HPV or cervical cancer and religious practices related to beliefs about vaccination, might be different in urban and rural areas in India (Eberhardt \& Pamuk, 2004; Das \& Pathak, 2012). As a result, the effect of awareness about HPV, knowledge about someone with cancer, and religion on parental beliefs about susceptibility and severity of HPV infection or cervical cancer, and beliefs about vaccination may not be similar in urban and rural areas in India.

There was relatively high intention to get daughters vaccinated with HPV vaccine (78.0\%) in the current study population. This intention to vaccinate with HPV vaccine was greater when compared to the rate reported among parents in other regions in India (46.0\%-74.0\%) (Basu et al., 2011; Montgomery et al., 2015), Malaysia (65.7\%) (Sam et al., 2009) and China (26.5\%) (Yu et al., 2016), but lower than the rate reported in Indonesia (96.1\%) (Jaspers et al., 2011), Japan (93.0\%) (Hanley et al., 2012), and Thailand (84\%-85\%) (Charakorn et al., 2011; Juntasopeepun et al., 2018). Even in Mysore district, the intention to HPV vaccination rate was greater among parents who 
were living in the rural (79.9\%) (Degarege et al., 2018) than those living in the urban (71.1\%) area (Madhivanan et al., 2014). This difference in the intention to HPV vaccination rate among parents in different regions of Mysore district in India or South Asian countries could be attributed to differences in the level of parental awareness/knowledge and beliefs/attitudes related to the risk and severity of HPV infection and cervical cancer as well as HPV vaccination. Indeed, intention to vaccination of daughters with HPV vaccine among Indian parents increased from $24 \%$ to $74 \%$ after parents read fact sheet about the relationship between HPV infection and cervical cancer as well as availability of effective and safe vaccine to protect cervical cancer (Basu et al., 2011).

These findings have possible implications both for practice and research. Health education programs aimed at reducing negative attitudes of parents about HPV vaccine (e.g. side effects, low efficacy) and vaccination in general (e.g. too many vaccines, get the disease and protected naturally), in addition to teaching facts about the vaccine, as well as creating awareness/knowledge about HPV infection and cervical cancer are important in India, particularly to those living in Mysore district, to improve their willingness to vaccinate their daughters with HPV vaccine. The health education program would be more beneficial (influential) if it targeted rural communities where the level of awareness/knowledge about HPV and cervical cancer might be low, and religious practices/cultures that do not encourage HPV vaccination may prevail. Furthermore, the current study suggests that the IBT can be appropriate to guide future studies that examine factors affecting HPV vaccine acceptability among the Indian communities. 
This study involved a randomly selected and reasonably large sample size and a high response rate. The analysis was done following a robust theory-based technique. Despite the above strengths, findings in this study should be interpreted in light of the following limitations. Although the RMSEA, CFI, and TLI values suggested that the proposed model based on the IBT fits with the current data, the chi-square statistics indicated significant difference in the covariance matrix by the proposed model and the observed data. However, as the chi-square test is an approximation and sensitive to sample size, the current model is still reasonable to assume to be valid to explain the data. With the value of $\chi 2 / \mathrm{df}=(4580.45 / 1616)$ being less than five, some scholars consider it a good fit (Carmines \& McIver, 1981; Marsh \& Hocevar, 1985). In addition, due to the cross-sectional nature of the study and lack of actual HPV vaccine uptake data, we are unable to establish cause and effect relationship between the variables and fully test the IBT. Moreover, interpretation of mediating effects must be done in the context of a crosssectional study. Furthermore, only parents of school going adolescent girls participated in this study. This may affect generalizability of the current findings to parents who do not have daughters attending schools. Finally, the data were self-reported. Thus, there could be some level of social desirability and information bias in responses. Furthermore, suspension of HPV vaccination in India in 2010 might have affected the beliefs and attitudes of parents about HPV infection, cervical cancer and HPV vaccine. Finally, the data for this study were collected between February 2010 and October 2011. There may have been changes in the parental opinion/views regarding cervical cancer, HPV infection and vaccine, and vaccination in general in the past years. This delay in the time for reporting the results after the data were collected may affect policy measures designed 
to change misperceptions of parents related to HPV infection, cervical cancer and HPV vaccine in order to improve HPV vaccine acceptance among parents in Mysore, India.

\section{Conclusions}

The current study identified parental perception about the benefits of HPV vaccination, and sources of information about HPV vaccine as the strongest direct positive predictors of intention-to-vaccinate girls with HPV vaccine, and parental beliefs about severity of HPV infection or cervical cancer, and beliefs about benefits of vaccination in general as indirect positive predictors of intention to HPV vaccination. Perceived barriers to HPV vaccination negatively predicted parental intention to vaccinate daughters with HPV vaccine. The study also confirmed complementary relationships of the socioeconomic factors and constructs related to beliefs and attitudes suggested by the IBT. However, further longitudinal studies that measure HPV vaccine uptake status is important to examine the causal influence of constructs of IBT on one another, and to fully verify whether IBT can be applied to appropriately guide studies that examine factors affecting HPV vaccination in the Indian population.

\section{Acknowledgements}

We would like to thank the study participants for taking time to complete the questionnaires. We would like thank also the Block Development Officer for Mysore and the administrative staff of the schools for their assistance during data collection. 


\section{Funding}

This study was funded by an Investigator Initiated Award from Merck \& Co., Inc. AD is funded by a Dissertation Year Fellowship from Florida International University. KK was a Global Health Equity Scholar funded by the National Institute for Health, FIC/NHLBI (D43 TW010540). The funders had no role in the study design, data collection, analysis, interpretation or publication of the manuscript.

\section{Conflict of interest}

The authors reported no conflict of interest.

\section{References}

Arora, S. (2017). National Immunization Schedule India: A Review. Res Rev J Immunol, 7(3): 2349-1280.

Azur, M.J., Stuart, E.A., Frangakis, C., \& Leaf, P.J. (2011). Multiple Imputation by Chained Equations: What is it and how does it work? Int J Methods Psychiatr Res, 20(1):40-9.

Basu, P., \& Mittal, S. (2011). Acceptability of human papillomavirus vaccine among the urban, affluent and educated parents of young girls residing in Kolkata, Eastern India. J Obstet Gynaecol, 37(5): 393-401.

Bentler, P.M., \& Chou, C. (1987). Practical issues in structural modeling. Sociological Methods \& Research, 16:78-117.

Bobdey, S., Sathwara, J., Jain, A., \& Balasubramaniam, G. (2016). Burden of cervical cancer and role of screening in India. Indian J Med Paediatr Oncol, 37(4):278-285.

Byrne, B.M. (2011). Structural Equation Modeling with Mplus: Basic Concepts, Applications and Programming. 2011. Routledge Academic, New York.

Carmines, E.G., \& McIver, J.P. (1981). Analyzing models with unobserved variables. In: Bohrnstedt, GW.; Borgatta, EF., editors. Social measurement: Current issues. Sage; Beverly Hills: 1981. p. 80.

Census, 2011, http://censusindia.gov.in/. [Accessed 29 July 2017].

Charakorn, C., Rattanasiri, S., Lertkhachonsuk, A.A., ...\& Wilailak, S. (2011). Knowledge of Pap smear, HPV and the HPV vaccine and the acceptability of the HPV vaccine by Thai women. Asia Pac J Clin Oncol, 7(2):160-7. 
Chatterjee, S., Chattopadhyay, A., Samanta, L., \& Panigrahi, P. (2016). HPV and Cervical Cancer Epidemiology - Current Status of HPV Vaccination in India. Asian Pac J Cancer Prev, 17(8):3663-73.

Das, D., \& Pathak, M. (2012). The growing rural-urban disparity in India: Some issues. Int J of Adv Res Tech, 1: 1-7.

Degarege, A., Krupp, K., Fennie, K., ...\& Madhivanan, P. (2018). Urban-rural inequities in the parental attitudes and beliefs towards Human papillomavirus infection, cervical cancer and HPV vaccine in Mysore, India. J Pediat Adolesc Gynecol, 31(5):494-502.

Degarege, A., Krupp, K., Fennie, K.,...\& Madhivanan, P. (2018). HPV vaccine acceptability among parents of adolescent girls in a rural area Mysore, India. J Pediat Adolesc Gynecol, 31(6):583-591.

Dikshit, R., Gupta, P.C., Ramasundarahettige, C., ... \& Badwe, R. (2012). Cancer mortality in India: a nationally representative survey. Lancet, 379(9828):1807-16.

Eberhardt, M.S., \& Pamuk, E.R. (2004). The Importance of Place of Residence: Examining Health in Rural and Non-rural Areas. Am J Public Health, 94 (10): 1682.

Fernandez, M.E., Allen, J.D., Mistry, R., \& Kahn, J.A. (2010). Integrating clinical, community, and policy perspectives on human papillomavirus vaccination. Annu Rev Public Health, 31:235-52.

Fishbein, M. (2000). The role of theory in HIV prevention. AIDS Care, 12(3): 273-278.

Grandah, M., Paek, S.C., Grisurapong, S., ...\& Lundberg, P. (2018). Parents' knowledge, beliefs, and acceptance of the HPV vaccination in relation to their socio-demographics and religious beliefs: A cross-sectional study in Thailand. PLoS One,13(2):e0193054.

Hanley, S.J., Yoshioka, E., Ito, Y., ...\& Sakuragi, N. (2012). Acceptance of and attitudes towards human papillomavirus vaccination in Japanese mothers of adolescent girls. Vaccine, 30(39):5740-7.

Hu, L., \& Bentler, P.M. (1999). Cutoff criteria for fit indexes in covariance structure analysis: Conventional criteria versus new alternatives. Structural Equation Modeling, 6(1): 1-55.

Indian Academy of Pediatrics Committee on Immunization (IAPCOI) (2008). Consensus recommendations on immunization, 2008. Indian Pediatr, 45: 635-648.

Jaspers, L., Budiningsih, S., Wolterbeek, R.,....\& Peters, A.A. (2011). Parental acceptance of human papillomavirus (HPV) vaccination in Indonesia: a cross-sectional study. Vaccine, 29(44):7785-93.

Juntasopeepun, P. \& Thana, K. (2018). Parental acceptance of HPV vaccines in Chiang Mai, Thailand. Int J Gynaecol Obstet, 142(3):343-348.

Lamontagne, D.S., \& Sherris, J.D. (2013). Addressing questions about the HPV vaccine project in India. Lancet Oncol, 14:e492. 
Madhivanan, P., Krupp, K., Yashodha, M.N.,...\& Reingold, A.L. (2009). Attitudes toward HPV vaccination among parents of adolescent girls in Mysore, India. Vaccine, 27(38):5203-5208.

Madhivanan, P., Li, T., Srinivas, V.,...\& Krupp, K. (2014). Human papillomavirus vaccine acceptability among parents of adolescent girls: obstacles and challenges in Mysore, India. Prev Med, 64:69-74.

Montgomery, M.P., Dune, T., Shetty, P.K., \& Shetty, A.K. (2015). Knowledge and acceptability of human papillomavirus vaccination and cervical cancer screening among women in Karnataka, India. J Cancer Educ, 30(1):130-7.

Marlow, L.A., Waller, J., \& Wardle, J. (2007). Parental attitudes to pre-pubertal HPV vaccination. Vaccine, 25: 1945-1952.

Marsh, H.W., Hocevar, D. (1985). Application of confirmatory factor analysis to the study of self-concept: First- and higher-order factor models and their invariance across groups. Psychological Bulletin 1985; 97:562-582.

Mishra, G.A., Pimple, S.A., \& Shastri, S.S. (2016). Prevention of Cervix Cancer in India. Oncol, 91:1-7.

Montaño, D.E., \& Kasprzyk, D. (2008). Theory of reasoned action, theory of planned behavior, and the integrated behavioral model. In Glanz K, Rimer BK, Viswanath K (Eds.), Health behavior and health education: Theory, research, and practice (4th ed., pp. 67-96). San Francisco: Jossey-Bass; 2008.

Muthe'n, B.O., du Toit, S.H.C., \& Spisic, D. (2018). Robust inference using weighted least squares and quadratic estimating equations in latent variable modeling with categorical and continuous outcomes. Retrieved from www.statmodel.com/bmuthen/articles/Article_075.pdf [Accessed April 2018].

Muthén, L.K., \& Muthén, B.O. Mplus User's Guide. Eighth Edition (1998-2017). Los Angeles, CA: Muthén and Muthén.

Paul, P., Tanner, A.E, Gravitt, P.E.,...\& Zimet, G.D. (2014). Acceptability of HPV Vaccine Implementation Among Parents in India. Health Care Women Int, 35 (10): 1148 61.

Sabeena, S., Bhat, P.V., Kamath, V., \& Arunkumar, G. (2018). Global human papilloma virus vaccine implementation: An update. J Obstet Gynaecol Res, 44(6):989-997.

Sam, I.C., Wong, L.P., Rampal, S., ...\& Kahar-Bador, M. (2009). Maternal acceptance of human papillomavirus vaccine in Malaysia. J Adolesc Health, 44(6):610-2.

Santhanes, D., Yong, C.P., Yap, Y.Y.,...\& Khan, T.M. (2018). Factors influencing intention to obtain the HPV vaccine in South East Asian and Western Pacific regions: A systematic review and meta-analysis. Sci Rep, 8(1):3640.

Saxena, U., Sauvaget, C., \& Sankaranarayanan, R. (2012). Evidence-based screening, early diagnosis and treatment strategy of cervical cancer for national policy in lowresource countries: example of India. Asian Pac J Cancer Prev,13(4):1699-703. 
The Asian age. Government orders HPV vaccine study, https://www.pressreader.com/india/the-asian-age/20150225/281852937018804.

[Accessed 10 June 2018].

The Indian Express. Universal Immunization Programme: To check cervical cancer, govt plans to launch HPV vaccine, http://indianexpress.com/article/india/india-newsindia/universal-immunisation-programme-to-check-cervical-cancer-govt-plans-to-launchhpv-vaccine/. [Accessed 10 June 2018]

Vashishtha, V.M., Choudhury, P., Kalra, A..,...\& Indian Academy of Pediatrics (2014). Indian Academy of Pediatrics (IAP) recommended immunization schedule for children aged 0 through 18 years - India, 2014 and updates on immunization. Indian Pediatr, 51:785-800.

Wang, L.D., Lam, W.W.T., \& Fielding, R. (2017). Determinants of human papillomavirus vaccination uptake among adolescent girls: A theory-based longitudinal study among Hong Kong Chinese parents. Prev Med, 102:24-30.

WHO. Punjab launches HPV vaccine with WHO support, http://www.searo.who.int/india/mediacentre/events/2016/Punjab_HPV_vaccine/en/. [Accessed 10 June 2018]

WHO (2018). Vaccine in National Immunization Programme Update. Accessed from http://www.who.int/entity/immunization/monitoring_surveillance/VaccineIntroStatus.ppt x. [Accessed 2 December 2018].

Yu, Y., Xu, M., Sun, J.,...\& Xu, A. (2016). Human Papillomavirus Infection and Vaccination: Awareness and Knowledge of HPV and Acceptability of HPV Vaccine among Mothers of Teenage Daughters in Weihai, Shandong, China. PloS one, 11: e0146 


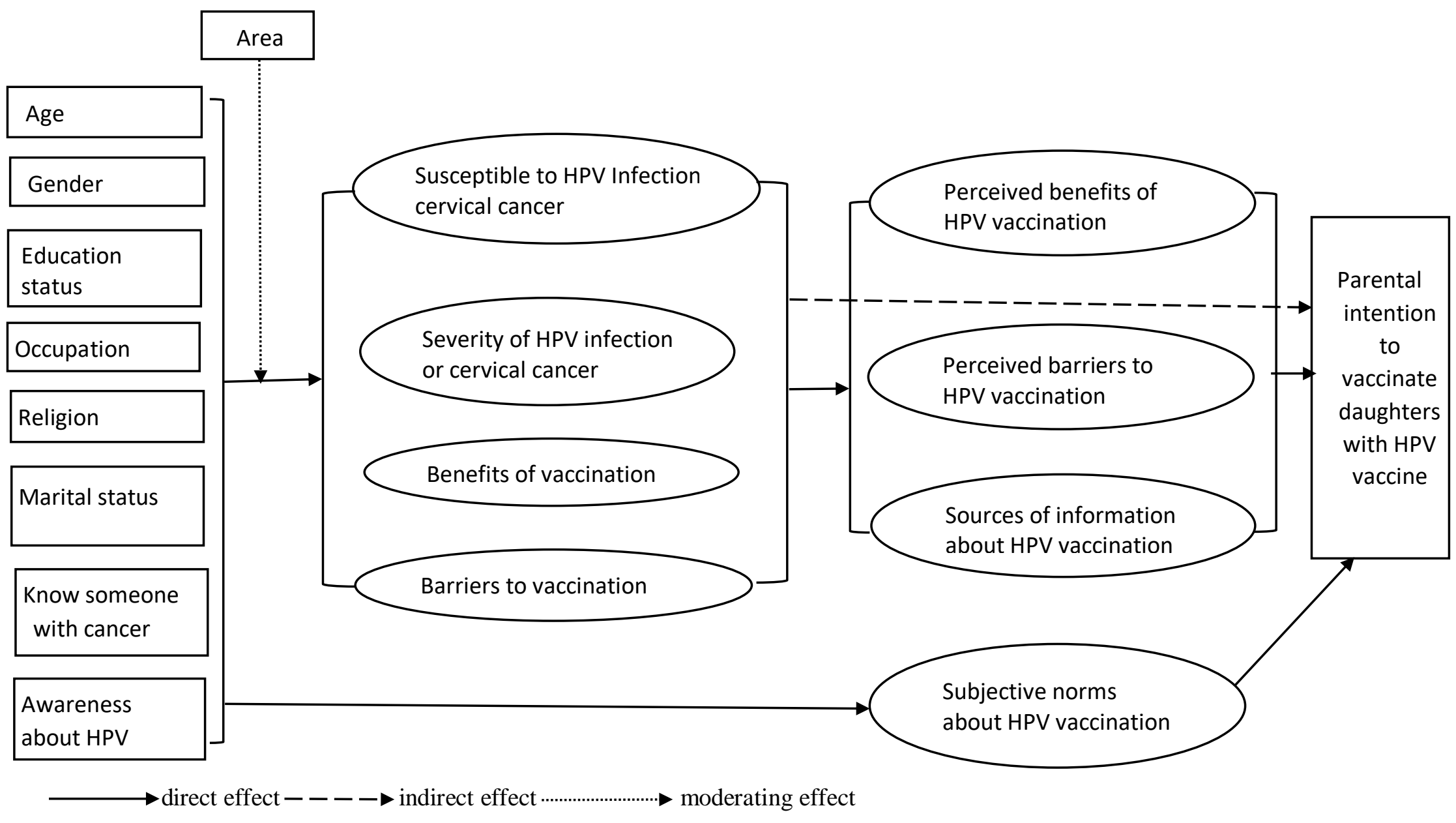

Fig 1. Proposed integrative behavior theory derived model for understanding factors predicting parental intention-to-vaccinate daughters with HPV vaccine 


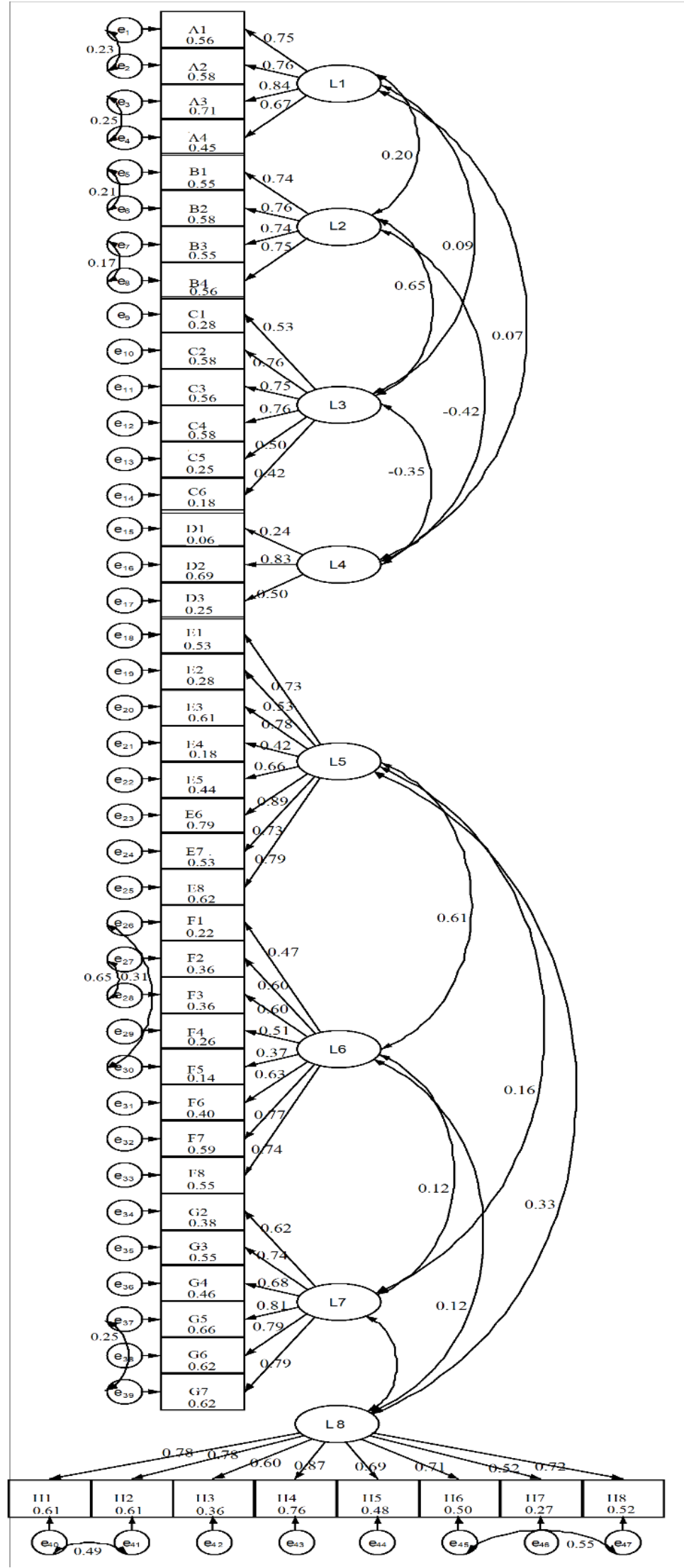

Fig 2. Measurement model of latent factors predicting parental intention-tovaccinate daughters with HPV vaccine in Mysore, India 2010/2011

L1=Susceptibility to HPV/cervical cancer L2=Severity of HPV/cervical cancer

L3=Benefits of vaccination L4=Barriers to vaccination L5=Benefits of HPV vaccination $\mathrm{L} 6=$ Barriers to HPV vaccination L7=Subjective norms about HPV vaccination L8=Source of information about HPV vaccine

* details of names of items measuring each latent factor is provided in table 1 


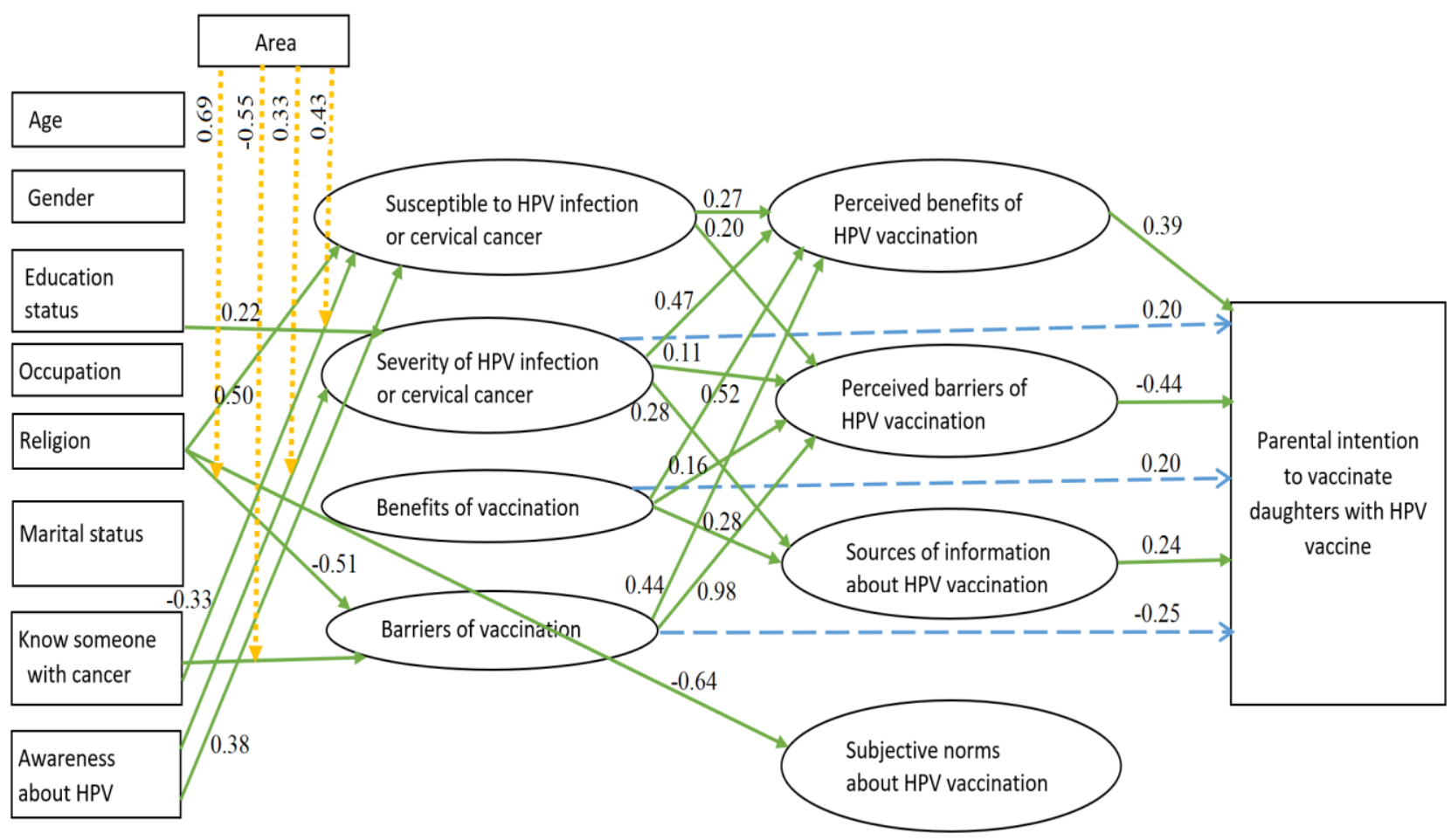

Parameter estimates are standardized regression coefficients

Only statically significant $(\mathrm{p}<0.05)$ paths are provided in this figure

Model fit statics: $\chi 2(\mathrm{df})=3550.61(1782), \mathrm{p}<0.001 ; \mathrm{RMSEA}=0.029,95 \% \mathrm{CI}=0.028,0.030 ; \mathrm{CFI}=0.92 ; \mathrm{TLI}=0.91$

$\longrightarrow$ direct effect $-\longrightarrow \longrightarrow$ indirect effect $\ldots . . . . . . . . . . . . . \rightarrow$ moderator effect

Fig 3. Structural equation model explaining factors predicting parental intention-tovaccinate daughters with HPV vaccine in Mysore, India 2010/2011 
Table 1. Latent variables/constructs and the corresponding measuring items along with their responses/scores

\begin{tabular}{|c|c|c|c|}
\hline Constructs & $\begin{array}{l}\text { Item } \\
\text { label }\end{array}$ & Item & Responses/Scores \\
\hline \multirow[t]{4}{*}{$\begin{array}{l}\text { Susceptibility to } \\
\text { HPV/cervical } \\
\text { cancer (L1) }\end{array}$} & $\mathrm{A} 1$ & $\begin{array}{l}\text { It is possible that my daughter will get cervical cancer } \\
\text { in the future. }\end{array}$ & $\begin{array}{l}1=\text { disagree }, \\
2=\text { do not know, } \\
3=\text { agree }\end{array}$ \\
\hline & $\mathrm{A} 2$ & $\begin{array}{l}\text { It is likely that my daughter may get cervical cancer } \\
\text { someday. }\end{array}$ & \\
\hline & A3 & $\begin{array}{l}\text { It is likely that my daughter may get HPV infection in } \\
\text { the future. }\end{array}$ & \\
\hline & A4 & My daughter may be at risk of getting HPV infection & \\
\hline \multirow[t]{4}{*}{$\begin{array}{l}\text { Severity of } \\
\text { HPV/cervical } \\
\text { cancer (L2) }\end{array}$} & B1 & I believe that cervical cancer is a serious disease & $\begin{array}{l}\text { 1=disagree, } \\
2=\text { do not know, } \\
3=\text { agree }\end{array}$ \\
\hline & B2 & I believe that cervical cancer can be extremely harmful & \\
\hline & B3 & I believe that HPV infection can be extremely harmful & \\
\hline & B4 & $\begin{array}{l}\text { I believe that HPV infection can cause serious health } \\
\text { problem }\end{array}$ & \\
\hline \multirow[t]{6}{*}{$\begin{array}{l}\text { Benefits of } \\
\text { vaccination } \\
\text { (L3) }\end{array}$} & $\mathrm{C} 1$ & Vaccines are effective in preventing disease & $\begin{array}{l}1=\text { no, } 2=\text { not } \\
\text { sure, } 3=\text { yes }\end{array}$ \\
\hline & $\mathrm{C} 2$ & $\begin{array}{l}\text { It is very important that my children receive all their } \\
\text { vaccination }\end{array}$ & \\
\hline & C3 & $\begin{array}{l}\text { Vaccine is one way that parents can ensure their child } \\
\text { health }\end{array}$ & \\
\hline & $\mathrm{C} 4$ & $\begin{array}{l}\text { I have a responsibility, to have my children vaccinated } \\
\text { for the protection of all children. }\end{array}$ & \\
\hline & $\mathrm{C} 5$ & $\begin{array}{l}\text { The government does a good job providing vaccination } \\
\& \text { health services }\end{array}$ & \\
\hline & C6 & $\begin{array}{l}\text { I would feel resp, if anything bad happened I did not } \\
\text { have my child }\end{array}$ & \\
\hline \multirow[t]{5}{*}{$\begin{array}{l}\text { Barriers to } \\
\text { vaccination } \\
\text { (L4) }\end{array}$} & D1 & I am concerned about vaccine side effects & $\begin{array}{l}1=\text { no, } 2=\text { not } \\
\text { sure, } 3=\text { yes }\end{array}$ \\
\hline & D2 & I am afraid of vaccination my children & \\
\hline & D3 & $\begin{array}{l}\text { It is better to get the disease and get protected naturally } \\
\text { vaccine }\end{array}$ & \\
\hline & D4 & $\begin{array}{l}\text { I would feel resp, if anything bad happened I had my } \\
\text { child vaccinated }\end{array}$ & \\
\hline & D5 & $\begin{array}{l}\text { There are too many vaccine already included childhood } \\
\text { vaccine schedule }\end{array}$ & \\
\hline $\begin{array}{l}\text { Benefits of } \\
\text { HPV } \\
\text { vaccination } \\
\text { (L5) }\end{array}$ & E1 & Recommendation from doctor or nurse & $\begin{array}{l}1=\text { not } \\
\text { important all, } \\
2=\text { important } \\
3=\text { very } \\
\text { important }\end{array}$ \\
\hline
\end{tabular}




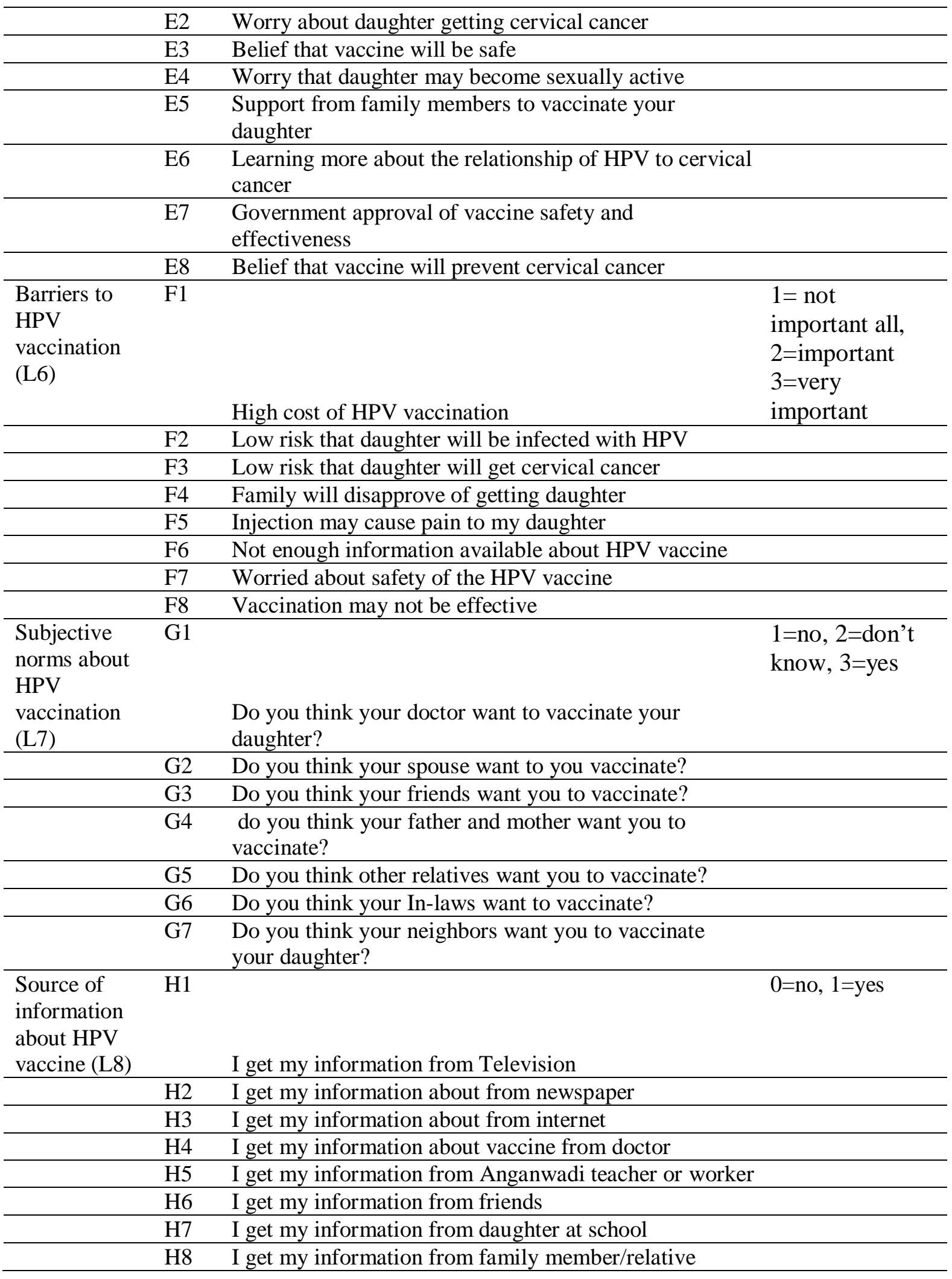


Table 2 Unstandardized $(B)$ and standardized $(\beta)$ effect of factors affecting willingness to HPV vaccination for the structural model

\begin{tabular}{|c|c|c|c|}
\hline \multirow[t]{2}{*}{ Factors } & & \multicolumn{2}{|c|}{ Willingness to HPV vaccination } \\
\hline & & $B(95 \% \mathrm{CI})$ & $\beta(95 \% \mathrm{CI})$ \\
\hline \multicolumn{4}{|l|}{ Direct } \\
\hline Benefits of HPV vaccination & & $0.51(0.29,0.74)$ & $0.39(0.23,0.55)$ \\
\hline Barriers to HPV vaccination & & $-0.92(-1.24,0.59)$ & $-0.44(-0.59,-0.30)$ \\
\hline Information about HPV & & $0.32(0.19,0.44)$ & $0.24(0.15,0.34)$ \\
\hline \multicolumn{4}{|l|}{ vaccination } \\
\hline Norms about HPV vaccination & & $0.05(-0.07,0.17)$ & $-0.44(-0.04,0.10)$ \\
\hline Indirect & Mediators & & \\
\hline Beliefs about benefits of & Benefits of HPV vaccination & $0.40(0.19,0.60)$ & $0.20(0.11,0.29)$ \\
\hline \multirow[t]{4}{*}{ vaccination } & Barriers to HPV vaccination & $-0.14(-0.25,-0.03)$ & $-0.07(-0.12,-0.02)$ \\
\hline & Information about HPV & $0.13(0.06,0.21)$ & $0.07(0.03,0.10)$ \\
\hline & vaccination & & \\
\hline & Sum of indirect effect & $0.39(0.22,0.56)$ & $0.20(0.13,0.27)$ \\
\hline Beliefs about barriers to & Benefits of HPV vaccination & $0.70(0.28,1.12)$ & $0.17(0.09,0.25)$ \\
\hline \multirow[t]{4}{*}{ vaccination } & Barriers to HPV vaccination & $-1.80(-2.58,-1.01)$ & $-0.43(-0.57,-0.30)$ \\
\hline & Information about HPV & $0.06(-0.03,0.14)$ & $0.01(-0.01,0.03)$ \\
\hline & vaccination & & \\
\hline & Sum of indirect effect & $-1.04(-1.51,-0.57)$ & $-0.25(-0.34,-0.16)$ \\
\hline Beliefs about susceptibility & Benefits of HPV vaccination & $0.14(0.07,0.21)$ & $0.10(0.06,0.15)$ \\
\hline \multirow[t]{4}{*}{ to HPV and cervical cancer } & Barriers to HPV vaccination & $-0.12(-0.18,-0.05)$ & $-0.09(-0.13,-0.04)$ \\
\hline & Information about HPV & $-0.01(-0.03,0.02)$ & $-0.01(-0.02,0.01)$ \\
\hline & vaccination & & \\
\hline & Sum of indirect effect & $0.02(-0.05,0.08)$ & $0.01(-0.03,0.06)$ \\
\hline Beliefs about severity of & Benefits of HPV vaccination & $0.24(0.13,0.35)$ & $0.18(0.10,0.26)$ \\
\hline \multirow[t]{4}{*}{ HPV and cervical cancer } & Barriers to HPV vaccination & $-0.07(-0.13,-0.01)$ & $-0.05(-0.09,-0.01)$ \\
\hline & Information about HPV & $0.09(0.05,0.14)$ & $0.07(0.04,0.100)$ \\
\hline & vaccination & & \\
\hline & Sum of indirect effect & $0.26(0.17,0.36)$ & $0.20(0.13,0.26)$ \\
\hline
\end{tabular}


Table 3. Unstandardized (B) and standardized effects $(\beta)$ of parental beliefs about HPV, cervical cancer and vaccination on parental attitudes and source of information related to HPV vaccination for the structural model

\begin{tabular}{|c|c|c|c|}
\hline Belief (exposure) & Attitude/information (outcome) & $B(95 \% \mathrm{CI})$ & $\beta(95 \% \mathrm{CI})$ \\
\hline \multirow[t]{3}{*}{ Benefits of vaccination } & Perceived benefits of HPV vaccination & $0.79(0.55,1.01)$ & $0.52(0.44,0.61)$ \\
\hline & Perceived barriers to HPV vaccination & $0.15(0.05,0.26)$ & $0.16(0.06,0.26)$ \\
\hline & $\begin{array}{l}\text { Sources of information about HPV } \\
\text { vaccination }\end{array}$ & $0.42(0.25,0.59)$ & $0.28(0.19,0.37)$ \\
\hline \multirow[t]{3}{*}{ Barriers to vaccination } & Perceived benefits of HPV vaccination & $1.37(0.83,1.90)$ & $0.44(0.36,0.52)$ \\
\hline & Perceived barriers to HPV vaccination & $1.96(1.32,2.60)$ & $0.98(0.96,0.99)$ \\
\hline & $\begin{array}{l}\text { Sources of information about HPV } \\
\text { vaccination }\end{array}$ & $0.17(-0.08,0.43)$ & $0.06(-0.02,0.13)$ \\
\hline \multirow{3}{*}{$\begin{array}{l}\text { Susceptibility to HPV } \\
\text { infection or cervical } \\
\text { cancer }\end{array}$} & Perceived benefits of HPV vaccination & $0.28(0.20,0.35)$ & $0.27(0.20,0.34)$ \\
\hline & Perceived barriers to HPV vaccination & $0.13(0.08,0.18)$ & $0.20(0.12,0.27)$ \\
\hline & $\begin{array}{l}\text { Sources of information about HPV } \\
\text { vaccination }\end{array}$ & $-0.03(-0.10,0.05)$ & $-0.03(-0.10,0.05)$ \\
\hline \multirow{3}{*}{$\begin{array}{l}\text { Severity of HPV } \\
\text { infection or cervical } \\
\text { cancer }\end{array}$} & Perceived benefits of HPV vaccination & $0.47(0.36,0.57)$ & $0.47(0.39,0.54)$ \\
\hline & Perceived barriers to HPV vaccination & $0.07(0.02,0.13)$ & $0.11(0.03,0.20)$ \\
\hline & $\begin{array}{l}\text { Sources of information about HPV } \\
\text { vaccination }\end{array}$ & $0.29(0.20,0.37)$ & $0.28(0.21,0.36)$ \\
\hline
\end{tabular}


Table 4. Unstandardized (B) and standardized ( $\beta$ ) effects of background factors on parental beliefs about HPV, cervical cancer and vaccination for the Structural Model

\begin{tabular}{|c|c|c|c|}
\hline $\begin{array}{l}\text { Background } \\
\text { (exposure) }\end{array}$ & beliefs/norm (outcome) & $B(95 \% \mathrm{CI})$ & $\beta(95 \% \mathrm{CI})$ \\
\hline \multirow[t]{5}{*}{ Age } & Susceptibility to HPV/cervical cancer & $-0.02(-0.03,0.001)$ & $-0.02(-0.04,0.002)$ \\
\hline & Severity of HPV/cervical cancer & $0.02(-0.001,0.03)$ & $0.020(-0.002,0.041)$ \\
\hline & Benefits of vaccination & $0.08(-0.003,0.02)$ & $0.02(-0.01,0.04)$ \\
\hline & Barriers to vaccination & $-0.002(-0.01,0.004)$ & $-0.01(-0.03,0.02)$ \\
\hline & $\begin{array}{l}\text { Subjective norms about HPV } \\
\text { vaccination }\end{array}$ & $-0.004(-0.02,0.01)$ & $-0.01(-0.03,0.01)$ \\
\hline \multirow[t]{5}{*}{ Gender } & Susceptibility to HPV/cervical cancer & $-0.08(-0.36,0.20)$ & $-0.11(-0.48,0.26)$ \\
\hline & Severity of HPV/cervical cancer & $0.023(-0.23,0.28)$ & $0.03(-0.30,0.361)$ \\
\hline & Benefits of vaccination & $-0.006(-0.19,0.18)$ & $-0.01(-0.36,0.34)$ \\
\hline & Barriers to vaccination & $-0.001(-0.09,0.09)$ & $-0.004(-0.38,0.37)$ \\
\hline & $\begin{array}{l}\text { Subjective norms about HPV } \\
\text { vaccination }\end{array}$ & $0.01(-0.18,0.20)$ & $0.02(-0.29,0.32)$ \\
\hline \multirow[t]{5}{*}{ Education } & Susceptibility to HPV/cervical cancer & $-0.05(-0.18,0.08)$ & $-0.07(-0.24,0.11)$ \\
\hline & Severity of HPV/cervical cancer & $0.17(0.04,0.29)$ & $0.22(0.06,0.38)$ \\
\hline & Benefits of vaccination & $0.09(-0.004,0.19)$ & $0.18(-0.003,0.36)$ \\
\hline & Barriers to vaccination & $-0.04(-0.08,0.01)$ & $-0.15(-0.32,0.03)$ \\
\hline & $\begin{array}{l}\text { Subjective norms about HPV } \\
\text { vaccination }\end{array}$ & $0.03(-0.07,0.12)$ & $0.05(-0.10,0.20)$ \\
\hline \multirow[t]{5}{*}{ Occupation } & Susceptibility to HPV/cervical cancer & $-0.09(-0.28,0.11)$ & $-0.11(-0.37,0.15)$ \\
\hline & Severity of HPV/cervical cancer & $-0.09(-0.28,0.11)$ & $-0.11(-0.36,0.14)$ \\
\hline & Benefits of vaccination & $-0.140(-0.28,0.00)$ & $-0.27(-0.54,-0.01)$ \\
\hline & Barriers to vaccination & $-0.01(-0.09,0.06)$ & $-0.06(-0.36,0.24)$ \\
\hline & $\begin{array}{l}\text { Subjective norms about HPV } \\
\text { vaccination }\end{array}$ & $0.03(-0.13,0.19)$ & $0.05(-0.20,0.30)$ \\
\hline \multirow[t]{3}{*}{ Religion } & Susceptibility to HPV/cervical cancer & $0.38(0.15,0.61)$ & $0.50(0.20,0.80)$ \\
\hline & Severity of HPV/cervical cancer & $0.12(-0.13,0.37)$ & $0.16(-0.17,0.48)$ \\
\hline & Benefits of vaccination & $-0.14(-0.33,0.06)$ & $-0.26(-0.64,0.12)$ \\
\hline
\end{tabular}




\begin{tabular}{|c|c|c|c|}
\hline & Barriers to vaccination & $-0.13(-0.24,-0.01)$ & $-0.51(-0.93,-0.09)$ \\
\hline & $\begin{array}{l}\text { Subjective norms about HPV } \\
\text { vaccination }\end{array}$ & $-0.40(-0.61,-0.19)$ & $-0.64(-0.97,-0.31)$ \\
\hline \multirow[t]{5}{*}{$\begin{array}{l}\text { Marital } \\
\text { status }\end{array}$} & Susceptibility to HPV/cervical cancer & $-0.16(-0.49,0.17)$ & $-0.21(-0.64,0.23)$ \\
\hline & Severity of HPV/cervical cancer & $-0.20(-0.50,0.10)$ & $-0.27(-0.66,0.12)$ \\
\hline & Benefits of vaccination & $0.09(-0.12,0.30)$ & $0.18(-0.23,0.58)$ \\
\hline & Barriers to vaccination & $0.04(-0.07,0.15)$ & $0.17(-0.28,0.62)$ \\
\hline & $\begin{array}{l}\text { Subjective norms about HPV } \\
\text { vaccination }\end{array}$ & $-0.01(-0.26,0.23)$ & $-0.02(-0.42,0.37)$ \\
\hline \multirow[t]{5}{*}{ Region } & Susceptibility to HPV/cervical cancer & $-0.53(-1.53,0.48)$ & $-0.69(-2.01,0.62)$ \\
\hline & Severity of HPV/cervical cancer & $0.41(-0.53,1.34)$ & $0.53(-0.69,1.74)$ \\
\hline & Benefits of vaccination & $-0.03(-0.71,0.65)$ & $-0.05(-1.37,1.26)$ \\
\hline & Barriers to vaccination & $0.15(-0.20,0.50)$ & $0.62(-0.78,2.02)$ \\
\hline & $\begin{array}{l}\text { Subjective norms about HPV } \\
\text { vaccination }\end{array}$ & $-0.30(-1.03,0.43)$ & $-0.48(-1.65,0.69)$ \\
\hline \multirow[t]{5}{*}{$\begin{array}{l}\text { Knowing } \\
\text { someone } \\
\text { with cancer }\end{array}$} & Susceptibility to HPV/cervical cancer & $-0.25(-0.50,0.00)$ & $-0.33(-0.66,-0.003)$ \\
\hline & Severity of HPV/cervical cancer & $0.12(-0.17,0.40)$ & $0.15(-0.22,0.52)$ \\
\hline & Benefits of vaccination & $0.11(-0.10,0.31)$ & $0.20(-0.18,0.60)$ \\
\hline & Barriers to vaccination & $0.07(-0.03,0.17)$ & $0.28(-0.12,0.69)$ \\
\hline & $\begin{array}{l}\text { Subjective norms about HPV } \\
\text { vaccination }\end{array}$ & $-0.05(-0.26,0.17)$ & $-0.07(-0.41,0.27)$ \\
\hline \multirow[t]{5}{*}{$\begin{array}{l}\text { Heard } \\
\text { about HPV }\end{array}$} & Susceptibility to HPV/cervical cancer & $0.29(0.08,0.50)$ & $0.38(0.10,0.66)$ \\
\hline & Severity of HPV/cervical cancer & $-0.03(-0.24,0.17)$ & $-0.04(-0.31,0.22)$ \\
\hline & Benefits of vaccination & $-0.001(-0.15,0.15)$ & $-0.002(-0.29,0.29)$ \\
\hline & Barriers to vaccination & $-0.03(-0.11,0.06)$ & $-0.10(-0.42,0.22)$ \\
\hline & $\begin{array}{l}\text { Subjective norms about HPV } \\
\text { vaccination }\end{array}$ & $0.04(-0.13,0.20)$ & $0.06(-0.21,0.33)$ \\
\hline
\end{tabular}


Table 5. Unstandardized and standardized effects of interaction between area and background factors in predicting parental beliefs about HPV, cervical cancer and vaccination for the structural model

\begin{tabular}{|c|c|c|c|}
\hline $\begin{array}{l}\text { Background } \\
\text { factors X } \\
\text { Area } \\
\text { (exposure) }\end{array}$ & Beliefs and norm factors (outcome) & $B(95 \% \mathrm{CI})$ & $\beta(95 \% \mathrm{CI})$ \\
\hline \multirow[t]{5}{*}{ Age } & Susceptibility to HPV/cervical cancer & $0.011(-0.01,0.03)$ & $0.25(-0.16,0.67)$ \\
\hline & Severity of HPV/cervical cancer & $-0.01(-0.03,0.01)$ & $-0.17(-0.58,0.24)$ \\
\hline & Benefits of vaccination & $0.004(-0.02,0.02)$ & $0.13(-0.31,0.57)$ \\
\hline & Barriers to vaccination & $-0.002(-0.01,0.01)$ & $-0.15(-0.61,0.31)$ \\
\hline & $\begin{array}{l}\text { Subjective norms about HPV } \\
\text { vaccination }\end{array}$ & $0.01(-0.01,0.02)$ & $0.14(-0.26,0.54)$ \\
\hline \multirow[t]{5}{*}{ Gender } & $\begin{array}{l}\text { Belief about susceptibility to HPV } \\
\text { infection and cervical cancer }\end{array}$ & $0.12(-0.20,0.43)$ & $0.08(-0.13,0.28)$ \\
\hline & $\begin{array}{l}\text { Belief about severity of HPV } \\
\text { infection and cervical cancer }\end{array}$ & $0.04(-0.26,0.33)$ & $0.02(-0.17,0.21)$ \\
\hline & Belief about benefits of vaccination & $0.10(-0.12,0.32)$ & $0.10(-0.11,0.31)$ \\
\hline & Belief about barriers to vaccination & $-0.02(-0.12,0.09)$ & $-0.04(-0.25,0.17)$ \\
\hline & $\begin{array}{l}\text { Subjective norms about HPV } \\
\text { vaccination }\end{array}$ & $0.05(-0.17,0.27)$ & $0.04(-0.13,0.22)$ \\
\hline \multirow[t]{5}{*}{ Education } & Susceptibility to HPV/cervical cancer & $0.03(-0.12,0.18)$ & $0.03(-0.11,0.17)$ \\
\hline & Severity of HPV/cervical cancer & $0.09(-0.06,0.23)$ & $0.08(-0.05,0.22)$ \\
\hline & Benefits of vaccination & $0.09(-0.03,0.20)$ & $0.12(-0.04,0.27)$ \\
\hline & Barriers to vaccination & $0.001(-0.05,0.05)$ & $0.002(-0.15,0.15)$ \\
\hline & $\begin{array}{l}\text { Subjective norms about HPV } \\
\text { vaccination }\end{array}$ & $-0.01(-0.12,0.11)$ & $0.10(-0.11,0.12)$ \\
\hline \multirow[t]{4}{*}{ Occupation } & Susceptibility to HPV/cervical cancer & $0.06(-0.17,0.28)$ & $0.04(-0.11,0.18)$ \\
\hline & Severity of HPV/cervical cancer & $0.06(-0.16,0.28)$ & $0.04(-0.11,0.18)$ \\
\hline & Benefits of vaccination & $0.13(-0.03,0.30)$ & $0.12(-0.04,0.27)$ \\
\hline & Barriers to vaccination & $0.00(-0.08,0.08)$ & $0.00(-0.17,0.17)$ \\
\hline
\end{tabular}




\begin{tabular}{|c|c|c|c|}
\hline & $\begin{array}{l}\text { Subjective norms about HPV } \\
\text { vaccination }\end{array}$ & $-0.04(-0.22,0.14)$ & $-0.03(-0.17,0.11)$ \\
\hline \multirow[t]{5}{*}{ Religion } & $\begin{array}{l}\text { Belief about susceptibility to HPV } \\
\text { infection and cervical cancer }\end{array}$ & $0.02(-0.26,0.30)$ & $0.01(-0.09,0.11)$ \\
\hline & $\begin{array}{l}\text { Belief about severity of HPV } \\
\text { infection and cervical cancer }\end{array}$ & $-0.06(-0.37,0.26)$ & $-0.02(-0.13,0.09)$ \\
\hline & Belief about benefits of vaccination & $-0.02(-0.27,0.22)$ & $-0.01(-0.14,0.11)$ \\
\hline & Belief about barriers to vaccination & $0.08(-0.04,0.20)$ & $0.09(-0.04,0.22)$ \\
\hline & $\begin{array}{l}\text { Subjective norms about HPV } \\
\text { vaccination }\end{array}$ & $0.43(0.18,0.68)$ & $0.19(0.08,0.29)$ \\
\hline \multirow[t]{5}{*}{ Marital status } & Susceptibility to HPV/cervical cancer & $0.15(-0.25,0.54)$ & $0.09(-0.15,0.32)$ \\
\hline & Severity of HPV/cervical cancer & $0.22(-0.15,0.58)$ & $0.13(-0.09,0.34)$ \\
\hline & Benefits of vaccination & $0.05(-0.21,0.32)$ & $0.05(-0.18,0.27)$ \\
\hline & Barriers to vaccination & $-0.08(-0.21,0.06)$ & $-0.14(-0.38,0.09)$ \\
\hline & $\begin{array}{l}\text { Subjective norms about HPV } \\
\text { vaccination }\end{array}$ & $0.13(-0.16,0.42)$ & $0.09(-0.12,0.30)$ \\
\hline \multirow[t]{5}{*}{$\begin{array}{l}\text { Knowing } \\
\text { someone with } \\
\text { cancer }\end{array}$} & Susceptibility to HPV/cervical cancer & $0.33(0.04,0.61)$ & $0.14(0.02,0.25)$ \\
\hline & Severity of HPV/cervical cancer & $0.14(-0.18,0.46)$ & $0.06(-0.07,0.19)$ \\
\hline & Benefits of vaccination & $-0.003(-0.24,0.23)$ & $-0.002(-0.15,0.14)$ \\
\hline & Barriers to vaccination & $-0.14(-0.26,-0.02)$ & $-0.18(-0.32,-0.03)$ \\
\hline & $\begin{array}{l}\text { Subjective norms about HPV } \\
\text { vaccination }\end{array}$ & $0.08(-0.16,0.32)$ & $0.04(-0.08,0.16)$ \\
\hline \multicolumn{3}{|l|}{ HPV } & $-0.10(-0.23,0.03)$ \\
\hline & Severity of HPV/cervical cancer & $0.25(0.02,0.48)$ & $0.13(0.01,0.26)$ \\
\hline & Benefits of vaccination & $0.13(-0.05,0.31)$ & $0.10(-0.04,0.24)$ \\
\hline & Barriers to vaccination & $0.01(-0.08,0.10)$ & $0.02(-0.13,0.17)$ \\
\hline & $\begin{array}{l}\text { Subjective norms about HPV } \\
\text { vaccination }\end{array}$ & $-0.05(-0.24,0.14)$ & $-0.03(-0.16,0.09)$ \\
\hline
\end{tabular}




\section{CONCLUSIONS}

Willingness to vaccinate daughters with HPV vaccine was high among parents in Mysore district, India. Parental perception about the benefits of HPV vaccination, and sources of information about HPV vaccine were the strongest direct positive predictors of parental intention-to-vaccinate daughters. Parental beliefs about severity of HPV infection or cervical cancer, and beliefs about benefits of vaccination also indirectly positively affected intention-to-vaccinate girls with HPV vaccine. However, perceived barriers to HPV vaccination negatively predicted intention-to-vaccinate.

In the rural area, willingness to vaccinate daughters with HPV vaccine was particularly greater among parents who believed that HPV vaccine was safe; or daughter may become sexually active; or if they have support from other family members to vaccinate their daughter; or if HPV infection causes severe health problems. On the other hand, willingness to vaccinate daughters with HPV vaccine was particularly lower among rural parents who were older or if they believed that there was low risk that a daughter would get cervical cancer; or if family would disapprove of getting a daughter vaccinated; or if the injection might cause pain.

In addition, the current study confirmed evidence of urban-rural differences in the parental attitudes and beliefs about HPV, cervical cancer and HPV vaccine. When compared to parents living in rural regions, urban parents were more likely to believe that HPV infection and cervical cancer caused serious health problems, but they were less likely to agree that HPV vaccination would make girls sexually active. Moreover, the current study showed evidence that area of residence moderated the effect of: i) awareness about HPV on parental beliefs about severity of HPV infection or cervical 
cancer; ii) knowing someone with cancer on parental beliefs about barriers to vaccination, and parents' perception about susceptibility of daughters to HPV infection or cervical cancer; and iii) religion on parental norms related to HPV vaccination.

Future public health education interventions tailored against parental negative attitudes and beliefs about HPV vaccine and vaccination in general will be important for the Indian communities to promote HPV vaccination and reduce HPV infection related cancers in the country. Health education in the rural area should target older aged parents as well as extended family members to ensure increased vaccination uptake. 
VITA

\section{ABRAHAM DEGAREGE MENGIST}

Born, Wottet Abay, Ethiopia

2001-2005

B.Ed., Biology

Bahir Dar University

Bahir Dar, Ethiopia

2005-2006

Graduate Assistant 1

Department of Biology, Bahir Dar University

Bahir Dar, Ethiopia

2006-2008

M.Sc., Biology (Specialization in Biomedical Science)

Addis Ababa University

Addis Ababa University, Ethiopia

2008-2010

Lecturer

Department of Biology, Bahir Dar University

Bahir Dar, Ethiopia

2010-2014

Lecturer

Department of Medical Parasitology, Addis Ababa

University

2015-2018

Addis Ababa University, Ethiopia

Graduate Assistant

Florida International University

Miami, Florida

2018-present

Dissertation Year Fellowship

Florida International University

Miami, Florida

2017-present

Doctorial Candidate

Florida International University

Miami, Florida

\section{PUBLICATIONS (Selected)}

Degarege, A., Krupp, K., Fennie K,...\& Madhivanan, P. (2019). An integrative behavior theory derived model to assess factors affecting HPV vaccine acceptance using structural equation modeling. Vaccine, 37(7):945-955. 
Degarege, A., Gebrezgi, M.T., Beck-Sague, M.C.,...\& Madhivanan, P. (2019). Effect of ABO blood group on asymptomatic, uncomplicated and placental Plasmodium falciparum infection: systematic review and meta-analysis. BMC Infect Dis, 19(1):86.

Degarege, A., Fennie, K., Degarege, D.,...\& Madhivanan, P. (2019). Improving socioeconomic status may reduce the burden of malaria in sub Saharan Africa: a systematic review and metaanalysis. Plos One, 14(1): e0211205.

Degarege, A., Gebrezgi, M.T., Ibanez, G.,...\& Madhivanan, P. (2019). Effect of the ABO blood group on susceptibility to severe malaria: a systematic review and meta-analysis. Blood Rev, 33: 53-62.

Degarege, A., Krupp, K., Fennie, K.,.. \& Madhivanan, P. (2018). HPV vaccine acceptability among parents of adolescent girls in a rural area Mysore, India. J Pediat Adolesc Gynecol, 31 (6): 583-591

Degarege, A., Krupp, K., Marlow, L.A.V.,...\& Madhivanan, P. (2018). Determinants of attitudes and beliefs towards Human papillomavirus infection, cervical cancer and HPV vaccine among parents of adolescent girls in Mysore, India. J Obstet Gynecol Res, 44 (11): 2091-2100.

Degarege, A., Krupp, K., Fennie, K,...\& Madhivanan, P. (2018). Urban-rural inequities in the parental attitudes and beliefs towards Human papillomavirus infection, cervical cancer and HPV vaccine in Mysore, India. J Pediat Adolesc Gynecol, 31(5):494-502.

Degarege, A., Yimam, Y., Madhivanan, P., \& Erko, B. (2017). The relationship between helminth infections and low haemoglobin levels in children with blood type A from Ethiopia. J Helminthol 2017, 91(3):278-283.

Degarege, A., Degarege, D., Veledar, E.,...\& Madhivanan, P. (2016). Plasmodium falciparum infection status among children with Schistosoma in Sub-Saharan Africa: A Systematic Review and Meta-analysis. PLoS Negl Trop Dis, 10(12): e0005193.

Degarege, A., Veledar, E., Degarege, D., ...\& Madhivanan, P. (2016). Plasmodium falciparum and soil-transmitted helminth co-infections among children in sub-Saharan Africa: a systematic review and meta-analysis. Parasit Vectors, 9(1):344.

Degarege, A., Mekonnen, Z., Legesse, M.,...\& Levecke, B. (2015). Comparison of individual and pooled urine samples for estimating the presence and intensity of Schistosoma haematobium infections at the population level. Parasit Vectors, 8:593.

Degarege, A., Mekonnen, Z., Levecke, B.,...\& Erko, B. (2015). Prevalence of Schistosoma haematobium infection among school-age children in Afar Region, northeast Ethiopia. PLoS One, 10(8): e0133142.

Degarege, A., Hailemeskel, E., \& Erko, B. (2015). Age-related factors influencing the occurrence of undernutrition in northeastern Ethiopia. BMC Public Health, 15:108. 